\title{
Union Européenne : atouts, défis et enjeux
}

\author{
Numéro spécial \\ Coordonné par \\ Liridon Lika et Audrey Weerts
}

Cahiers de Science Politique de l'Université de Liège

Février 2021 


\section{Remerciements}

Ce numéro spécial, publié dans la revue les Cahiers de Science politique de l'Université de Liège, découle de la douzième édition des Après-midis de recherche du Département de Science politique qui a eu lieu le vendredi 3 mai 2019, à la Salle du Conseil de la Faculté de Droit, de Science politique et de Criminologie de l'Université de Liège (ULiège), Quartier Agora, Place des Orateurs 3, Bâtiment B31, Sart-Tilman, 4000 Liège.

Cet événement scientifique fut organisé par cinq chercheur(e)s du Département de Science politique : François Debras, Liridon Lika, Jérôme Nossent, Audrey Weerts et Sophie Wintgens. Cette douzième édition portait sur la thématique générale suivante : «Atouts, défis et enjeux de l'Union européenne ».

Comme pour les précédentes éditions, cet événement a été financé par le Département de Science politique de l'ULiège, présidé par Sebastian Santander. Nous tenons à le remercier vivement pour le soutien financier et logistique.

Nous remercions également tou(te)s les participant(e)s d'avoir présenté leurs recherches respectives et certain(e)s d'entre eux/elles d'avoir également accepté de publier - après un processus externe de peer review - leur travail dans le présent numéro. Nos remerciements vont également à ceux et celles qui ont accepté d'évaluer les contributions de manière anonyme, augmentant ainsi la qualité scientifique de cette publication.

Nos chaleureux remerciements vont aussi à toutes les personnes qui nous ont soutenues dans la bonne organisation de la douzième édition des Après-midis de recherche et notamment au professeur Sebastian Santander pour son mot d'introduction; au keynote speaker Arben Hajrullahu ; aux présidentes de panels : Cindy Regnier et Audrey Weerts ; aux intervenant(e)s : Jean-Claude Mputu, Alizée Dauchy, Kamal Bayramzadeh, André Dumoulin, Philippe Vincent, Aminata Ndiaye et Vincent Bricart ; aux discutant(e)s : Daniela Vintila et Jean-Claude Mputu ; à Liridon Lika pour son mot de clôture.

Remarque : les points de vue exprimés dans ce numéro spécial n'engagent que les auteurs à titre individuel et pas les coordinateurs de ce numéro spécial ni l'équipe de la revue les Cahiers de Science Politique de l'Université de Liège. 
Table des matières

L'Union Européenne, un inépuisable objet d'étude - Sebastian 7 Santander

Le processus de plasticité stratégique et tactico-opérationnelle 18 des pays membres de l'Union européenne - André Dumoulin

La limite de puissance de l'Union Européenne dans les relations 30 internationales : les divergences et les convergences de l' $U E$ avec les États-Unis, en particulier depuis l'arrivée au pouvoir de Donald Trump, sur l'Accord du nucléaire iranien de 2015 : le Joint Comprehensive Plan of Action (JCPOA) - Kamal Bayramzadeh

Les nouveaux accords commerciaux conclus par l'Union 54 Européenne - Philippe Vincent

Politique commerciale extérieure : quel rôle pour les assemblées 77 parlementaires? Le cas des États-Unis et de l'Union Européenne - Vincent Bricart

Jeux et enjeux de l'Union Européenne : quels enseignements 103 peut-on tirer ? - Liridon Lika et Audrey Weerts 


\section{Biographies}

\section{Du coordinateur et de la coordinatrice}

Liridon Lika est chargé de cours adjoint et maître de conférences au Center for International Relations Studies (CEFIR) du Département de Science politique de l'Université de Liège (ULiège). Il est également chercheur postdoctoral à la Faculty of Arts and Social Sciences FASoS) de l'Université de Maastricht (UM). Liridon Lika est titulaire d'une thèse de doctorat en sciences politiques et sociales de l'ULiège (2020). Il a également obtenu le diplôme de master en Science politique, orientation relations internationales, à finalité spécialisée, à l'ULiège (2011) et le diplôme de master complémentaire en Analyse interdisciplinaire de la construction européenne à l'Institut d'Études Européennes (IEE) de l'Université Libre de Bruxelles (ULB) (2012). Ses recherches portent sur les États des Balkans occidentaux, notamment le Kosovo et l'Albanie, l'action extérieure de l'Union Européenne (UE) et la politique étrangère des puissances émergentes à l'égard des Balkans occidentaux.

Audrey Weerts est assistante au Département de Science politique de l'Université de Liège (ULiège). À la fois membre de l'unité d'étude des systèmes politiques belges et de la Cellule d'Appui Politologique Afrique-Caraïbes (CAPAC-ULiège), elle est titulaire d'un master en relations internationales (ULiège) et d'un master en sciences de gestion (HEC-ULiège). Ses travaux portent notamment sur des questions de gouvernance et de gestion des ressources naturelles dans la région des Grands Lacs en Afrique.

\section{Des auteurs}

Sebastian Santander est professeur ordinaire en science politique, directeur du Center for International Relations Studies (www.cefir.be) et président du département de Science politique à l'Université de Liège (ULiège). Il est également membre associé au Centre d'Études sur l'Intégration et la Mondialisation (CEIM) de l'Université du Québec à Montréal. Ses recherches s'inscrivent dans le domaine de l'économie politique internationale et s'intéressent à la distribution du pouvoir dans la gouvernance mondiale. Le sujet est traité à travers l'étude des organisations régionales dans une approche comparative et géopolitique, de l'action extérieure de l'Union Européenne (UE) et de l'Amérique latine, de la politique étrangère des puissances traditionnelles (États-Unis) et des puissances dites (re-)émergentes (Chine, Brésil). Ses articles ont, notamment, été publiés dans des revues scientifiques évaluées par les pairs tels que European Foreign Affairs Review ; Foreign Affairs Latinoamérica ; Journal of European Integration ; Relations internationales ; Études internationales; Politique européenne ; Relazioni Internazionali ou Cuadernos sobre relaciones internacionales, regionalismo y desarrollo. Ses publications sont consultables sur le site orbi : https://orbi.uliege.be/

André Dumoulin est, depuis 2013, rattaché à l'Institut Royal Supérieur de Défense (IRSD) dans les murs de l'École Royale Militaire (ERM). Il est également chargé de cours à l'Université de Liège (ULiège) sur les problèmes de défense et la Politique de Sécurité et de Défense Commune (PSDC). Membre du comité de lecture de la Revue de Défense nationale (Paris) et plus récemment membre du nouveau Centre d'Étude du Terrorisme et la 
Radicalisation (CETR), créé par le professeur criminologue Michaël Dantinne (ULiège), il est l'auteur de nombreuses publications portant notamment sur la politique européenne de sécurité et de défense.

Kamal Bayramzadeh est enseignant en Relations internationales à l'Université de Paris 13 et chercheur invité au Département de Science politique de l'Université de Liège (ULiège). Il est membre associé l'Institut de Droit Public, Sciences Politiques et Sociales de Paris 13 (IDPS) (Paris 13), membre du Center for International Relations Studies (CEFIR) (ULiège) et membre associé de la Chaire Raoul-Dandurand en études stratégiques à l'Université du Québec à Montréal (UQAM-Montréal). Ses publications sont consultables sur le site orbi : https://orbi.uliege.be/

Philippe Vincent est licencié en droit de l'Université de Liège, licencié en droit européen de l'Université de Gand et docteur en droit de 1'Université de Paris X Nanterre. Sa thèse portait sur l'évolution du statut des pays en développement au sein du GATT et de l'OMC. Il enseigne actuellement le droit des relations internationales, les Institutions économiques internationales et le droit de la mer à l'Université de Liège. Il est l'auteur de nombreuses publications traitant notamment du droit international économique et des relations extérieures de l'Union Européenne (UE).

Vincent Bricart est diplômé d'un master en science politique à l'Université de Liège (ULiège) en 2017 et travaille depuis 2018 comme assistant en Relations internationales à l'ULiege et comme chercheur au sein du Center for International Relations Studies (CEFIR). Spécialisé dans l'étude de la politique étrangère des États-Unis et des attributions parlementaires en Relations internationales dans l'Union Européenne (UE) et aux États-Unis, il entame depuis 2020 sa thèse de doctorat. 


\section{L’Union Européenne, un inépuisable objet d'étude}

Sebastian Santander ${ }^{1}$

Mots-clés: Construction européenne ; dimensions interne et externe ; enjeux et défis

\section{L'Union à la rescousse de l'Europe}

L'Union Européenne (UE) constitue une entité politique dynamique dont l'évolution permanente à travers le temps accroit toujours davantage son indéniable complexité et partant augmente la difficulté de sa compréhension. D'autant que l'Union est, comme l'aimait à dire Jacques Delors - président de la Commission européenne de 1985 à 1995 - un « objet politique non-identifié ». Il ne s'agit ni d'un État ni d'une simple organisation internationale, mais de quelque chose entre les deux qui dispose de caractéristiques de l'un et de l'autre. L'intégration européenne constitue une entité économique, institutionnelle et politique sui generis basée sur une association volontaire d'États européens officiellement créée après la Deuxième Guerre mondiale (IIGM) avec le traité de Rome du 25 mars 1957. Plusieurs propositions visant à créer une organisation régionale en Europe entre États voisins furent avancée avant la IIGM. Néanmoins, les temps n'étaient pas mûrs pour la concrétisation de ces projets d'union. Ils échouèrent face à un ordre politique d'Europe occidentale marqué par des rivalités de pouvoir, des nationalismes agressifs, des conquêtes coloniales et des guerres de grande ampleur. Il faudra attendre l'Après-guerre pour voir émerger un contexte propice à la construction européenne.

Trois raisons politiques principales peuvent expliquer le lancement du projet d'UE dans 1'Après-guerre. La première d'entre elles a trait au déclin de la civilisation européenne. Durant les années 1940 et 1950, le monde est confronté à la déchéance de l'Europe en tant que puissance internationale. Les deux guerres mondiales, la crise financière de 1929 et la perte des empires coloniaux dévastent politiquement, socialement et économiquement l'Europe. Elle est également touchée par une crise morale du fait que les valeurs humaines les plus fondamentales sont violées durant les IIGM. La construction de l'unité européenne a donc été rendue possible parce que l'Europe vivait un déclin.

La deuxième raison est liée à la crainte de la France de voir l'Allemagne refaire surface comme une puissance autonome dans l'Après-guerre. Les autorités françaises considèrent que pour éviter une future guerre, il est important de lier l'Allemagne au reste de l'Europe. Pour atteindre cet objectif, le ministre français des Affaires étrangères, Robert Schuman, propose le 9 mai 1950 la création d'un cadre communautaire de coopération franco-allemand ouvert à d'autres pays européens. La Déclaration Schuman marque le début de l'intégration européenne faisant du 9 mai le jour de l'Europe. Deux ans plus tard est créé la Communauté Européenne du Charbon et de l'Acier (CECA), dont les membres (France, Allemagne, Italie, Belgique, Pays-Bas, Luxembourg) mettent en commun la production de charbon et d'acier. La CECA,

\footnotetext{
${ }^{1}$ Sebastian Santander est professeur ordinaire en science politique, directeur du Center for International Relations Studies (www.cefir.be) et président du département de Science politique à l'Université de Liège (ULiège). Il est également membre associé au Centre d'Études sur l'Intégration et la Mondialisation (CEIM) de l'Université du Québec à Montréal.
} 
qui sera administrée tant par des institutions supranationales qu'intergouvernementales, est considérée comme le précurseur de l'actuel projet d'intégration européenne.

La troisième et dernière raison pouvant être invoquée pour expliquer la concrétisation du projet d'union de l'Europe dans l'Après-guerre a trait à la volonté de constituer un rempart contre l'Union des Républiques Socialistes Soviétiques (URSS) et la diffusion du communisme ${ }^{1}$. Cette contrainte extérieure fut un facteur déterminant dans la construction de l'intégration européenne.

\section{Une entité politique en constante évolution}

Depuis son démarrage, le projet européen a fait face à plusieurs phases et avec le relâchement des tensions internationales des années 1980 et la fin de la guerre froide, l'Union est entrée dans une nouvelle étape de son développement. Les décideurs européens ont souhaité adopter un dessein beaucoup plus ambitieux permettant à l'Europe d'occuper une place plus conséquente sur la scène internationale. Le traité de Maastricht de 1992 a cherché à refléter ces ambitions européennes. L'adoption de ce dernier a marqué un tournant historique dans l'évolution de l'UE car il a ouvert la voie à l'intégration politique européenne, renforcée ultérieurement par l'adoption des traités d'Amsterdam (1997), de Nice (2000) et de Lisbonne (2009). Ceux-ci ont consolidé la structure interne de l'UE. Certaines institutions se sont vues renforcées telles que la Commission européenne qui a désormais plus de pouvoir dans le domaine des négociations commerciales puisque dorénavant elle peut négocier au nom des États membres non plus seulement des sujets ayant trait aux biens commerciaux mais aussi aux questions liées aux services, aux droits de propriété intellectuelle et aux investissements. Le rôle et le pouvoir du Parlement européen s'est également vu considérablement augmenté dans la ratification des accords commerciaux et dans l'établissement du budget européen. Sans compter qu'il a dorénavant la possibilité d'obliger la Commission à démissionner. Par ailleurs, de nouvelles institutions ont été créées telles que le Comité des régions ${ }^{2}$, la Banque centrale européenne ${ }^{3}$, le Haut représentant de la politique étrangère de l'UE ${ }^{4}$, le Service Européen pour l'Action Extérieure (SEAE) ${ }^{5}$ ou le Président permanent du Conseil européen ${ }^{6}$. L'intégration s'est également vue consolidée avec l'adoption de nouvelles politiques communes dans les domaines de la citoyenneté ${ }^{7}$ ou monétaire (création d'une monnaie commune), et le lancement de plusieurs programmes européens dans les secteurs de l'éducation, de la recherche, du développement technologique ou de l'environnement. À ceci se sont ajoutées les différentes initiatives visant à développer la visibilité, la reconnaissance, la présence et/ou le rôle de l'UE sur la scène internationale : lancement d'une Politique Étrangère et de Sécurité Commune (PESC) autorisant l'UE à effectuer, notamment, des missions de rétablissement de la paix (conflits en cours) ou des opérations de maintien de la paix (après un conflit); renforcement de la politique commerciale permettant à l'Union de conclure des accords commerciaux bilatéraux, interrégionaux ou multilatéraux davantage ambitieux. Les différents instruments d'action extérieure dont l'UE a été dotée lui ont permis de développer tout un tissu de relations diplomatiques avec des puissances, des pays et/ou des groupements régionaux d'Asie, d'Afrique, des Amériques, d'Europe ou du Moyen-Orient.

\footnotetext{
1 WALLACE, W. (1994), Regional Integration: the West European Experience, Washington, Brookings Institution, p. 11 et $s q$.

${ }^{2}$ Comité consultatif représentant 329 membres représentant les autorités régionales et locales des 27 États membres de l'UE.

${ }^{3}$ En charge de la politique monétaire dans la zone euro.

${ }^{4}$ Il conduit la Politique étrangère et de sécurité commune (PESC) de l'UE.

${ }^{5}$ Service diplomatique de l'UE.

${ }^{6}$ Il assure la continuité des travaux de l'institution qu'il préside.

${ }^{7}$ Le citoyen européen, résidant dans un autre État membre que son pays d'origine, est autorisé à voter et à se porter candidats aux élections municipales et européennes.
} 
Parallèlement à la dynamique de l'approfondissement, le projet européen a connu un processus d'élargissement dont l'objectif consiste à intégrer de nouveaux États en son sein. Pour l'UE et ses États membres la politique d'élargissement doit leur permettre de jouer un rôle de stabilisateur de leur périphérie. Étant donné l'effet d'attraction qu'elle exerce sur toute une série de pays et plus particulièrement sur son voisinage, l'UE a du établir une série de critères contraignants visant à réglementer toute adhésion à son projet. Ces critères dit de Copenhague sont au nombre de trois. Le critère économique impose au candidat de disposer d'une économie de marché viable et la capacité de faire face à la concurrence et aux forces du marché. Le critère politique stipule que le candidat doit avoir des institutions stables garantissant la démocratie, l'État de droit, le respect des droits de l'homme et la protection des minorités. Le troisième critère exige que le candidat soit administrativement et institutionnellement capable de mettre en œuvre l'acquis communautaire (transposer l'ensemble des règles européennes en vigueur dans la législation nationale). Il existe un quatrième critère qui a fait l'objet de polémiques entre les États membres. Cette condition ne dépend pas de l'État candidat mais de la capacité d'absorbation de l'UE. En d'autres mots, l'Union doit être jugée apte, sur le plan de son opinion publique mais aussi de sa capacité décisionnelle, budgétaire ou politique, à accueillir en son sein de nouveaux membres. Le projet européen a connu trois processus d'élargissement durant la guerre froide ${ }^{1}$ et cinq dans l'après-guerre froide ${ }^{2}$. Depuis son lancement, le nombre de ses membres a été multiplié par quatre et d'autres élargissements se préparent puisqu'aujourd'hui cinq pays sont candidats officiels à l'adhésion (Albanie, Macédoine du Nord, Monténégro, Serbie et Turquie).

\section{La construction européenne face à ses défis}

Il est évident que l'intégration européenne n'a plus grande chose à avoir avec le projet initial. Ceci étant, malgré les progrès spectaculaires réalisés dans les domaines de l'approfondissement et l'élargissement, l'intégration européenne est loin de constituer un long fleuve tranquille. L'évolution de la construction européenne ne s'est pas faite de manière continue et régulière. Au contraire, elle a connu des avancées, des ralentissements, des retours en arrière et de nouvelles relances. En réalité, l'histoire de l'intégration européenne est faite de crises et de défis ce qui faisait dire à Jean Monnet que « l'Europe se fera dans les crises et elle sera la somme des solutions apportées à ces crises $»^{3}$.

Comme à chaque étape de son histoire, les défis face auxquels l'intégration européenne est aujourd'hui confrontée sont multiples. Ceux-ci sont aussi bien d'ordre interne qu'externe. Certains d'entre eux sont séculaires alors que d'autres sont plus récents. Parmi ceux-ci, on peut évoquer la question de la démarcation spaciale de l'UE et de son extension à d'autres contrées. Tel que mentionné précédemment, le projet européen s'est élargi huit fois et d'autres pays se préparent à le rejoindre. La politique d'élargissement pose la question de la frontière du projet européen. L’Union rencontre des difficultés à définir clairement ses limites en termes géographiques.

Cette situation crée une tension entre les processus d'élargissement et d'approfondissement de l'Union. L'élargissement a été considéré comme l'outil de politique étrangère le plus efficace de l'Union. Mais l'extension incessante du projet européen à d'autres pays tiers n'est pas sans risques. Elle peut engendrer des difficultés dans l'efficacité du fonctionnement de l'UE voire faire courir à l'intégration européenne un risque de dilution. Par ailleurs, plus l'Union s'élargit, moins elle a de chances de devenir une véritable union politique. En revanche, le repli sur soi crée des déçus dans les pays tiers désireux de rejoindre le projet

\footnotetext{
${ }^{1} 1973$ : Danemark, Irlande et Grande-Bretagne ; 1981 : Grèce ; 1986 : Portugal et Espagne.

21990 : Allemagne de 1'Est ; 1995 : Autriche, Finlande et Suède ; 2004 : Chypre, Estonie, Hongrie, Lettonie, Lituanie, Malte, Pologne, République tchèque, Slovaquie, Slovénie ; 2007 : Bulgarie et Roumanie ; 2013 : Croatie. ${ }^{3}$ MONNET, J. (1976), Mémoires, Paris, Fayard, p. 488.
} 
européen et affaiblit de manière relative la présence européenne dans son voisinage proche face aux puissances extrarégionales (Chine, Russie). Cette situation soulève une série d'autres questions ayant trait à la place de l'UE dans la multipolarisation croissante du monde, aux réponses à apporter aux ambitions globales de la Chine ou de la Russie, au rôle à exercer dans la régulation de la mondialisation ou aux voies d'autonomie à emprunter pour faire face à la puissance américaine dont l'action n'est plus un facteur de fédération pour l'Europe mais de fragilisation.

Le projet européen est également confronté à la question de sa légitimité politique ainsi qu'à celle de la distance qui sépare l'Europe communautaire de ses citoyens. Ces derniers peinent à s'identifier à une construction qu'ils perçoivent avant tout comme une machine bureaucratique, non-transparente et non-démocratique. L'opinion dominante conçoit l'UE comme un acteur qui opère davantage en faveur des grands groupes économiques privés que des populations européennes. Ce désintérêt pour la chose publique européenne contribue à miner sa légitimité politique ainsi qu'à alimenter l'essor de mouvements souverainistes et nationalistes portés par des sentiments eurosceptiques voire europhobes. Le Brexit est en grande partie le résultat de la montée en force d'un souverainisme britannique anti-européen. Cette difficulté que rencontre l'Europe communautaire à connecter avec ses citoyens s'explique également par la compétition inégale entre l'UE et ses États membres qui la défavorise : contrairement à la plupart des États membres, la construction européenne peine à s'enraciner dans une communauté politique (polity) d'autant qu'il n'y a pas de « peuple européen » duquel elle pourrait retirer une légitimité. Dès lors, la question qui se pose est de savoir comment l'UE politique peut se construire sans un sentiment d'appartenance surtout dans une période d'exacerbation des particularités nationales.

À ceci s'ajoute un autre enjeu pour l'UE, celui de l'absence d'un projet politique européen clair. Les récits fondateurs sur la réconciliation et la paix qui ont servis à l'unification européenne après les deux conflits mondiaux dévastateurs ne suffisent plus. Le discours sur l'union et la prospérité par le marché ne semble pas non plus suffire. Dès lors, sur base de quel projet politique l'UE peut-elle se construire ? Les décideurs européens manquent d'inspiration ou de boussole. Dès lors, étant donné que la réponse à la question tarde à se faire connaître, l'intégration européenne tend à naviguer à vue avec tous les risques de collision que cela comporte.

\section{L'Union européenne comme objet d'étude}

L'ensemble de ces questions ainsi que bien d'autres font l'objet de recherches incessantes de la part de politologues, juristes, économistes, historiens, sociologues et/ou philosophes. Il existe aujourd'hui une importante communauté scientifique aussi bien en UE qu'en dehors de celle-ci intéressée et animée par l'objet d'étude européen. Les recherches qui ressortent de l'activité scientifique de cette communauté portent bien évidement sur la dynamique, les problèmes et les enjeux internes à la construction européenne. Avec le temps, la dimension extérieure a commencé à capter l'attention des spécialistes en études européennes donnant ainsi lieu à de nombreuses publications sur le sujet.

Ceci étant, les recherches sur la construction européenne se sont longtemps caractérisées par une certaine tendance au «nombrilisme». En d'autres termes, elles avaient une propension à se concentrer principalement sur la dimension interne du projet européen en accordant une attention distraite à ses relations internationales et à l'impact de ses politiques extérieures. Les chercheurs et les publications scientifiques allaient surtout s'intéresser à l'étude des retombées de la construction du marché commun pour les États membres et les économies nationales ${ }^{1}$. Ils

${ }^{1}$ ESHAG, É. (1966), Present system of trade and payments versus full employment and welfare state, Oxford, Blackwell, 42 p.; TORRE, J. et BACCHETTA, M. (1980), « The uncommon market: European policies towards the clothing industry in the 1970s », Journal of Common Market Studies, vol. 19, n² 2, 95-122; GUIEU, P. et 
se penchaient sur le déploiement des politiques publiques européennes (politique agricole commune, politique commune de la pêche) et leurs impacts à l'échelle nationale ${ }^{1}$. Ils s'intéressaient au processus décisionnel, au partage des compétences, aux dynamiques de l'organisation (fonctionnement, accomplissements, limites) ainsi qu'à l'influence politique de la bureaucratie européenne («comitologie ») ${ }^{2}$. Ils s'interrogeaient également sur le type de régime politique pouvant naître au niveau européen dû à l'adoption de nouveaux traités, à la cessation de nouvelles compétences et/ou à la création de nouvelles instances à l'échelle supranationale. Le processus de construction européenne était-il en train de donner naissance à un État fédéral, à un système confédéral ou plutôt à des formes politiques plus proches du condominium $?^{3}$. D'autres qui investiguaient sur le rôle et le poids politique croissant des lobbies et groupes de pressions de toutes sortes gravitant autour des instances décisionnelles supranationales basées à Bruxelles s'interrogeaient sur l'essor d'une « lobbycratie » à l'échelle européenne ${ }^{4}$.

L'agenda des chercheurs en études européennes était aussi fortement conditionné par l'intérêt que ces derniers portaient aux thématiques ayant trait à la question de la légitimité (et aux canaux de légitimation) des institutions européennes et plus largement à la problématique du déficit démocratique en lien avec le processus décisionnel de l'UE$^{5}$. Telles étaient certaines des questions majeures qui préoccupaient et animaient la recherche en études politiques européennes.

Proportionnellement, la dimension extérieure était sous-étudiée. Il est vrai que le bloc européen disposait, à ses débuts, de compétences limitées en matière de politique internationale.

BONNET, C. (1987), « Completion of the Internal Market and Indirect Taxation », Journal of Common Market Studies, vol. $25 \mathrm{n}^{\circ} 3$, pp. 209-222.

${ }^{1}$ BUTTERWICK, M. W. et ROLFE, E. N. (1968), Food, Farming and the Common Market, Oxford, Oxford University press, 259 p. ; ALLEN, R. (1982), «Fishing for a Common Policy », Journal of Common Market Studies, 19, 2, pp. 123-139 ; FENNELL, R. (1985), «A Reconsideration of the Objectives of the Common Agricultural Policy », Journal of Common Market Studies, vol. 23, n 3, pp. 257-276; MOYER, W. H. et JOSLING, T. E. (1990), Agricultural Policy Reform: Politics and Process in the EU and the USA, Royaume-Uni, Harvester Wheatsheaf, 1990, 235 p.

${ }^{2}$ HAAS, E. (1958), The Uniting of Europe: Political, social and economic forces 1950-1957, Standford, Standford University Press, 552 p. ; LINDBERG, L. (1963), The political dynamics of European economic integration, Standford, Standford University Press, 367 p. ; LINDBERG, L. (1967), « The European Community as a political system: notes toward the construction of a model », Journal of Common Market Studies, vol. 5, n 4, pp. $344-387$; WAllaCE, H., WALlACE, W. et WEBB, C. (1977), Policy-Making in the European Communities, New York, John Wiley, 323 p. ; PELKMANS, J. et WINTERS, A. L. (1988), Europe's Domestic Market, Londres, Routledge, 149 p.

${ }^{3}$ MITRANY, D. (1965), « The prospect of integration: federal or functional », Journal of Common Market Studies, vol. 4, n 2, pp. 119-149; WALLACE, W. (1982), « Europe as a Confederation: The Community and the NationState », Journal of Common Market Studies, vol. 21, n 1, pp. 57-68 ; SCHMITTER, P. C. (1991), « The European Community as an Emergent and Novel Form of Political Domination », Working Paper/Instituto Juan March de Estudios e Investigaciones, Madrid, n² 26, 33 p. ; CAPARASO, J. A. (1996), « The European Union and Forms of State: Westphalian, Regulatory or Post-Modem? », Journal of Common Market Studies, vol. 34, n 1, pp. 2952.

${ }^{4}$ MEYNAUD, J. et SIDJANSKI, D. (1969), Les groupes de pression dans la Communauté européenne 19581968. Structure et actions des organisations professionnelles, Montréal, Université de Montréal, 503 p.; GOLDSTEIN, J. (1996), « The State and Interest Groups in a Framework of multilevel decision-making: the case of the European Union », Journal of European Public Policy, vol. 3, n 3, pp. 318-338 ; CLAEYS, P-H., GOBIN, C., SMETS, I., et WINAND, P. (1988), Lobbyisme, Pluralisme et intégration européenne, Bruxelles, Peter Lang, $455 \mathrm{p}$.

${ }^{5}$ LINDBERG, L. et SCHEIN-GOLD, S. (1970) Europe's Would-Be Polity: Patterns of Change in the European Community, Englewood Cliffs, Prentice-Hall, 314 p. ; TSOUKALIS, L. (1983), The European Community: past, present \& future, Oxford, B. Blackwell, 244 p. ; ADAMS, W. J. (1992), Singular Europe: Economy and Polity of the European Community after 1992, Michigan, University of Michigan Press, 388 p. ; TELÒ, M. (1995), Démocratie et construction européenne, Bruxelles, Éditions de l'Université de Bruxelles, 366 p. ; ANDERSEN, S. et ELIASSEN, K. (1996), The European Union: How Democratic is It? Londres, Sage, 295 p. 
Toutefois, elles n'étaient pas absentes de son champ d'action puisqu'il pouvait les déployer via la politique commerciale ou la coopération au développement sans compter que certaines politiques internes de l'Europe communautaire avaient déjà une composante externe, à l'instar du marché commun ou de la politique agricole commune.

Il arrivait que la dimension extérieure fasse l'objet d'une attention mais au détour de l'étude de la dialectique entre l'approfondissement et l'élargissement ${ }^{1}$ ou entre intergouvernementalisme et supranationalisme ${ }^{2}$. Souvent cette thématique était guidée par des questions tournant autour des implications que la consolidation ou l'extension du projet européen pouvaient avoir pour son fonctionnement. En d'autres mots, les réflexions scientifiques cherchaient à déterminer si un processus d'extension continue à d'autres États tiers ne risquait pas de contribuer à dissoudre la Communauté européenne en une vaste zone de libreéchange et partant affaiblir durablement tout projet d'Europe politique. En retour, d'autres étudiaient les implications de l'approfondissement de la construction européenne pour ses États membres et s'interrogeaient sur l'impact du phénomène de souveraineté partagée («pooled souverenity $»^{3}$ ) pour le pouvoir national. Il arrivait également que l'action internationale de l'Europe communautaire soit étudiée au travers de l'étude des relations transatlantiques ${ }^{4}$ ou de la politique commerciale commune ${ }^{5}$. Toutefois, l'étude de la dimension extérieure du bloc européen restait malgré tout fort limitée.

Toutefois, avec la fin de la guerre froide, la structure communautaire existante est consolidée, de nouvelles institutions sont créées, de nouvelles stratégies communes sont adoptées à l'échelle européenne et le projet d'une Europe politique est mis sur les rails. À mesure qu'il se développe, le bloc européen se voit davantage confronté à l'international. L'agenda des chercheurs s'élargit débouchant sur une réflexion plus systématique sur des thématiques davantage liées à la dimension extérieure de l'Union.

Plusieurs explications permettent de comprendre l'intérêt croissant que les chercheurs vont accorder à l'étude de la dimension extérieure de l'Union. Parmi ceux-ci, nous pouvons en épingler trois. Tout d'abord, le fait que l'Europe communautaire dispose dorénavant d'un éventail de politiques qui couvre l'ensemble des enjeux les plus conséquents de la politique globale contemporaine. En effet, les outils dont l'Union dispose, lui permettent, théoriquement, de mener des actions dans le domaine de la sécurité et de la défense, d'exercer un rôle dans le commerce international, le développement ou l'humanitaire, ainsi que de tisser des liens étroits avec des acteurs de son environnement géographique proche et éloigné tant au travers de ses

\footnotetext{
${ }^{1}$ KOHNSTAMM, M. et HAGER, W. (1973), A Nation Writ Large? Foreign-Policy Problems before the European Community, Londres, Macmillan, 275 p.; PUISSOCHET, J-P. (1974), L'élargissement des Communautés européennes, Paris, Éditions Techniques et Économiques, 640 p.; DEUBNER, C. (1980), « The southern enlargement of the European Community: opportunities and dilemmas from a West German point of view », Journal of Common Market Studies, vol. 18, $\mathrm{n}^{\circ} 3$, pp. 229-245 ; EVERLING, U. (1980), « Possibilities and limits of European integration », Journal of Common Market Studies, vol. 18, n 3, pp. 217-228 ; GORCE, M. (1980), « Spain: Knocking on the Door », Harvard International Review, vol. 4, n ${ }^{\circ}$ 5, pp. 38-40.

${ }^{2}$ SMITH, A. (2004), Le gouvernement de l'Union européenne. Une sociologie politique, Paris, Librairie générale de droit et de jurisprudence, $195 \mathrm{p}$.

${ }^{3}$ Ce terme est utilisé pour désigner le partage des pouvoirs de décision entre les États au sein d'organisations multilatérales à l'instar de l'Union européenne ; cf. RITTBERGER, B. (2009), "Pooled sovereignty », dans MCLEAN, I. et MCMILLAN, A. (2009), The Concise Oxford Dictionary of Politics (3).

4 KAISER, K. et SCHWARTZ, H-P, (1979), America and Western Europe: problems and prospects, Massachusetts, Lexington Books, 447 p. ; SERFATY, S. (1979), Fading Partnership: America and Europe after 30 years, Eastbourne, Praeger, 115 p. ; ALLEN, D. et SMITH, M. (1982), «Europe, the United States and the Middle East: A Case Study in Comparative Policy Making », Journal of Common Market Studies, vol. $22, \mathrm{n}^{\circ} 2$, pp. 125-146.

5 TWITCHETT, K. J. (1976), Europe and the World: The External Relations of the Common Market, Londres, Europa Publications, 210 p. ; YANNOPOULOS, G. N. (1985), «EC External Commercial Policies and East-West Trade in Europe », Journal of Common Market Studies, vol. 24, n 1, pp. 21-38.
} 
politiques d'élargissement et de voisinage que de ses relations diplomatiques ${ }^{1}$. Il faut, ensuite, mentionner que l'Europe communautaire non seulement renforce ses politiques internes mais en outre se dote d'une panoplie d'instruments internes ayant une composante externe (euro, environnement, marché commun, visas). La troisième explication qui peut être avancée concerne une prise de conscience : dans un monde globalisé où ce qui arrive quelque part peut affecter la vie des acteurs partout ailleurs, il n'est plus possible de penser l'intégration européenne sans l'appréhender dans son rapport avec le monde extérieur. Les chercheurs prennent acte du fait que l'UE et ses États membres n'évoluent pas dans un vide politique mondial et que ces derniers sont loin d'être exempts d'influences exercées par des acteurs et facteurs extérieurs. Les évènements du 11 septembre 2001, la crise systémique de 2008, les «printemps arabe» de 2011, la crise migratoire de 2015, la guerre commerciale sinoaméricaine déclenchée à partir de 2018 ou la pandémie du Covid-19 ont toutes eu des répercussions sur l'intégration européenne. En outre, l'UE n'est pas à l'abri d'influence d'acteurs extérieurs. L'action d'États tiers comme celle déployée par les États-Unis ou les organisations multilatérales, à l'instar du Fonds Monétaire International (FMI), de la Banque Mondiale (BM), de l'Organisation Mondiale du Commerce (OMC) ou de l'Organisation du Traité de l'Atlantique Nord (OTAN), peuvent avoir une certaine incidence sur le contenu des politiques publiques (commerce, économie, coopération au développement, diplomatie ou sécurité) de l'UE².

\section{Les contributions aux Cahiers de science politique}

Le présent numéro spécial des Cahiers de science politique est le résultat d'une réflexion menée à l'occasion d'une journée d'étude scientifique organisée dans le cadre de l'Après-midi de recherche du département de Science politique de l'Université de Liège autour de la question du projet européen et plus particulièrement des Atouts, défis et enjeux de l'Union européenne.

Les organisateurs de cet événement et coordinateurs de cet ouvrage ont fait le choix avisé d'inscrire cette double activité scientifique dans une démarche d'ouverture et de dialogue interdisciplinaires en faisant participer à la réflexion des chercheurs spécialistes de politique comparée, de relations internationales, de politique publique, de droit économique ou de politique interne.

Les recherches reprises dans ce numéro spécial traitent de sujets forts variés relevant du nucléaire, de la politique commerciale, des questions stratégiques et militaires, des relations extérieures ou de la place des institutions et des États dans le processus décisionnel européen. Chacune des contributions présentées dans cette publication aborde des sujets très spécifiques.

\footnotetext{
${ }^{1}$ BRETHERTON, C. et VOGLER, J. (2006), The European Union as a Global Actor, Londres, Routledge, 273 p ; PETITEVILlE, F. (2006), La politique internationale de l'Union européenne, Paris, Les Presses Sciences Po, 280 p. ; ORBIE, J. (dir.), (2008), Europe's Global Role, Angleterre, Ashgate, 267 p. ; TELÒ, M. et PONJAERT, F. (dir.) (2013), The EU's Foreign Policy. What Kind of Power and Diplomatic Action? Londres, Ashgate, 248 p. ; BARBÉ, E. (dir.), (2014), La Unión Europea en las Relaciones Internacionales, Madrid, Tecnos, 443 p.; KEUKELEIRE, S. et DELREUX, T. (2014), The Foreign Policy of the European Union, New York, Palgrave Macmillan, 408 p. ; SMITH, M., KEUKELEIRE, S. et VANHOONAKER, S. (dir.) (2016), The Diplomatic System of the European Union, New York, Routledge, 310 p. ; HILL, C., SMITH, M. et VANHOONACKER, S. (dir.) (2017), International Relations and the European Union, Oxford, Oxford University Press, 570 p.

2 SANTANDER, S. (2008), Le régionalisme sud-américain, l'Union européenne et les États-Unis, Bruxelles, Éditions de l'Université de Bruxelles, 2008, 280 p.; SANTANDER, S. (dir.) (2012), Les puissances émergentes : un défi pour l'Europe? Paris, Ellipses, 384 p. ; SANTANDER, S. (2014), « The EU and the Shifts of Power in the International Order: Challenges and Responses », European Foreign Affairs Review, vol. 19, n 1, pp. 65-81 ; SANTANDER, S. et VLASSIS, A. (2020), «EU in global affairs: constrained ambition in an unpredictable world? », European Foreign Affairs Review, vol. 25, n 1, pp. 3-21 ; SANTANDER, S. (2020), « The Atlantic Triangle in the Era of China's Rising Power in Latin America », dans TELÒ, M. and FENG, Y. (dir.) (2020), China and the EU in the Era of Regional and Interregional Cooperation, Bruxelles, Peter Lang, pp. 239-256.
} 
Toutefois, elles possèdent toutes un seul et unique objet d'étude, celui de l'intégration européenne.

La première contribution porte sur les rapports entre l'UE et ses États. Ceux-ci sont appréhendés au travers de la sécurité coopérative et de la défense au sein de l'Union. Comme le précise André Dumoulin, ce sont deux domaines qui relèvent de la compétence des États membres. Toutefois, bien que ces derniers soient les maîtres du jeu, il existe des mécanismes via lesquels un nombre limité d'États membres peuvent déployer au nom de l'UE des actions dans le domaine sécurité-défense à condition que ceux qui s'abstiennent de participer n'entravent pas la mission. Ceci étant l'abstention constructive - ou ce que l'auteur appelle «flexibilité conditionnelle»-rencontre des limites. Raisons pour lesquelles la réflexion d'André Dumoulin cherche à savoir quelles pourraient être les conditionnalités structurelles à un véritable intégratif sécurité-défense. Pour lui, une des clés pourrait venir de l'aboutissement d'une réelle autonomie diplomatique européenne parallèlement à un souverainisme partagé européen.

Alors que la première contribution présentée dans ce numéro explore en priorité le processus décisionnel interne, celle proposée par Kamal Bayramzadeh se propose d'évaluer l'impact de l'Union sur l'environnement international à partir de ses politiques. La réflexion tourne donc autour de la question de la construction de l'UE comme acteur international. Pour ce faire, elle s'intéresse à son action extérieure et plus particulièrement au rôle qu'elle exerce dans la résolution des crises internationales. L'étude de cas qui anime cette recherche concerne la crise du nucléaire iranien et le rôle exercé par l'UE dans la conclusion de l'accord sur le nucléaire iranien de 2015. Pour l'auteur, l'UE dispose d'une série d'attributs de la puissance qui lui permettent d'exercer une certaine influence internationale. Elle participe à la médiation, à la gestion des crises, à l'instauration de la paix et à la démocratisation de plusieurs pays. Son rôle doit également être mesuré, selon l'auteur, en fonction du contexte, des conditions politiques et du facteur des rapports des forces internationaux. Ceci permet de mieux entrevoir la portée de l'action internationales de l'UE qui comparée à l'action des grandes puissances étatiques, reste limitée d'autant plus quand il s'agit du domaine relevant de la « high politics » (sécurité-défense).

La contribution de Philippe Vincent mobilise une double démarche méthodologique. Elle se propose, d'une part, d'analyser la mécanique interne à l'UE par le truchement de l'étude des rapports interinstitutionnels européens et, d'autre part, d'observer l'impact des politiques déployées par l'Union sur le monde extérieure. Pour ce faire, l'auteur se concentre sur l'étude de la Politique commerciale européenne et constate que, suite au blocage des négociations commerciales multilatérale au sein de l'OMC, l'UE n'hésite pas à chercher des voies alternatives afin d'avoir accès à de nouveaux marchés et à signer des accords commerciaux bilatéraux de "nouvelle génération » avec toute une série d'acteurs tiers. Ces accords sont portés par un agenda ambitieux qui couvre aussi bien le commerce de marchandises que le commerce des services, la propriété intellectuelle ou les investissements internationaux. Les accords de nouvelle génération sont négociés par la Commission européenne au nom des États membres. Toutefois, ce sont ces derniers qui octroient le mandat de négociation à la Commission. Depuis le traité de Lisbonne (2009), une troisième institution est entrée dans le jeu. Il s'agit du Parlement européen. Tout accord négocié doit être ratifié aussi bien par le Conseil que par le Parlement européen. Mais on oublie souvent que d'autres institutions européennes peuvent intervenir dans ce jeu. C'est le cas de la Cour de Justice de l'Union Européenne (CJUE) qui comme le rappelle Philippe Vincent a fait l'objet de deux demandes d'avis sur les accords de nouvelle génération. Les avis émis par celle-ci peuvent contraindre l'UE à modifier sa position dans les négociations avec les partenaires tiers.

La quatrième et dernière contribution est celle de Vincent Bricart qui prolonge la réflexion sur la Politique commerciale européenne menée dans l'article précédent. La 
perspective adoptée dans la présente est double : il s'agit d'analyser la place des institutions à partir d'une approche comparative. La contribution s'intéresse aux rôles exercés par les assemblées parlementaires des États-Unis et de l'UE en matière de politique commerciale et plus précisément en lien avec les accords de nouvelle génération, tels que le Partenariat Transatlantique de Commerce et d'Investissement (TTIP), l'Accord Économique et Commercial Global (CETA) et l'Accord de Partenariat Transpacifique (TPP). La question qui anime la présente est de savoir si les assemblées parlementaires comme le Congrès américain et le Parlement européen sont à même de peser dans les processus décisionnels de leur pays et d'infléchir le résultat final des tractations commerciales. Le constat dégagé par Vincent Bricart est le suivant : face à l'impact grandissant de la globalisation sur le quotidien des citoyens, les assemblées législatives tendent à s'impliquer davantage dans le domaine de la diplomatie commerciale et partant gagnent en importance et en visibilité dans leur fonction vis-à-vis de ces accords commerciaux de nouvelle génération.

\section{Bibliographie}

ADAMS, W. J. (1992), Singular Europe: Economy and Polity of the European Community after 1992, Michigan, University of Michigan Press, 388 p.

ALLEN, R. (1982), «Fishing for a Common Policy », Journal of Common Market Studies, vol. 19, $\mathrm{n}^{\circ} 2$, pp. 123-139.

ALLEN, D. et SMITH, M. (1982), «Europe, the United States and the Middle East: A Case Study in Comparative Policy Making », Journal of Common Market Studies, vol. 22, ${ }^{\circ}$ 2, pp. $125-146$.

ANDERSEN, S. et ELIASSEN, K. (1996), The European Union: How Democratic is It? Londres, Sage, 295 p.

BUTTERWICK, M. W. et ROLFE, E. N. (1968), Food, Farming and the Common Market, Oxford, Oxford University press, 259 p.

CAPARASO, J. A. (1996), "The European Union and Forms of State: Westphalian, Regulatory or Post-Modem? », Journal of Common Market Studies, vol. 34, n 1, pp. 29-52.

ClAEYS, P-H., GOBIN, C., SMETS, I. et WINAND, P. (1998), Lobbyisme, Pluralisme et intégration européenne, Bruxelles, Peter Lang, 455 p.

DEUBNER, C. (1980), « The southern enlargement of the European Community: opportunities and dilemmas from a West German point of view », Journal of Common Market Studies, vol. 18, n 3 , pp. 229-245.

ESHAG, É. (1966), Present system of trade and payments versus full employment and welfare state, Oxford, Blackwell, $42 \mathrm{p}$.

EVERLING, U. (1980), «Possibilities and limits of European integration », Journal of Common Market Studies, vol. 18, n 3, pp. 217-228. 
FENNELL, R. (1985), «A Reconsideration of the Objectives of the Common Agricultural Policy », Journal of Common Market Studies, vol. 23, n 3, pp. 257-276.

GOLDSTEIN, J. (1996), "The State and Interest Groups in a Framework of multilevel decision-making: the case of the European Union », Journal of European Public Policy, vol. 3, $\mathrm{n}^{\circ} 3$, pp. 318-338.

GORCE, M. (1980), «Spain: Knocking on the Door », Harvard International Review, vol. 4, $\mathrm{n}^{\circ} 5$, pp. 38-40.

GUIEU, P. et BONNET, C. (1987), «Completion of the Internal Market and Indirect Taxation », Journal of Common Market Studies, vol. 25, n³ 3, pp. 209-222.

HAAS, E. (1958), The Uniting of Europe: Political, social and economic forces 1950-1957, Standford, Standford University Press, 552 p.

KAISER, K. et SCHWARTZ, H-P. (1979), America and Western Europe: problems and prospects, Massachusetts, Lexington Books, $447 \mathrm{p}$.

LINDBERG, L. (1963), The political dynamics of European economic integration, Standford, Standford University Press, 367 p.

LINDBERG, L. et SCHEIN-GOLD, S. (1970), Europe's Would-Be Polity: Patterns of Change in the European Community, Englewood Cliffs, Prentice-Hall, 314 p.

LINDBERG, L. (1967), « The European Community as a political system: notes toward the construction of a model », Journal of Common Market Studies, vol. 5, n 4, pp. 344-387.

KOHNSTAMM, M. et HAGER, W. (1973), A Nation Writ Large? Foreign-Policy Problems before the European Community, Londres, Macmillan, 275 p.

MEYNAUD, J. et SIDJANSKI, D. (1969), Les groupes de pression dans la Communauté européenne 1958-1968. Structure et actions des organisations professionnelles, Montréal, Université de Montréal, 503 p.

MITRANY, D. (1965), «The prospect of integration: federal or functional », Journal of Common Market Studies, vol. 4, n² 2, pp. 119-149.

MONNET, J. (1976), Mémoires, Paris, Fayard, 642 p.

MOYER, W. H. et JOSLING, T. E. (1990), Agricultural Policy Reform: Politics and Process in the EU and the USA, Royaume-Uni, Harvester Wheatsheaf, $235 \mathrm{p}$.

PELKMANS, J. et WINTERS, A. L. (1988), Europe's Domestic Market, Londres, Routledge, $149 \mathrm{p}$.

PUISSOCHET, J-P. (1974), L'élargissement des Communautés européennes, Paris, Éditions Techniques et Économiques, 640 p. 
RITTBERGER, B. (2009), « Pooled sovereignty », dans MCLEAN, I. et MCMILLAN, A., The Concise Oxford Dictionary of Politics (3).

SANTANDER, S. (2008), Le régionalisme sud-américain, l'Union européenne et les ÉtatsUnis, Bruxelles, Éditions de l’Université de Bruxelles, 280 p.

SANTANDER, S. (dir.) (2012), Les puissances émergentes : un défi pour l'Europe ? Paris, Ellipses, $384 \mathrm{p}$.

SANTANDER, S. (2014), "The EU and the Shifts of Power in the International Order: Challenges and Responses », European Foreign Affairs Review, vol. 19, n 1, pp. 65-81.

SANTANDER, S. et VLASSIS, A. (2020), «EU in global affairs: constrained ambition in an unpredictable world? », European Foreign Affairs Review, vol. 25, n 1, pp. 3-21.

SANTANDER, S. (2020), « The Atlantic Triangle in the Era of China's Rising Power in Latin America », dans TELÒ, M. and FENG, Y. (dir.) (2020), China and the EU in the Era of Regional and Interregional Cooperation, Bruxelles, Peter Lang, pp. 239-256.

SCHMITTER, P. C. (1991), «The European Community as an Emergent and Novel Form of Political Domination », Working Paper/Instituto Juan March de Estudios e Investigaciones, Madrid, $\mathrm{n}^{\circ} 26,33 \mathrm{p}$.

SMITH, A. (2004), Le gouvernement de l'Union européenne. Une sociologie politique, Paris, Librairie générale de droit et de jurisprudence, $195 \mathrm{p}$.

TSOUKALIS, L. (1983), The European Community: past, present \& future, Oxford, B. Blackwell, $244 \mathrm{p}$.

SERFATY, S. (1979), Fading Partnership: America and Europe after 30 years, Eastbourne, Praeger, $115 \mathrm{p}$.

TELÒ, M. (1995), Démocratie et construction européenne, Bruxelles, Éditions de l'Université de Bruxelles, $366 \mathrm{p}$.

TORRE, J. et BACCHETTA, M. (1980), « The uncommon market: European policies towards the clothing industry in the 1970s », Journal of Common Market Studies, vol. 19, $\mathrm{n}^{\circ}$ 2, pp. 95 122.

TWITCHETT, K. J. (1976), Europe and the World: The External Relations of the Common Market, Londres, Europa Publications, 210 p.

WALLACE, W. (1982), «Europe as a Confederation: The Community and the Nation-State », Journal of Common Market Studies, vol. 21, $\mathrm{n}^{\circ}$ 1, pp. 57-68.

WAllace, H., WAllaCE, W. et WEBB, C. (1977), Policy-Making in the European Communities, New York, John Wiley, 323 p.

YANNOPOULOS, G. N. (1985), «EC External Commercial Policies and East-West Trade in Europe », Journal of Common Market Studies, vol. 24, n 1, pp. 21-38. 


\title{
Le processus de plasticité stratégique et tactico- opérationnelle des pays membres de l'Union Européenne
}

\author{
André Dumoulin ${ }^{1}$
}

\section{Résumé}

La flexibilité conditionnelle dans le domaine de la sécurité coopérative et de la défense au sein de l'Union Européenne (UE) renvoie à l'idée de volontariat et de souveraineté des États. Ces derniers sont les maitres du jeu et le refus de s'engager repose sur de nombreuses motivations : refus ou peur de grimper sur le terrain, refus d'être emporté par une opinion publique interventionniste, absence d'intérêts stratégiques, géopolitiques ou économiques en matière d'engagement, absence de mandat de l'Organisation des Nations Unies (ONU), faible disponibilité des ressources militaires et civiles, évaluation négative des pertes estimées, manque de conviction, manque de culture stratégique interventionniste (première entrée), hostilité des citoyens envers les engagements extérieurs, manque de consensus au sein du gouvernement et/ou parlement, calendrier électoral trop proche, manque d'informations sur la situation sur le terrain ou manque de partenaires pour une coalition.

L'une des clés pourrait provenir de l'aboutissement d'une véritable autonomie diplomatique européenne parallèlement à une souveraineté européenne partagée mais aussi et surtout d'assurer «le suivi des décisions adoptées » et de parvenir à une forte cohérence en matière de politique étrangère qui devrait être unique. Le constructivisme n'est pas loin avec ses jeux d'influence, le partage des normes, les croyances partagées, la socialisation institutionnelle et les pratiques communes entre les forces militaires dans les opérations de la Politique de Sécurité et de Défense Commune (PSDC), l'union faisant la force. Il reste à clarifier et à respecter une feuille de route politique autant qu'une capacité de plus de cohérence et d'autonomie stratégique. Les États membres de l'UE devront proposer une analyse commune des menaces, définir les intérêts, puis les capacités, « pour protéger tous ses citoyens sur le sol européen ».

Mots-clés: Coopération ; Prise de risque ; Souveraineté ; PSDC ; Capacitaire

\footnotetext{
${ }^{1}$ André Dumoulin est, depuis 2013, rattaché à l'Institut Royal Supérieur de Défense (IRSD) dans les murs de l'École Royale Militaire (ERM). Comme chargé de cours, il donne également cours à l'l'Université de Liège (ULiège) sur les problèmes de défense et la Politique de Sécurité et de Défense Commune (PSDC). Membre du comité de lecture de la Revue de Défense nationale (Paris) et plus récemment membre du nouveau Centre d'Étude du Terrorisme et la Radicalisation (CETR), créé par le professeur criminologue Michaël Dantinne (ULiège).
} 


\section{Introduction}

Lorsque nous abordons le processus décisionnel au sein de l'Union Européenne (UE) en matière de sécurité-défense, nous ne pouvons que confirmer combien la dimension intergouvernementale est prégnante. Elle gouverne bien des décisions et permet aux États membres de conserver un degré important de souveraineté politique et stratégique. La souveraineté est une thématique largement abordée en théorie de science politique mais aussi en droit, en philosophie et en sociologie. Elle interroge aussi les notions d'alliance et de coalition ${ }^{1}$.

Pour Gérard Mairet, elle peut reposer sur des fondements métaphysiques, juridiques, éthiques et historiques ${ }^{2}$. Il s'agira ici de prendre le terme dans sa définition externe à savoir la façon d'organiser, de structurer et de diriger un espace géographique délimité à l'intérieur duquel est «enfermé » le citoyen. Certes, aujourd'hui, la souveraineté ne peut plus avoir son caractère absolu à l'image de la pensée du philosophe Thomas Hobbes et de son Léviathan. La mondialisation et la globalisation ${ }^{3}$, le droit de la guerre, le droit international humanitaire, le devoir d'ingérence et la responsabilité de protéger, tout comme les poussées régionalistes des nationalismes périphériques ${ }^{4}$ ont fortement entravé et bousculé l'hégémonie étatique des pays occidentaux et engagé le resserrement des interdépendances ${ }^{5}$ entre les États. Quant à la définition juridique, elle stipule qu'un État ne peut être contraint par aucun autre État sauf consentement express.

Même les règles communautaires de l'UE imposent une nouvelle définition des compétences des États membres vers un certain affaiblissement étatique ${ }^{6}$. Pour les États qui y ont adhéré volontairement, c'est alors l'acceptation d'une réduction de leur souveraineté. Néanmoins, pour Jean L. Cohen, la globalisation ne remet pas nécessairement en cause l'État et la souveraineté qui y est associée ; elle tend à créer les conditions d'un ordre mondial dualiste où le droit de la société interétatique (avec l'État vu comme sujet et créateur des règles du droit international) doit s'articuler avec les valeurs communes et universelles ${ }^{7}$.

Mais si la souveraineté dite absolue n'est dès lors plus le véhicule des relations internationales, la conception d'une souveraineté territoriale vu comme territoire précis reste préservée. La territorialité est un élément moteur de ce qui va fondre l'expression étatique du pouvoir mais aussi les interactions entre les nations, les enjeux multinationaux, les alliances.

Aussi, le premier interlocuteur reste l'État souverain lorsqu'il s'agira de définir sa politique de défense et négocier la solidarité, la prise de risque, l'engagement multinational. Dès lors que c'est autour de la souveraineté que s'ordonne la pensée du politique, à l'époque contemporaine c'est l'État qui est à la fois «porteur du titre », disposant du monopole de la force publique, et principal sujet du droit international avec la zone grise juridique et politique que sont les société privées de sécurité. La souveraineté produit en quelque sorte l'indépendance des États, avec, en filigrane, toute la dialectique de la puissance politique et de l'autonomie de décision et d'action.

\footnotetext{
${ }^{1}$ Cf. à ce sujet HOLEINDRE J.V. et ROBIN M. (2019), « Qu’est-ce qu’un allié ? », Inflexions, n 41, Paris, pp.67 et sv.

${ }^{2}$ MAIRET G. (1997), Le principe de souveraineté. Histoires et fondements du pouvoir moderne, Gallimard, pp. 185 et sv.

${ }^{3}$ BADIE B. (1999), Un monde sans souveraineté. Les États entre ruse et responsabilité, Fayard.

${ }^{4}$ DIECKHOFF A. (2000), La Nation dans tous ses États. Les identités nationales en mouvement, Flammarion.

${ }^{5}$ DEVIN, G. (2013), Un seul monde : évolution de la coopération internationale, CNRS Editions.

${ }^{6}$ ROUET G. (2011), Citoyennetés et nationalités en Europe. Articulations et pratiques, L'Harmattan.

${ }^{7}$ COHEN J.L. (2012), Globalization and Sovereignty-Rethinking legality, legitimacy and constitutionalism, Cambridge University Press.
} 


\section{De la flexibilité des engagements extérieurs}

Dans le domaine des interventions en gestion de crises, le principe de l'unanimité est requis mais l'abstention constructive inscrite dans l'article 31 du Traité sur l'Union Européenne (TUE) de Lisbonne permet, par une Déclaration formelle d'un ou de plusieurs États membres, de ne pas participer sans bloquer le processus d'engagement. La solidarité est de mise tout en permettant de sortir de l'inertie de certaines capitales, nonobstant l'existence d'une minorité de blocage si un tiers des États membres et un tiers de la population de l'UE (double conditionnalité) refuse le principe d'une mission ou d'une opération de Politique de Sécurité et de Défense Commune (PSDC).

Cette flexibilité conditionnelle renvoie à l'idée du volontariat et de la souveraineté des États. Ces derniers sont maîtres du jeu et le refus d'engagement repose sur bien des motivations : refus ou peur de l'escalade sur le terrain, refus de se laisser entraîner par une opinion publique interventionniste, absence d'intérêts stratégiques, géopolitiques ou économiques dans la zone d'engagement, absence de mandat onusien, faible disponibilité en moyens militaires et civils, évaluation négative des pertes estimées, absence de conviction, manque de culture stratégique ${ }^{1}$ interventionniste (premier entré), hostilité citoyenne face aux engagements extérieures, absence de consensus au sein du gouvernement et/ou du parlement, calendrier électoral trop proche, défaut de renseignements sur la situation sur le terrain ou manque de partenaires pour une coalition.

Ainsi, pour la France, «l'utilisation des forces armées est toujours politique, toujours. Elle doit répondre à des objectifs qui sont fixés par le pouvoir politique et correspondre aux intérêts de la France qui sont définis par les gouvernements et par le président de la République, bien entendu, car c'est le sens d'une démocratie et de nos institutions $»^{2}$. D'autres pays ont également assimilé ces principes, avec leurs spécificités politiques et parlementaires.

Parmi ces critères, celui de la prise de risque reste majeur. En effet, les opérations militaires en général et les opérations associées à la PESD/PSDC de l'UE (ou dans le cadre de l'Organisation du Traité de l'Atlantique Nord (OTAN)) ne peuvent être étudiées si on ne prend pas en compte, très en amont, quatre critères : la solidarité entre États participants et leurs forces multinationalisées, le poids de la souveraineté et des restrictions associées à la prise de risque militaire et politique, la question de la prise de risque et, au final, la capacité d'entrer en premier dans les zones d'intervention.

Il s'agira pour les observateurs de définir les facteurs sociologiques, militaires, politiques, médiatiques et techno-doctrinaux qui influent en tout ou en partie dans la dimension hautement délicate de la prise de risque en missions et opérations. Les conséquences en sont aussi plurielles : privatisation de la sécurité, gradualisme des engagements, prise de distance dans un jeu asymétrique en miroir avec l'usage de drones, érosion subtile de la dimension de guerrier, différentiel de la valeur des vies à défendre, prise de conscience renouvelée du posttraumatique. Quel équilibre dès lors entre le volontarisme d'États qui partent en premier, la prudence attentiste des autres et ceux qui suivent, avec effet retard, comme " poissons-pilotes » qui, comme chacun le sait, ne guident pas le prédateur, mais s'accrochent à lui ? La défense territoriale n'est plus l'expression militaire la plus visible. Ce constat va provoquer également

\footnotetext{
${ }^{1} C f$. à ce sujet la culture de prudence allemande associée au poids du Bundestag et à la permanence d'une « armée dite parlementaire » (HECK D. (2012), La culture stratégique allemande face à la guerre en Afghanistan, mémoire de master, ULB, Bruxelles; KAIM M. (2010), L'engagement militaire allemand en Afghanistan. Conditions, évaluation, perspectives, note du CERFA 76, IFRI, Paris ; DAVIS W. (2012), "The public opinion-foreign policy paradox in Germany: integrating domestic and international levels of analysis conditionally", European Security, $\mathrm{n}^{\circ}$ 3, pp. 347-369 ; BROCKMEIER S. (2013-2014), "Germany and the Intervention in Libya", Survival, vol. 55 $\mathrm{n}^{\circ}$ 6, IISS, pp. 63-70. Par exemple, au titre des caveats, un soldat allemand hors du territoire national doit recevoir les soins dans des conditions identiques à ceux qu'il pourrait avoir dans son pays.

2 PHILIPPE E., Premier ministre, à propos de la mort de 13 militaires dans le Liptako malien, 25 novembre 2019, Opération Barkhane.
} 
une révolution des esprits, toujours en cours aujourd'hui, passant du mental du militaire-citoyen aux valeurs à défendre et à faire partager dans un cadre européen. La question de la létalité est ici prégnante, sachant aussi qu'il y a une hiérarchie dans la prise des risques et ses conséquences morbides selon les moments, les lieux et les organisations ${ }^{1}$.

\section{Les restrictions nationales à l'emploi des forces}

Certaines restrictions nationales à l'emploi des forces en multinational (les caveats) concernent par exemples les tâches (pas d'intervention militaire dans la lutte anti-terroriste) les lieux (pas d'intervention en dehors des zones de responsabilité) ou le temps (nuit), là où les troupes peuvent opérer. Cela peut même aboutir à la non utilisation offensive de la force.

Certains caveats peuvent par exemple concerner la nécessité que les militaires soient clairement informés quand ils protègent des personnes ou des biens qui n'appartiennent pas à l'Organisation des Nations Unies (ONU) (ou à l'OTAN) ou encore une règle à propos de la force mortelle, qui ne peut être utilisée pour empêcher la fuite d'une personne détenue que si ladite personne utilise elle-même la force mortelle pendant son évasion. Il peut aussi s'agir de l'interdiction d'emploi de mines anti-personnel ou d'armes incendiaires, l'interdiction de l'utilisation de la force pour la défense des biens, y compris militaires ${ }^{2}$ ou le refus de bombarder des champs de pavot considérés comme des cibles civiles. Le processus de fixation des caveats est assez codifié. Un projet de Règles d'engagement (ROE) est d'abord établi par le commandement (UE ou OTAN). Le projet est ensuite transmis pour avis aux différentes capitales et plus précisément vers la hiérarchie militaire.

Pour les Belges, la Direction Générale Appui Juridique et Médiation (DGJM) (juristes) donne son avis avant que celui-ci reparte vers le quartier général national qui peut alors fixer les caveats. Les autorités civiles donnent ensuite leur feu vert pour l'opération avec ses restrictions nationales, mais elles peuvent y ajouter d'autres caveats, comme par exemple, la non-intervention en première ligne là où se déroulent les combats (exemples : hélicoptère sanitaire et avions de transport belges au Mali) ${ }^{3}$. Globalement, les ROE dépendent toujours de la nature de l'adversaire et du type de mission ; une des difficultés étant que certains caveats non annoncés apparaissent en cours de mission.

Parallèlement, nous pouvons noter un possible lien entre le degré de contrainte/contrôle via les caveats et la rapidité politique à s'engager dans une opération. Ainsi, les Baltes, les Géorgiens et les Polonais ont été très réactifs lorsqu'il s'est agi de répondre aux sollicitations françaises pour s'engager à leurs côtés en République Centre Africaine (RCA).

Dans d'autres circonstances, nous pouvons constater un différentiel dans la prise de risque et le choix des lieux de déploiement selon les forces nationales concernées, entre les forces déployées en zone d'engagement et celles disposées en zones «pacifiées », entre les engagements prudents et progressifs et un volontarisme solidaire et véloce. Il peut même s'agir de participer mais de manière discrète afin d'être vue comme une puissance civile, permettant d'engranger prestige et influence sans payer le prix politique qui est inévitablement associé à des pertes nationales.

La culture de la prudence atteint les États par une géométrie variable et inégalitaire. Elle repose sur l'histoire des Nations, le poids des parlements nationaux sur le contrôle des opérations extérieures et le degré de prise en compte des opinions publiques selon la culture militaire et l'histoire nationale des États. Ainsi, nous avons pu constater l'existence du jeu des doubles subordinations ou de surveillance des Quartiers Généraux (QG) multinationaux par les

\footnotetext{
${ }^{1}$ VAN DER LIJN J. and DUNDON J. (2014), "Peacekeepers at Risk: the lethality of peace Operations", Sipri Policy Brief, SIPRI.

${ }^{2}$ Seuls alors les tirs d'avertissement et le non-létal seraient permis.

${ }^{3}$ Cela n'empêcha aucunement les moyens belges de suivre, par sauts de puce, mais à distance, les changements des zones d'engagements franco-africains.
} 
différentes capitales engagées. Les officiers au service desdits QG communiquaient des renseignements à leurs propres capitales malgré l'engagement prioritaire à servir les opérations communes.

Réserve aussi, au vu de la culpabilité allemande issue de la Seconde Guerre mondiale aboutissant à des engagements minimaux ${ }^{1}$ ou à du non-engagement, malgré un débat en $2014^{2}$ sur une prise de conscience interne des conséquences négatives de ladite prudence opérationnelle. Cette frilosité opérationnelle n'entraîne pas nécessairement une sous-évaluation de la diplomatie mais elle la fragilise en partie. Attitude prudente qui peut également apparaître à la carte, dans d'autres capitales, selon les enjeux, les moments politiques internes, les choix diplomatiques nationaux et multilatéraux et certaines pressions indirectes provenant des alliances. Les États restent fortement associés à différentes formes de nationalisme ${ }^{3}$ avec l'idée d'identité nationale prise comme ciment majeur et comme référent dans les conflits ${ }^{4}$.

Cette plasticité, prise au sens d'agilité et d'adaptabilité, renvoie aux interdépendances entre les États, quand bien même la norme de souveraineté régalienne nationale et les intérêts sous-jacents sont toujours « en embuscade $»^{5}$. Interdépendance par une multinationalisation des opérations souhaitée par soucis de légalisme, de légitimité de partage des moyens. La spécialisation des moyens et les niches d'excellence, souvent par défaut des États les plus faibles, impose alors une dépendance des capitales entre elles lors des interventions pour ceux qui acceptent d'y participer. Certes, les perceptions sécuritaires des États membres de l'UE restent centrées sur leur immédiat voisinage (posture nordique, vision Sud, perception Est) mais l'étroitesse de l'espace commun impose un tropisme géopolitique commun, tel qu'illustré par la Stratégie européenne de sécurité (2003, 2008), puis la Stratégie globale (2016), devenue intégrée de l'UE (2018) mais aussi le nouveau programme stratégique 2019-2024 du Conseil de l'UE. Il y a bien imbrication d'intérêts géopolitiques, économiques et sécuritaires au sein de l'UE (perception partagée des menaces terroristes, hybrides et cyber), malgré l'absence d'un Livre blanc européen de la sécurité-défense, si souvent réclamé et jamais obtenu.

Les États conservent une double attitude : adoption par tous de Stratégies déclaratoires européennes partagées et maintien par chacun du critère géographique leur permettant de se garantir une souplesse et un capacitaire spécifique dans les engagements. De toute évidence, bien des outils multinationaux créés et organisés entre certains États sont associés à des espaces régionaux limitrophes : coopération franco-allemande dans le domaine du transport tactique aérien, bataillon balte, brigade italo-slovéno-hongroise, bataillon polono-lituanien, Nordscaps des États scandinaves, corps dano-germano-polonais pour la Baltique, partenariat brigades franco-belge, l'Eurocorps «carolingien», l'Amiral Benelux, régiments néerlandais directement intégrés dans des divisions allemandes ou l'Euromarforce des quatre pays de la rive nord de la Méditerranée. Et même après le Brexit, la Combined Joint Expedionary Force (CJEF) franco-britannique ou le groupe amphibie anglo-néerlandais seront toujours bel et bien présents. De manière conjoncturelle, on constate des coopérations militaires à la carte avec, par exemple, les Pays-Bas qui rejoignent, fin 2019, une mission européenne de sécurité maritime

\footnotetext{
1 DAVIS W. (2012), "The public opinion-foreign policy paradox in Germany: integrating domestic and international levels of analysis conditionally", op. cit, pp. 347-369; PACREAU X (2012), "Les conditions juridiques des operations extérieures allemandes », Annuaire français de relations internationales 2012, Centre Thucydide, La Documentation française, pp. 389-418.

${ }^{2}$ LEMAÎTRE F. (2014), « Pour une diplomatie allemande, l'indifférence n'est plus une option », Le Monde, 23 février; MAJOR C. et MÖLLING C. (2014), La politique de défense allemande en 2014 et au-delà : un changement est-il possible?, Note du Cerfa $\mathrm{n}^{\circ} 113$, IFRI.

${ }^{3}$ Cf. SMITH A. (1991), National Identity, University of Nevada Press ; ANDERSON B. (2006), L'imaginaire national, La Découverte ; GELLNER E. (1989), Nations et nationalisme, Payot.

${ }^{4}$ IGNATIEFF M. (2000), L'honneur du guerrier, pp. 33-72.

${ }^{5}$ Des forces nationales françaises intégrées dans une mission de l'ONU ont été « resorties » discrètement de ladite mission pour être «prêtées », sous contrôle national, pour une opération hors ONU (opération Barkhane).
} 
dans le Golfe baptisée « European-led mission Awareness Strait of Hormuz » ou l'étude lancée à l'été 2019 d'un mécanisme de présence maritime coordonnée entre Européns. De même, la souplesse tactico-opérationnelle est bel et bien présente autour d'exercices comme celui associant un C-130 belge atterrissant sur une plage danoise pour débarquer des Pathfinders néerlandais.

Quant aux Battlegroups de l'UE en alerte (Groupements tactiques 1500), ils sont organisés de manière volontaire (avec parfois des difficultés à remplir la grille des participations semestrielles ou annuelles) par des États recherchant une multinationalité de proximité. Et lorsque la coopération n'est pas uniquement basée sur des visions régionalistes, elle peut reposer aussi sur une complicité politique et doctrinale renvoyant à des États pouvant rapidement être associée avec la France, maître d'œuvre, pour des réflexions communes mais aussi pour des éventuels engagements hors du cadre institutionnel de l'UE.

C'est le cas de l'Initiative européenne d'intervention ${ }^{1}$ du président Macron (2018) qui peut être analysée comme un contournement éventuel des possibles lenteurs des instances de l'UE dans le cadre de la PSDC. Quant à la clause de défense partagée franco-allemande (Traité d'Aix-la-Chapelle, janvier 2019), n'est-elle pas aussi une réponse aux enseignements tirés de la mobilisation de la clause d'assistance mutuelle suite aux attentats de Paris où le constat fut fait d'une solidarité à la carte sinon frileuse des États européens ${ }^{2}$ à la demande de soutien provenant de l'Hexagone. Ou qu'elle peut être une réponse alternative à un blocage au sein de l'OTAN ? L'objectif officiel, qui fut précisé le 25 juin 2018, sera d'élaborer des prévisions stratégiques, scénarios d'engagement et du partage de renseignements, rédiger des scénarios et de la planification (facilitateur d'interventions), retour d'expérience/doctrine, soutenir des opérations et alimenter des retours d'expérience (RETEX) ${ }^{3}$, cela en organisant des échanges d'officiers. L'objectif est à la fois proactif mais aussi de pouvoir disposer si nécessaire d'une forte réactivité et des engagements opérationnels en cas de besoin autour de la France (secrétariat permanent à Paris), seul pays européen à pouvoir entrer en premier en prenant les premiers risques. Ceci en mobilisant d'autres pays volontaires avec lesquels la France a des habitudes de travail. Au final, est-ce les prémices d'un Eurogroupe de défense ?

\section{De la flexibilité capacitaire}

Nous pouvons de la même manière, dans le champ de la coopération en matière d'armement, décomposer la coopération en quatre niveaux autour du concept de «flexilatéralisme ». Selon Samuel Faure, il peut s'agir d'unilatéralisme (pas de coopération), de bilatéralisme, de minilatéralisme (coopération exclusive) ou de multilatéralisme (coopération inclusive) $)^{4}$. Dans ce paysage de la coopération, on devine aisément que c'est l'État qui va adapter son niveau de coopération en fonction de paramètres reposant prioritairement sur des intérêts nationaux. C'est d'autant plus vrai des nations-cadres et des puissances moyennes européennes disposant de vastes champs de compétences et d'industries stratégiques. La Coopération Structurée Permanente $(\mathrm{CSP})^{5}$, relancée par les quatre « Grands » européens en marge du Conseil franco-allemand de défense et de sécurité du 13 juillet 2017, et ses projets de coopération capacitaire et modulaire déposés finalement en décembre 2017 et en

\footnotetext{
${ }^{1}$ DUMOULIN A. (2018), L'initiative européenne d'intervention. Enjeux et supports, e-Notes n 25, Bruxelles, IRSD.

2 «La France a agi seule, sans consulter nos partenaires, et a ensuite eu du mal à obtenir un soutien pour nos opérations là-bas » (Florence Parly, ministre français de la Défense, ECFR, 28 mai 2018).

${ }^{3}$ Cf. à ce sujet, PANNIER A. (2017), Leçons opérationnelles et coopération interalliée : état des lieux et voies d'amélioration, Note de recherche $\mathrm{n}^{\circ} 48$, IRSEM.

${ }^{4}$ FAURE S. (2018), « La politique du 'flexilatéralisme' : le cas de la politique française d'armement dans le contexte du Brexit », Les champs de Mars, n³0, pp.73-101.

${ }^{5}$ MAULNY J.-P. et DI BERNARDINI L. (2019), Moving PeSCo forward : what are the next steps ?, Policy Paper n³9, Armament Industry European Research Group.
} 
décembre 2018, les processus de participation aux programmes de l'Agence Européenne de Défense (AED), le caractère volontaire du Mécanisme de l'examen coordonné en matière de défense (CARD) ${ }^{1}$ afin de réduire les duplications, la nouvelle place de la Commission dans le financement de la $R \& D$ et des prototypes ${ }^{2}$ et le nouveau Plan d'action sur la mobilité militaire (2018) sont autant de lieux où apparaissent cette géométrie variable des contributions et collaborations dans des espaces où la coopération est utile, nécessaire et budgétairement indépassable. Ce sont bien les capitales qui fixent les programmes de recherche et préparent les appels d'offres avant d'y répondre, à la carte.

Le partage des capacités opérationnelles et la spécialisation (niches) reposent sur l'idée qu'une nation détient une capacité réduite ou ne la détient pas ou plus et donc s'en remet à une ou plusieurs autres nations pour compléter ou suppléer. Cela impose un accord parfait en matière de politique étrangère, les uns dépendant fortement des autres. Dans l'UE, la politique des niches atteint la plupart des États membres - volontairement ou par défaut - créant un paysage où les États ne disposent plus de la totalité des moyens capacitaires. Une question se pose alors : comment mettre à disposition de son partenaire des capacités qui lui font défaut, alors que les buts et les risques ne sont pas partagés ${ }^{3}$ et que n'existe pas encore de Livre blanc européen de la sécurité-défense malgré bien des tentatives ${ }^{4}$ ?

Ces notions imposent une concertation toute en confiance sur les abandons étatiques, certes déjà favorablement assimilés par les petits États européens, mais suscitant quelques inquiétudes souveraines pour les États aux capacités dites stratégiques qui peuvent s'affronter en matière d'études technologiques ${ }^{5}$ ou en préservation de capacités industrielles nationales ${ }^{6}$.

Aussi, les abandons et les mutualisations concernent le plus souvent des secteurs moins sensibles politiquement ( $s o f t$ ), comme par exemple le médical ou le transport bien que tout autant stratégiques. La souveraineté dans le capacitaire est encore trop souvent dictée par la défense d'intérêts industriels, technologiques et d'emplois ${ }^{7}$. En outre, les liens transatlantiques et une géopolitique nationale aboutissent souvent à ce que certains États européens acquièrent du matériel américain, associant réponse au partage du fardeau, réassurance stratégique et pressions commerciales. Il n'y a pas de préférence européenne codifiée.

\section{Les garde-fous nationaux et leurs dépassements}

Il y a bien des limites à l'action commune et intégrée dans le cadre de la PSDC. Les automatismes sont fragilisés par l'intergouvernementalisme et l'emprise sur les actions par les États les plus influents, vus comme ressources d'autorité, de volonté et de puissance. Le refus d'adopter la proposition de Juncker et Mogherini sur le vote à la majorité qualifiée (abandon de

\footnotetext{
${ }^{1}$ VAN REYBROECK R. (2019), « What's in the CARDs ?», Security Policy Brief, $\mathrm{n}^{\circ}$ 103, Egmont Institute.

${ }^{2}$ Programme européen de développement industriel dans le domaine de la défense (EDIDP) et Fonds européen de défense (FEDef).

${ }^{3}$ FAUGÈRE J.-M. (2013), « Europe de la défense. Mutualisation de moyens et partage capacitaire... », DSI n ${ }^{\circ} 88$, pp. 56-58.

${ }^{4}$ MAURO F. (2018), EU Defence: The White Book implementation process, Directorate-General For External Policies, Policy Department, European Parliament, Brussels ; DUMOULIN A. (2011), «Vers un Livre blanc européen de la sécurité et de la défense : entre «objet non identifié et fenêtre d'opportunité » internationale et stratégique, $\mathrm{n}^{\circ} 82$, IRIS, Paris.

${ }^{5}$ Cf. par exemple, CHASSILLAN M. (2019), «Quel calibre pour le futur char franco-allemand (MGCS) ? », Tribune $\mathrm{N}^{\circ} 1075$, www.defnat.fr (consulté le $1^{\text {er }}$ juillet 2019) ; GIEGERICH B. (2019), « La coopération francoallemande de sécurité et de défense et l'autonomie stratégique européenne », Revue Défense nationale, $\mathrm{n}^{\circ} 821, \mathrm{pp}$. 43-49.

${ }^{6}$ BECHT O. et TROMPILLE S. (2019), Rapport d'information 1574 en conclusion des travaux d'une mission d'information sur le secteur spatial de défense, Assemblée nationale.

7 TECHAU J. (2013), “Will Europeans ever agree on the use of military Force ?”, Policy Paper, n 65, Notre Europe Jacques Delors Institute and Carnegie Europe. Cf. également les tensions franco-allemandes autour du commerce des armes en zones de conflits.
} 
l'unanimité qui reflète le poids de la souveraineté nationale) dans le domaine de la PESC en est un des exemples ${ }^{1}$. La politique étrangère européenne commune (et non unique) reste le plus petit commun dénominateur des politiques étrangères nationales qui sont « embusquées » bien en amont du collectif du rond-point Schuman. Et dans le domaine de la sécurité-défense, les verrous sont plus nombreux, les capitales veillent car il y a une responsabilité nationale régalienne dans la prise de risque face à leurs propres citoyens. Outre le fait que les intérêts géopolitiques et économiques nationaux ne sont pas toujours partageables et que les modes de pensée, l'histoire sociologique nationale et les cultures militaires restent complexes à fusionner. On en veut pour preuve la difficulté d'une France centralisée ${ }^{2}$ à saisir le brouillard politique, régionaliste et communautaire belge autour de la décision du remplacement des F-16.

S'il y a bien stratégies coopératives via des intérêts communs définis et partagés (constructivisme), les engagements restent à la carte, en noyaux limités, avec des processus d'influence, de persuasion, de séduction plutôt que de puissance. Il s'agit de maximiser les gains et réduire les coûts (calcul coûts/bénéfices), sachant qu'au final les interdépendances restent relatives surtout concernant les puissances européennes moyennes ${ }^{3}$.

Dans ce paysage mouvant et très plastique, quelles pourraient être les conditionnalités structurelles à un véritable intégratif sécurité-défense ? Bien des analyses furent faites autour de la montée en puissance de l'UE et à sa seconde fenêtre d'opportunité ${ }^{4}$ autant que sur les limites et les difficultés à dépasser l'inertie «naturelle» des États membres et les logiques corporatistes propres aux bureaucraties nationales, sans citer l'éparpillement de l'effort budgétaire. Et nous pouvons considérer que les coopérations à la carte et la géométrie variable ne suffisent pas à construire un outil de défense cohérent et intégratif, sauf à imaginer une avantgarde qui stimulerait l'ensemble des capitales.

Malgré les relations sociales propres aux agents européens du Comité Politique et de Sécurité (COPS), du Service Européen pour l'Action Extérieure (SEAE), de l'Agence Européenne de Défense (AED) et du Comité Militaire de 1'Union Européenne (CMUE) ${ }^{5}$ et leur narration partagée, les clivages transgouvernementaux restent persistants ${ }^{6}$ au point de rendre complexe toute convergence des cultures stratégiques nationales vers une culture stratégique partagée ${ }^{7}$.

Une des clés pourrait venir de l'aboutissement d'une réelle autonomie diplomatique européenne parallèlement à un souverainisme partagé européen mais aussi et surtout d'assurer « le suivi des décisions adoptées ${ }^{8}$ et d'aboutir à une forte cohérence en matière de politique étrangère qui se devrait d'être unique. Le constructivisme n'est pas loin avec ses jeux

\footnotetext{
${ }^{1}$ GROS-VERHEYDE N., « Le passage à la majorité qualifiée dans la politique étrangère remise à plus tard », 2 mai 2019, https://www.bruxelles2.eu/2019/05/02/le-passage-a-la-majorite-qualifiee-dans-la-politiqueetrangere-remise-a-plus-tard/ (consulté le 30 juin 2019).

${ }^{2}$ DUMOULIN A. (2018), « La coopération militaire belgofrançaise : oscillations politiques et identitaire », Revue Défense nationale, $\mathrm{n}^{\circ} 813$, pp. 116-122.

${ }^{3}$ Reste que la France dépend pour ses opérations en Afrique du transport stratégique britannique et américain.

${ }^{4}$ DUMOULIN A (2018), « PSDC : un basculement vers le haut », Défense \& sécurité internationale, hors-série $\mathrm{n}^{\circ}$ 61, Areion ; GROS-VERHEYDE N. (2019), https://club.bruxelles2.eu/2019/05/reflechir-a-leurope-de-ladefense-demain/ et https://club.bruxelles2.eu/2017/06/n52-le-paquet-defense-2017/ (consulté le 18 mai 2019); MAURO F. et JEHIN O. (2019), Défendre l'Europe, Nuvis ; Collectif, « Relancer la défense de l'Europe » (2019), Revue Défense nationale, $\mathrm{n}^{\circ} 819$, pp. 15-100 ; Collectif, «L'affirmation stratégique des Européens » (2019), Revue de Défense nationale, ${ }^{\circ} 821$, pp. 9-116.

${ }^{5}$ MAULNY J.-P. et NIVET B. (2008), Les acteurs et réseaux de la politique européenne de sécurité et de défense, Les Documents du C2SD n 97, Ministère de la Défense ; MERAND F. (2007), «L'Europe des diplomates, 1'Alliance des militaires. La PESD comme enjeu de luttes symboliques », Les champs de Mars. Questions de défense, $\mathrm{n}^{\circ} 19$, La Documentation française.

${ }^{6}$ WALLACE W. (1990), The Dynamics of European Integration, Pinter.

${ }^{7}$ BIAVA A. (2011), Vers une culture stratégique européenne ?, Université de Genève, Academia L'Harmattan.

${ }^{8}$ MOGHERINI F. (2017), Extrait déclaration faite le mercredi 17 avril 2017 au Parlement européen de Strasbourg (https://club.bruxelles2.eu/2019/04/mogherini-mes-cinq-annees-avec-vous/) (consulté le 9 juillet 2019).
} 
d'influence, le partage de normes, croyances partagées, une socialisation institutionnelle et des pratiques communes entre forces militaires en opérations PSDC, l'union faisant la force. Reste à clarifier et à respecter une feuille de route politique autant que capacitaire pour davantage de cohérence et d'autonomie stratégique. Il s'agira pour les États membres de l'UE d'aboutir à une analyse partagée des menaces, de définir les intérêts, puis les capacités « pour protéger tous ses citoyens sur le sol européen $»^{1}$. Quid d'un Conseil de sécurité européen ?

\section{Les futures orientations}

L'avenir de la PSDC sera dépendante aussi du paysage extrêmement mouvant d'aujourd'hui: Brexit, place de la Turquie dans le champ sécuritaire euro-atlantique, positionnement du curseur transatlantique et américain en Europe, perception sécuritaire des mouvements de migration et le niveau d'implication de la PSDC dans ce cadre, évolution de la relation franco-allemande toujours en dents de scie, degré de volonté à lutter contre les duplications et gaspillages versus corporatisme, concurrences et intérêts industriels et stratégiques nationaux avec le coût estimé dans la non-Europe autour de 22,15 milliards d'euros par an dans ce domaine, capacité à répondre au possible déclassement stratégique et à la dépendance aux technologies américaines. De même, pour Ronan le Gleut, il s'agira de « combler les lacunes capacitaires de nos armées et pas uniquement à faire des projets industriels portés par les entreprises » dans le cadre du Fonds européen de défense, tout en imaginant la création d'un commissaire européen de la défense.

Entre une UE qui pèse $22 \%$ de l'économie mondiale mais ne disposant pas encore d'une analyse vraiment partagée de la menace aboutissant à une vision stratégique commune, impliquant un territoire à défendre et d'une puissance à affirmer face aux nouveaux défis mondiaux et une UE des petits pas avec quelques États fortement intégrés en matière de sécurité-défense, les hypothèses restent multiples et les inconnues tout autant. La cohérence européenne et la volonté politique commune restant à venir.

L'intégration politico-militaire est lente et reste fragile mais elle devrait aboutir plus rapidement avec d'autant plus de pertinence si d'aventure le paysage du Vieux continent devait être concrètement menacé dans un environnement qui, aujourd'hui, voit réapparaître la compétition militaire parallèlement à la compétition commerciale et technologique et ses rivalités de puissance dans une grammaire complexe et multidimensionnelle ${ }^{2}$, quand bien même la réponse (au vu de l'article 42.7 du TUE) devra passer par la mobilisation de l'article 5 de l'OTAN en ce qui concerne les États membres de l'UE membres de l'Alliance atlantique !

\section{Bibliographie}

ANDERSON B. (2006), L ’imaginaire national, La Découverte.

BADIE B. (1999), Un monde sans souveraineté. Les États entre ruse et responsabilité, Fayard.

BECHT O. et TROMPILLE S. (2019), Rapport d'information 1574 en conclusion des travaux d'une mission d'information sur le secteur spatial de défense, Assemblée nationale.

BIAVA A. (2011), Vers une culture stratégique européenne ?, Université de Genève, Academia L'Harmattan.

\footnotetext{
${ }^{1}$ MAULNY J.-P. (2019), «Vers une autonomie stratégique européenne », Revue Défense nationale, $\mathrm{n}^{\circ} 821, \mathrm{pp}$. 86-87.

${ }^{2}$ Cf. BUHLER P. (2018), La puissance au XXIe siècle, CNRS Editions. Pour l'analyse de la hiérarchie entre États et les critères de classification, cf. SUR S. (2004), Relations internationales, Montchrestien, pp. 260-272.
} 
BROCKMEIER S. (2013-2014), "Germany and the Intervention in Libya", Survival, vol. 55, $\mathrm{n}^{\circ}$ 6, IISS, pp. 63-70.

BUHLER P. (2018), La puissance au XXI siècle, CNRS Éditions.

CHASSILLAN M. (2019), «Quel calibre pour le futur char franco-allemand (MGCS) ?», Tribune $\mathrm{N}^{\circ} 1075$, www.defnat.fr (consulté le $1^{\text {er }}$ juillet 2019).

COHEN J.L. (2012), Globalization and Sovereignty-Rethinking legality, legitimacy and constitutionalism, Cambridge University Press.

Collectif, «L'affirmation stratégique des Européens » (2019), Revue de Défense nationale, $\mathrm{n}^{\circ} 821$, pp. 9-116.

Collectif, «Relancer la défense de l'Europe » (2019), Revue Défense nationale, $\mathrm{n}^{\circ}$ 819, pp. 15100 .

DAVIS W. (2012), "The public opinion-foreign policy paradox in Germany: integrating domestic and international levels of analysis conditionally", European Security, n ${ }^{\circ} 3$, pp. 347369.

DEVIN, G. (2013), Un seul monde: évolution de la coopération internationale, CNRS Editions.

DIECKHOFF A. (2000), La Nation dans tous ses États. Les identités nationales en mouvement, Flammarion.

DUMOULIN A (2018), «PSDC: un basculement vers le haut», Défense \& sécurité internationale, hors-série $\mathrm{n}^{\circ} 61$, Areion.

DUMOULIN A. (2011), «Vers un Livre blanc européen de la sécurité et de la défense : entre « objet non identifié et fenêtre d'opportunité » », La Revue internationale et stratégique, $\mathrm{n}^{\circ} 82$, IRIS, Paris.

DUMOULIN A. (2018), « La coopération militaire belgofrançaise : oscillations politiques et identitaire », Revue Défense nationale, ${ }^{\circ}$ 813, pp. 116-122.

DUMOULIN A. (2018), L'initiative européenne d'intervention. Enjeux et supports, e-Notes $\mathrm{n}^{\circ} 25$, Bruxelles, IRSD.

FAUGÈRE J.-M. (2013), «Europe de la défense. Mutualisation de moyens et partage capacitaire... », DSI n ${ }^{\circ} 88$, pp. 56-58.

FAURE S. (2018), «La politique du 'flexilatéralisme': le cas de la politique française d'armement dans le contexte du Brexit », Les champs de Mars, ${ }^{\circ}$ 30, pp. 73-101.

GELLNER E. (1989), Nations et nationalisme, Payot.

GIEGERICH B. (2019), «La coopération franco-allemande de sécurité et de défense et l'autonomie stratégique européenne », Revue Défense nationale, n ${ }^{821}$, pp. 43-49. 
GROS-VERHEYDE N. (2019), « Le passage à la majorité qualifiée dans la politique étrangère remise à plus tard », 2 mai 2019, https://www.bruxelles2.eu/2019/05/02/le-passage-a-la-majorite-qualifieedans-la-politique-etrangere-remise-a-plus-tard/ (consulté le 30 juin 2019).

GROS-VERHEYDE N. (2019), https://club.bruxelles2.eu/2019/05/reflechir-a-leurope-de-ladefense-demain/ et https://club.bruxelles2.eu/2017/06/n52-le-paquet-defense-2017/ (consulté le 18 mai 2019).

HECK D. (2012), La culture stratégique allemande face à la guerre en Afghanistan, mémoire de master, ULB, Bruxelles.

HOLEINDRE J.V. et ROBIN M. (2019), «Qu'est-ce qu'un allié ? », Inflexions, n 41, Paris.

IGNATIEFF M. (2000), L'honneur du guerrier.

KAIM M. (2010), L'engagement militaire allemand en Afghanistan. Conditions, évaluation, perspectives, note du CERFA 76, IFRI, Paris.

LEMAÎTRE F. (2014), « Pour une diplomatie allemande, l'indifférence n'est plus une option », Le Monde, 2-3 février.

MAIRET G. (1997), Le principe de souveraineté. Histoires et fondements du pouvoir moderne, Gallimard.

MAJOR C. et MÖLLING C. (2014), La politique de défense allemande en 2014 et au-delà : un changement est-il possible ?, Note du Cerfa $n^{\circ} 113$, IFRI.

MAULNY J.-P. (2019), «Vers une autonomie stratégique européenne », Revue Défense nationale, $\mathrm{n}^{\circ} 821$.

MAULNY J.-P. et DI BERNARDINI L. (2019), Moving PeSCo forward: what are the next steps?, Policy Paper $n^{\circ} 39$, Armament Industry European Research Group.

MAULNY J.-P. et NIVET B. (2008), Les acteurs et réseaux de la politique européenne de sécurité et de défense, Les Documents du C2SD n ${ }^{\circ}$ 97, Ministère de la Défense.

MAURO F. (2018), EU Defence: The White Book implementation process, Directorate-General For External Policies, Policy Department, European Parliament, Brussels.

MAURO F. et JEHIN O. (2019), Défendre l'Europe, Nuvis.

MERAND F. (2007), «L'Europe des diplomates, l'Alliance des militaires. La PESD comme enjeu de luttes symboliques », Les champs de Mars. Questions de défense, $\mathrm{n}^{\circ} 19$, La Documentation française.

MOGHERINI F. (2017), Extrait déclaration faite le mercredi 17 avril 2017 au Parlement européen de Strasbourg (https://club.bruxelles2.eu/2019/04/mogherini-mes-cinq-annees-avecvous/) (consulté le 9 juillet 2019). 
PACREAU X (2012), «Les conditions juridiques des operations extérieures allemandes », Annuaire français de relations internationales 2012, Centre Thucydide, La Documentation française, pp. 389-418.

PANNIER A. (2017), Leçons opérationnelles et coopération interalliée : état des lieux et voies d'amélioration, Note de recherche $\mathrm{n}^{\circ} 48$, IRSEM.

ROUET G. (2011), Citoyennetés et nationalités en Europe. Articulations et pratiques, L'Harmattan.

SMITH A. (1991), National Identity, University of Nevada Press.

SUR S. (2004), Relations internationales, Montchrestien.

TECHAU J. (2013), “Will Europeans ever agree on the use of military Force?”, Policy Paper, $\mathrm{n}^{\circ}$ 65, Notre Europe Jacques Delors Institute and Carnegie Europe.

VAN DER LIJN J. and DUNDON J. (2014), "Peacekeepers at Risk: the lethality of peace Operations", Sipri Policy Brief, SIPRI.

VAN REYBROECK R. (2019), «What's in the CARDs? », Security Policy Brief, $\mathrm{n}^{\circ} 103$, Egmont Institute.

WALLACE W. (1990), The Dynamics of European Integration, Pinter. 


\section{La limite de puissance de l'Union Européenne dans les relations internationales : les divergences et les convergences de l'UE avec les États-Unis, en particulier depuis l'arrivée au pouvoir de Donald Trump, sur l'Accord du nucléaire iranien de 2015 : le Joint Comprehensive Plan of Action (JCPOA) Kamal Bayramzadeh ${ }^{1}$}

\section{Résumé}

Cet article se donne pour objectif de montrer le rôle de l'Union Européenne (UE) dans la résolution des crises internationales, en l'occurrence la crise nucléaire iranienne. L'UE est dotée d'une «politique étrangère commune » depuis 1993 et, en raison de sa capacité d'influence politique et économique dans certains dossiers internationaux, elle peut être qualifiée d'acteur international. Nous voulons examiner les différentes dimensions de la puissance européenne afin de mettre en évidence la limite de sa puissance normative en nous focalisant sur la crise nucléaire iranienne et les divergences de l'UE avec les États-Unis depuis l'arrivée au pouvoir de Donald Trump. Après avoir expliqué les concepts analytiques de puissance douce, de puissance normative et d'acteur, nous allons d'abord mettre en exergue les caractéristiques de la puissance de l'UE. Cette étude va ensuite analyser les différents aspects de la politique de l'UE à l'égard de l'Iran et en particulier son projet nucléaire de 1992 à 2020. Nous mettrons finalement en évidence les impacts de l'arrivée au pouvoir de Donald Trump sur les relations des États-Unis avec l'UE. Il s'agit de montrer comment la nouvelle approche politique et économique des États-Unis (néomercantilisme) sous la présidence de D. Trump a changé l'orientation de la politique étrangère des États-Unis en particulier à l'égard de l'UE et de l'accord nucléaire de 2015 du P5+1 avec 1'Iran. En 2018, les États-Unis se sont retirés de l'accord et ont imposé leur loi extraterritoriale aux entreprises étrangères en interdisant de commercer avec l'Iran. En dépit de sa protestation, l'UE n'a pas pu empêcher que cette loi soit imposée aux entreprises européennes, ce qui a illustré la limite de sa puissance.

Mots-clés : Iran ; Union Européenne ; États-Unis ; Crise nucléaire iranienne ; Donald Trump ; Puissance normative ; Néomercantilisme ; Dialogue critique ; Loi extraterritoriale

\footnotetext{
${ }^{1}$ Kamal Bayramzadeh est enseignant en Relations internationales à l'Université Sorbonne Paris Nord (Paris 13) et chercheur invité au Département de Science politique de l'Université de Liège (ULiège). Il est membre associé de l'Institut de Droit Public, Sciences Politiques et Sociales de Paris 13 (IDPS), membre du Center for International Relations Studies (CEFIR) (ULiège) et membre associé de la Chaire Raoul-Dandurand en études stratégiques à l'Université du Québec à Montréal (UQAM), Observatoire sur le Moyen-Orient et l'Afrique du Nord.
} 


\section{Introduction}

L'accession à la présidence américaine de Donald Trump a contribué à la dégradation des relations entre l'Union européenne (UE) et les États-Unis en raison d'une nouvelle approche en matière de politique étrangère, axée plus particulièrement sur l'unilatéralisme, et d'une nouvelle politique économique liée au néomercantilisme ${ }^{1}$. Depuis son installation, le nouveau président n'a pas manqué de qualifier la Chine, la Russie et l'UE d'ennemies. L'un des problèmes majeurs qui a révélé les divergences entre l'UE et les États-Unis est le retrait de ces derniers de l'accord multilatéral du Plan global d'action conjoint portant sur le projet nucléaire iranien. Non seulement la première puissance mondiale s'est retirée en 2018 de l'Accord, mais au demeurant, elle a instauré une loi extraterritoriale interdisant aux autres pays de commercer avec l'Iran, et a contraint les entreprises européennes de se retirer d'Iran. En dépit de l'importance de cet Accord pour elle, l'UE a montré la limite de sa puissance et de sa souveraineté économique vis-à-vis des États-Unis, alors qu'elle avait joué un rôle essentiel en tant qu'acteur de médiation et de négociation dans sa conclusion en 2015.

L'UE avait noué des relations avec l'Iran dans le cadre du dialogue critique (1992) et dans le dialogue global (1998) en insistant sur plusieurs conditions ; notamment la nonprolifération des armes de destruction massive. Durant des années, l'UE a choisi de dialoguer et de coopérer avec l'Iran en utilisant sa puissance normative (normative power), alors que les États-Unis ont opté pour une politique de sanction et de pression économique afin de limiter la puissance iranienne au Moyen-Orient. Mais depuis 2010, l'UE a changé sa stratégie et mis en œuvre la politique de l'arme économique ${ }^{2}$ afin d'amener l'Iran à la table de négociations pour y traiter de l'accélération de son projet nucléaire. Dans ce contexte international, l'avènement du conflit syrien et l'implication de l'Iran pour défendre le régime de Bachar el-Assad ont contribué au changement des rapports de force sur le plan régional en faveur de Téhéran; ce nouvel équilibrage n'ayant pas manqué d'inquiéter d'autres puissances du Moyen-Orient dont l'Arabie Saoudite et Israël. À partir de 2013, quatre facteurs ont marqué la poursuite des négociations multilatérales relatives au nucléaire iranien. Premièrement, l'élection d'un nouveau président en Iran (Hassan Rohani) favorable à la négociation avec les pays occidentaux. Deuxièmement, les effets des sanctions économiques contre l'Iran. Troisièmement, la montée en puissance de l'Iran au Moyen-Orient. Quatrièmement, le changement de l'approche américaine relative au nucléaire iranien qui sous la présidence de Barack Obama épousa fortement celle de $1^{\prime} U^{3}, c^{\prime}$ 'est-à-dire reconnaître à l'Iran le droit d'accéder au nucléaire civil. Cette approche engendra des négociations directes entre les ÉtatsUnis et l'Iran et transforma la crise nucléaire iranienne en objectif des négociations multilatérales entre le groupe $\mathrm{P} 5+1$ et 1 'Iran. Ces efforts diplomatiques aboutirent à l'Accord de 2015 qualifié d'historique par les acteurs concernés en dépit de l'opposition d'Israël et de l'Arabie Saoudite.

Cet article se donne pour objectif d'analyser le rôle de l'UE dans la résolution des crises internationales, en l'occurrence celle du nucléaire iranien. L'UE est dotée d'une " politique étrangère commune » depuis 1993 et, en raison de sa capacité d'influence politique et économique dans certains dossiers internationaux, elle peut être qualifiée d'acteur international, mais le concept ne fait pas l'unanimité. Nous examinerons les différentes dimensions de la puissance normative européenne afin de mettre en évidence leurs limites en nous focalisant sur la crise nucléaire iranienne et les divergences opposant l'UE aux États-Unis de D. Trump.

\footnotetext{
${ }^{1}$ SANTANDER, S., VLASSIS, A. (2018), «L’UE, une puissance commerciale bousculée », Diplomatie, $\mathrm{n}^{\circ} 47$, p. 74.

2 DEVIN, G. (2013), Sociologie des relations internationales, Paris, La Découverte, p. 76.

${ }^{3}$ FIEDLER, R. (2018), « Iran and the European Union after the Nuclear Deal », CES Working Papers, Alexandru Ioan Cuza University of Iasi, Centre for European Studies, Iasi, vol. 10, Issue 3, p. 297.
} 
L'axe majeur auquel nous nous attèlerons sera de déterminer comment et dans quelle mesure le retrait des États-Unis de l'Accord nucléaire (JCPOA, 2018) et l'imposition de la loi extraterritoriale américaine aux entreprises européennes ont révélé la limite et la faiblesse de la puissance de l'UE vis-à-vis des États-Unis. Cette question centrale peut se diviser en plusieurs sous-questions. Quelles sont les conséquences de l'arrivée au pouvoir de D. Trump sur les relations transatlantiques? Quelles sont les conditions du dialogue entre l'UE et l'Iran ? Pourquoi les États-Unis se sont retirés de l'Accord de 2015 ? Quels sont les effets de l'opposition de l'Arabie Saoudite et d'Israël à ce Traité sur la politique des États-Unis ? Pourquoi le projet nucléaire iranien a été perçu comme une menace par les États-Unis et l'UE ? À partir de ces questions, nous montrerons la différence des approches américaine et européenne au sujet de l'Iran. Notre travail se compose de trois parties. Dans la première, nous mobiliserons quelques concepts théoriques (puissance normative, soft power et acteur) afin de particulariser la puissance de l'UE. La deuxième partie se penchera, d'une part, sur la politique de l'UE à l'égard de l'Iran, et en particulier de son projet nucléaire, et d'autre part sur les négociations menées par le P5+1 avec l'Iran entre 2012 et 2015 (1'Accord multilatéral). Enfin, la troisième partie se focalisera sur le retrait états-unien de l'Accord de 2015 et sur les limites de la puissance européenne vis-à-vis de cette rétraction unilatérale.

\section{A) Les caractéristiques de la puissance de l'Union Européenne}

Pour comprendre les différents aspects de la puissance européenne, il importe de définir quelques concepts de sciences politiques relatifs à l'étude des Relations internationales. Il est nécessaire d'expliquer le concept de puissance (notamment le soft power), celui de puissance normative ainsi que celui dit « de l'acteur ». Ces trois vecteurs sont importants pour notre étude dans la mesure où l'UE est souvent qualifiée d'acteur international doté de puissance douce (soft power) ou de puissance normative, notamment par Ian Manners ${ }^{1}$.

\section{1) Le concept de puissance et sa typologie}

Le concept de puissance est évolutif, multidimensionnel et complexe. Sa définition varie en fonction des différentes approches des Relations internationales. Les réalistes mettent l'accent sur les aspects matériels, ou tangibles, de la puissance tandis que d'autres approches évoquent aussi les aspects immatériels comme la puissance structurelle et la puissance douce. Selon le penseur réaliste Hans J. Morgenthau, la politique internationale s'apparente à une lutte pour le pouvoir et la puissance se définit comme «l'emprise d'un homme sur les esprits et les actions des autres $»^{2}$. En raison du caractère anarchique de la société internationale, les États essayent de maximiser leur puissance et c'est pourquoi " [ils] cherchent à acquérir toute la puissance qu'ils peuvent obtenir $»^{3}$. Par ailleurs, d'après le fondateur du réalisme offensif, John Mearsheimer, : «ce que la monnaie est à l'économie, la puissance l'est pour les relations internationales ${ }^{4}$. Raymond Aron définit la puissance comme «la capacité d'une entité politique d'imposer sa volonté aux autres unités $»^{5}$. La puissance de l'État produit des aspects tangibles et non tangibles, et chaque dimension de la puissance revêt ses propres attributs. Joseph Nye, l'un des théoriciens de l'interdépendance complexe, a contribué à l'évolution du concept en introduisant une nouvelle typologie : la puissance douce (soft power) et la puissance dure (hard power). D'après lui, le soft power représente un pouvoir de séduction, un pouvoir de cooptation qui repose sur des ressources intangibles comme la culture, les institutions, les

\footnotetext{
${ }^{1}$ MANNERS, I. (2002), « Normative Power Europe: A contradiction in Terms? », Journal of Common Market Studies, vol. 40, n $^{\circ}$ 2, p. 236.

${ }^{2}$ MORGENTHAU, H. (1948), Politics Among Nations. The struggle for Power and Peace, New York, Knopf, p. 13.

${ }^{3}$ MEARSHEIMER, J. (2014), The Tragedy of Great Power Politics, USA, University of Chicago, p. 22.

${ }^{4}$ Ibid., p. 12.

${ }^{5}$ ARON, R. (1962), Paix et guerre entre les nations, Paris, Calmann-Lévy, pp. 16-17.
} 
idées... Il permet à son détenteur d'inciter les autres acteurs à l'imiter ${ }^{1}$. Le soft power accorde à l'État qui le détient la possibilité de « structurer une situation de telle sorte que les autres pays fassent des choix ou définissent des intérêts qui s'accordent avec les siens $»^{2}$. Au départ de cette définition du soft power, Nye met l'accent sur les nouvelles formes d'influence dans les Relations internationales à la fin de la guerre froide, et en particulier dans la pratique de la politique étrangère états-unienne.

\section{2) La puissance douce (soft power) et la puissance normative de l'Union Européenne}

En ce qui concerne le soft power de l'UE, il peut être défini comme tout ce qui lui permet de séduire, d'attirer et d'influencer le monde extérieur, sans recourir à la coercition ${ }^{3}$. On distingue deux formes de soft power: le «moderne» lié à la modernité politique et le « traditionnel ». Le soft power de l'UE est de type moderne et a une vocation universelle. Les différentes dimensions de la puissance douce de l'UE se manifestent par l'adoption de principes basiques : le respect des droits de l'Homme, l'État de droit, les droits des minorités, le modèle politique démocratique, le modèle de la paix démocratique par le biais du marché à travers une politique d'intégration, etc. Ces différentes valeurs constituent les facteurs de séduction et établissent la capacité d'influence de l'UE dans une partie de la communauté internationale, en particulier dans les sociétés civiles et auprès d'une partie des élites au Moyen-Orient dont les iraniennes. Dans ce cadre, nous pouvons également citer le cas des pays candidats à l'adhésion européenne. Dans les Relations internationales actuelles, on observe que les États tentent de mettre en œuvre une stratégie de soft power qui, depuis 1991, joue un rôle important dans la politique internationale.

Comme nous l'avons souligné supra, l'UE est qualifiée de puissance normative par une partie des chercheurs et, pendant la guerre froide, François Duchêne avait qualifié la Communauté européenne en termes de puissance civile (civilian power $)^{4}$. Mais ce concept a été critiqué par différents chercheurs, notamment par Hedley Bull ${ }^{5}$. La notion de puissance normative a été élaborée par Ian Manners pour qui l'UE demeure une puissance normative fondée sur un socle solide de valeurs, de normes et d'une identité, européenne et supranationale, qui oriente sa politique étrangère ${ }^{6}$. La puissance normative de l'UE comprend plusieurs aspects qui contribuent à sa diffusion dans les Relations internationales. Ian Manners en mentionne six : la contagion (contagion), la diffusion informationnelle (informational), la diffusion procédurale (procedural), le transfert (transference), la diffusion manifeste (overt diffusion) et le filtre culturel (cultural filter). Le premier (la contagion) se traduit par la diffusion de normes, de manière non intentionnelle, dont la substance ou l'idée est reprise et imitée par d'autres pays ou régions du monde à l'instar du Mercosur. La deuxième (la diffusion informationnelle) s'effectue via des communications stratégiques par des initiatives et des déclarations produites par les instances européennes. La troisième (la diffusion procédurale) se réalise dans une relation institutionnalisée entre l'UE et une tierce partie, à l'image de l'élargissement de l'UE vers des pays candidats à l'adhésion au projet européen. La quatrième (le transfert) se déploie lorsque Bruxelles échange des biens et accorde de l'aide ou de l'assistance technique à des pays tiers par le biais de moyens essentiellement matériels ou financiers, en exportant les standards

\footnotetext{
1 PAQUIN, S. (2009), "L'économie politique internationale et la mondialisation », dans PAQUIN, S. et DESCHÈNES, D. (dir.), Introduction aux relations internationales. Théories, pratiques et enjeux, Montréal, Chenelière, p. 37.

${ }^{2}$ NYE, J. (1990), Bound to lead. The Changing Nature of American Power, New York, Basic Books Publishers, p. 173.

${ }^{3}$ LEFEBVERE, M. (2011), La politique étrangère européenne, Paris, PUF, p. 68.

${ }^{4}$ DUCHENE, F, « Europe's role in world peace », in Richard Mayen (ed.), Europe tomorrow. Sixteen Europeans look ahead, London, Collins, 1972, p.35.

${ }^{5}$ PETITEVILLE, F. (2002), «L'Union européenne, un acteur international 'global' », Revue internationale et stratégique, $\mathrm{n}^{\circ} 43$, pp. 145-157.

${ }^{6}$ MANNERS, I. (2002), op. cit., p. 252.
} 
communautaires et en recourant à la politique « de la carotte et du bâton », soit par des récompenses financières ou des sanctions économiques, comme par exemple dans le cadre du programme d'aide communautaire aux pays d'Europe centrale et orientale (PHARE). La cinquième (la diffusion manifeste) se produit par le biais d'une présence physique de l'UE dans les pays tiers à travers des délégations de la Commission et des ambassades des États membres. Enfin, la sixième et dernière (le filtre culturel) affecte, à travers l'interaction, les normes internationales et l'apprentissage politique dans les pays tiers. La diffusion des droits de l'Homme en Turquie par exemple ${ }^{1}$ illustre cette expression normative qui, on doit le souligner, rencontre des difficultés de diffusion dans des pays comme la Chine ${ }^{2}$, la Russie, l'Iran, etc.

Zaki Laïdi, un autre auteur à avoir qualifié l'UE de puissance normative internationale, estime que « [1]a puissance renvoie à la force et la norme à la règle. La puissance appelle la puissance. Elle s'inscrit dans une dynamique de force ne reconnaissant ainsi que les limites qu'elle se fixe elle-même. À l'inverse, la règle renvoie à la contrainte, à la limite qu'il convient de fixer, à l'ordre qu'il faut préserver, aux frontières qu'il importe de ne pas dépasser. Pourtant norme et puissance se rejoignent sur un point essentiel : elles cherchent toutes les deux à contraindre $»^{3}$.

Depuis la fondation de l'UE, les normes ont joué un rôle déterminant dans sa transformation en espace de paix démocratique : « [1]a préférence de l'Europe pour la norme tient fondamentalement à l'essence même du projet européen depuis 1957. L'Europe cherche à dépasser les traditionnels conflits entre États en recourant au principe de souveraineté partagée sans pour autant abolir la souveraineté de ces mêmes États. Dans ces conditions, le seul moyen de lier durablement le destin de ces États, c'est de les faire adhérer à une norme commune d'autant plus contraignante qu'elle aura été négociée ${ }^{4}$. Pour Zaki Laïdi, la puissance normative de l'UE est composée à la fois des «normes politiques» et des «normes de marché », les secondes occupant un rôle primordial : «la puissance normative de l'Europe découle largement de son pouvoir de marché, mais l'impact de celui-ci dépasse le simple cadre du marché $»^{5}$. Selon l'auteur, il existe un lien entre la limite d'influence de la puissance normative de l'UE et les rapports de forces internationaux. Étant donné qu'elle ne dispose pas de toutes les fonctions régaliennes d'un État, « elle montre la limite de sa puissance dans la politique internationale en raison de l'absence d'une force militaire capable de défendre ses normes et d'une vision du monde relativement cohérente ${ }^{6}$. À travers cette étude, nous constatons quelques similitudes entre le soft power européen et une partie de sa puissance normative. Mais l'application des normes, liées à la puissance normative dans les relations internationales de l'UE, transite par des règles contraignantes. Cet examen préalable du concept de puissance (et sa typologie exprimée en puissances douce et normative), nous permet à présent d'expliquer la signification de l'acteur afin de répondre à la question : l'UE est-elle un acteur dans les Relations internationales, et en particulier dans le dossier nucléaire iranien ?

\section{3) Le concept de l'acteur et ses caractéristiques}

Dans la société internationale classique l'État est considéré comme le seul acteur des Relations internationales. Mais celles-ci ont évolué et d'autres composantes ont émergé et relativisé la souveraineté étatique. Il s'agit, notamment, selon James Rosenau, des acteurs

\footnotetext{
${ }^{1}$ Ibid., pp. 244-245.

${ }^{2}$ CABESTAN, J-P. (2015), La politique internationale de la Chine, Paris, Sciences Po, pp. 454-456.

3 LAÏDI, Z. (2009), «L'Europe, puissance normative internationale », dans DEHOUSSE, R., Politiques européennes, Paris, Presse de Sciences Po, p. 227.

${ }^{4}$ Ibid., p. 229.

${ }^{5}$ Ibid., p. 230.

${ }^{6}$ Ibid., p. 241
} 
«hors souveraineté ${ }^{1}$. L'histoire des Relations internationales montre que, parfois, ces éléments peuvent se muer en acteurs étatiques suite à un changement systémique comme une révolution ou l'arrivée d'un régime politique soutenu par des forces étrangères, à l'exemple des partis politiques kurdes en Irak après la chute de Saddam Hussein.

Le concept d'acteur est malaisé à cerner étant donné la multitude de définitions qui le caractérisent et l'absence d'unanimité parmi les spécialistes, en particulier dans le cadre de l'UE. Nous pouvons le définir comme une entité politique nantie de la capacité d'influencer le comportement d'une autre entité politique, étatique ou non-étatique. Cette capacité présente un caractère multiforme et comprend les aspects politique, militaire, culturel, économique et idéologique. Par ailleurs, la capacité d'influence peut prendre une dimension régionale ou mondiale selon le niveau de puissance de l'acteur concerné. Selon le dictionnaire des relations internationales, l'acteur peut être défini : «comme une entité dont les actions dans le champ international ou transnational ont un impact sur la distribution des ressources et sur la définition de certaines valeurs au niveau global $»^{2}$. Une étude, réalisée par Marcel Merle dans les années 1980, souligne les trois caractéristiques de l'acteur dans les Relations internationales : «par acteur, écrit-il, il faut entendre toute autorité, tout organisme, tout groupe et même, à la limite toute personne susceptible de jouer un rôle dans le champ social, en l'espèce sur la scène internationale $»^{3}$. Selon Merle, il se distingue par trois traits : «autorité, autonomie, et cohérence $»^{4}$.

D'autres chercheurs ont contribué à faire évoluer la notion d'acteur. Parmi eux, Joseph Jupille et James Caporaso ont ajouté une quatrième dimension au statut : « [1]a reconnaissance, en d'autres termes le fait que les autres acteurs acceptent d'interagir avec l'acteur concerné $»^{5}$. Cette reconnaissance contribue au façonnement de la personnalité juridique de l'acteur dans les Relations internationales. À partir de ces quatre critères, le statut d'acteur de l'UE dans les relations internationales peut être considéré à travers son rôle dans la politique internationale. Il faut aussi savoir que l'UE est dotée d'une personnalité juridique depuis le traité de Lisbonne et que cette particularité a renforcé son rôle international. Dans notre étude, nous appliquerons ces concepts aux cas de l'UE, de l'Iran et des États-Unis.

L'UE est une organisation régionale fondée sur des valeurs universelles. Depuis sa création, la politique d'intégration européenne a contribué à l'instauration de la paix et de la sécurité entre ses membres. Le processus d'élargissement de l'UE montre que celle-ci conditionne l'adhésion des nouveaux membres au respect de certaines exigences, en particulier les critères de Copenhague. Par le biais de ses critères et de ses normes, l'UE est en mesure de contribuer à la démocratisation de certains pays, il en a été ainsi pour les pays d'Europe centrale et orientale (Peco). Dans le cas de la Turquie, son adhésion est conditionnée à la réalisation de telles réformes. L'UE demeure aussi un acteur de médiation, de réconciliation et de paix (peacemaker) entre certains pays qui veulent devenir membre de l'UE : c'est le cas entre le Kosovo et la Serbie ${ }^{6}$.

\footnotetext{
${ }^{1}$ ROSENEAU, J. (1990), Turbulence in World Politics. A Theory of Change and Continuity, Princeton, Princeton University Press, p. 36.

2 BATTISTELlA, D., SMOUT, M-C., VENNESSON, P., PETITEVILlE, F. (2006), Dictionnaire des relations internationales, Paris, Dalloz, pp. 1-2.

${ }^{3}$ MERLE, M. (1988), Sociologie des relations internationales, Paris, Dalloz, p. 317.

${ }^{4}$ Ibid., p. 318.

5 JUPILlE, J. and CAPORASO, J. (1998), «States, Agency and Rules: The European Union in Global Environmental Politics » in RHODES, C. (ed.), The European Union in the World Community, Boulder, Colorado, Lynne Rienner, p. 214.

6 LIKA, L. (2016), «La pénétration turque dans les Balkans occidentaux: quels défis pour le projet d'élargissement de l'UE ? », dans SANTANDER, S. (dir.), Concurrences régionales dans un monde multipolaire émergent, Bruxelles, P.I.E. Peter Lang, pp. 250-251.
} 
Dans le cas du dialogue critique entre l'Iran et l'UE, celle-ci a conditionné ce dialogue au respect de cinq conditions. Elle a tenté de contraindre l'Iran à accepter ses normes dans la mesure où Téhéran avait besoin de l'UE dans un contexte marqué par des tensions avec les États-Unis. La capacité d'influence de l'UE dépend des rapports de force ; elle peut parfois imposer ses conditions aux acteurs étatiques ou non-étatiques qui sont moins forts qu'elle. Par ailleurs, quand l'UE présente des convergences avec de grandes puissances, elle peut se muer en acteur majeur dans la résolution de crise, à l'instar du rôle qu'elle a joué dans la conclusion de l'Accord nucléaire de 2015 entre l'Iran et le P5+1 et où elle a pu démontrer sa capacité d'influence diplomatique sur les autres acteurs.

L'évolution des relations internationales, en particulier le décentrage ${ }^{1}$ de la puissance dans le nouveau contexte mondial, affecte la puissance européenne. L'exemple des puissances émergentes, notamment la Chine $^{2}$ et la Russie, illustre parfaitement la limite de la puissance normative de l'UE. Durant les quelques années qui ont succédé à 1991, l'UE disposait d'une capacité d'influence politique et diplomatique à l'endroit de la Russie, mais l'arrivée au pouvoir de Poutine et la montée en puissance de la Russie ont changé la donne : «Il y a longtemps que l'UE ne sait pas bien quoi faire avec la Russie postsoviétique, malgré l'élaboration de divers partenariats économiques et stratégiques au cours des années 1990. Quant à la crise en Ukraine, déclenchée en 2013, elle traduit de manière plus spectaculaire encore les limites de la puissance 'civile' et 'normative' de l'UE $»^{3}$. À partir de ces observations théoriques et conceptuelles, nous allons à présent examiner les différentes étapes des relations entre l'UE et l'Iran, et en particulier les enjeux de la crise nucléaire iranienne.

\section{B) La Politique de l'Union Européenne à l'égard de l'Iran depuis 1992 jusqu'à nos jours}

En 1991, les Relations internationales sont entrées dans une nouvelle période caractérisée par l'hégémonie sans rival des États-Unis, même si cette hégémonie a pu être contestée $^{4}$ et affaiblie quelques années plus tard. Avec la fin du monde bipolaire, les dirigeants européens, sous l'égide de François Mitterrand et d'Helmut Kohl, ont relancé le projet de construction de l'Europe politique. L'un des objectifs de ce projet a été de contribuer à l'émergence d'un monde multipolaire dans lequel l'UE devait jouer un rôle important, un monde fondé sur l'équilibre des forces afin de limiter le pouvoir des États-Unis. Dans ce cadre, le Moyen-Orient constitue l'une des zones stratégiques où se joue la rivalité politique et économique entre l'UE et les États-Unis. Les divergences de Donald Trump et de l'UE sur la question iranienne résultent, en partie, de cette compétition dans la mesure où les États-Unis entendent affaiblir la puissance commerciale de l'UE.

\section{1) Les relations entre l'Union Européenne et l'Iran de 1992 à 1997 : le dialogue critique, un test pour la puissance normative de l'Union Européenne}

La politique de l'UE à l'égard de l'Iran s'inscrit dans le cadre de sa politique moyenorientale. Ses objectifs peuvent être décrits ainsi : favoriser les intérêts de l'UE par des relations commerciales et économiques, contribuer à la sécurité de la région riche en réserves de pétrole, contribuer à la paix régionale, promouvoir le respect des droits de l'Homme, et lutter contre la prolifération nucléaire. En effet, ces principes sont conformes aux objectifs de la politique

\footnotetext{
${ }^{1}$ SANTANDER, S. (2016) (dir.), Concurrences régionales dans un monde multipolaire émergent, Bruxelles, P.I.E. Peter Lang, p. 15.

${ }^{2}$ WANG, Y. (2009), «The Identity Dilemmas of EU Normative Power: Observations from Chinese Traditional Culture », in GERRITS André (ed.), Normative Power Europe in a Changing World: A Discussion, The Hague, Netherlands, Clingendael European Papers $n^{\circ}$ 5, pp. 73-74.

${ }^{3}$ PETITEVILLE, F. (2016), «L'Union européenne, acteur conditionnel de la résolution des conflits », dans BAZIN, A. et TENENBAUM, C. (dir.), L'Union européenne et la paix, Paris, Presses de Sciences Po, p. 129.

${ }^{4}$ BADIE, B. (2019), L'Hégémonie contestée. Les nouvelles formes de domination internationale, Paris, Odile Jacob, p. 9.
} 
étrangère commune européenne par le biais desquels l'UE s'emploie à diffuser ses normes sur le plan international; en l'occurrence dans ses relations avec l' $\operatorname{Iran}^{1}$. Mais la puissance normative européenne montre ses limites dans ces rapports étant donné que le régime iranien de nature théocratique (République islamique) ne reconnait pas l'universalisme des normes européennes.

Depuis 1992, la politique de l'UE envers l'Iran s'est poursuivie dans le cadre d'un « dialogue critique », suivi d'un « dialogue global » (constructif), dans le cadre duquel s'est tenue une réunion semestrielle entre une troïka européenne et les responsables iraniens. À l'origine, en 1992, les douze chefs des États membres de l'UE se sont réunis en Conseil à Edimbourg afin de déterminer la politique à suivre à l'égard du gouvernement iranien qui voulait développer ses relations avec l'UE. Le conseil Edimbourg généra : «(..) une stratégie de dialogue qui pos[a] le principe d'une concertation continue et cohérente avec l'Iran en vue d'inviter ce dernier à un comportement constructif sur des questions fondamentales pour l'Europe $»^{2}$. La demande de l'Iran s'inscrivait dans une double dimension. D'une part, au lendemain de la guerre avec l'Irak, sa situation socio-économique et politique se trouvait dans un état critique et le gouvernement de Rafsandjani n'avait d'autre choix que de redéfinir sa politique étrangère à travers une approche pragmatique. D'autre part, en raison de l'hostilité entre Téhéran et Washington, l'UE était la seule voie disponible pour rompre l'isolement et sortir de la crise économique.

Il est important de rappeler qu'un intérêt réciproque conditionnait les relations euroiraniennes. Soulignons de même que l'Iran est entouré de quinze pays, dont une partie possède de grandes réserves d'hydrocarbures, et qu'il se situe sur le chemin le plus direct pour l'acheminement vers l'Europe du pétrole de pays comme l'Azerbaïdjan. De son côté, l'Iran dispose de grandes réserves pétrolières et gazières (les deuxièmes plus importantes du monde). Au demeurant, avec 80 millions de citoyens qui composent sa population, il représente un grand marché avec des débouchés régionaux substantiels pour l'économie européenne. Selon la Commission européenne «[d]es raisons politiques et économiques se trouvent à la base de l'intérêt de l'UE pour l'Iran. Avec une position géographique stratégique et une importante réserve de gaz et de pétrole, ce pays pourrait jouer un rôle clé dans l'avenir de la région du Golfe. Selon la Commission, une démocratisation accrue et un plus grand respect des droits de 1'homme en Iran contribueraient à promouvoir la stabilité et la paix dans cette zone $»^{3}$.

En vertu de ces facteurs, l'UE a établi ses relations avec l'Iran dans le cadre du « dialogue critique » par lequel elle lui demandait les points suivants : « $1:$ respecter les droits de l'Homme en Iran ; 2 : renoncer au terrorisme et au soutien des mouvements intégristes ; 3 : non-prolifération des armes de destruction massive ; 4 : abolir la fatwa contre Salman Rushdie, écrivain britannique auteur des Versets sataniques ; 5 : cesser de s'opposer au processus de paix au Proche-Orient $»^{4}$. L'un des objectifs de l'UE par le dialogue critique a été d'influencer la politique de l'Iran sur deux plans. D'une part, elle lui demandait de procéder aux réformes sur les plans politique et économique; d'autre part, elle souhaitait une amélioration en ce qui concerne le respect des droits fondamentaux liés à la personne humaine. La réaction iranienne révéla deux approches. Comme l'explique A. V. Engeland-Nourai : « [1]e droit international des droits de l'homme n'a plus été la référence iranienne. Les Iraniens s'en sont remis au droit

\footnotetext{
${ }^{1}$ DUFAYS, N. (2012), «Les relations de l'Union européenne avec la République islamique de l'Iran : enjeux, perspectives et perceptions », dans MAKINSKY, M. (dir.), L'Iran et les grands acteurs régionaux et globaux, Paris, L'Harmattan, p. 432.

2 SCANDELLA, J. (2005), «L'Union européenne et l'Iran : entre institutionnalisation et suspension des relations », Les Cahiers de l'Orient, $\mathrm{n}^{\circ}$ 79, p. 105.

${ }^{3}$ Communication de la Commission au Conseil et au Parlement européen, Relations EU-République Islamique de l'Iran, le 7 février 2001.

${ }^{4}$ BAYRAMZADEH, K. (2004), Les enjeux principaux des relations entre l'Iran et l'Europe de 1979 à 2003 , Paris, l'Harmattan, p. 135.
} 
musulman pour définir la norme de référence des droits de l'homme. Toute dénonciation venue de l'Occident concernant la situation des droits fondamentaux était considérée comme une ingérence dans les affaires iraniennes $»^{1}$. Pendant le dialogue critique, l'UE et l'Organisation des Nations Unies (ONU) ont exercé une pression sur l'Iran à ce sujet et, dans un rapport sur la violation de ces droits daté de mars 1995, le gouvernement iranien fut mis en cause : «La commission des droits de l'homme de l'ONU a prolongé le mandat de son représentant pour une autre année. En août de la même année, la sous-commission des droits de l'Homme a condamné le gouvernement iranien pour la discrimination à l'égard des minorités ethniques en Iran, et les exécutions sommaires $»^{2}$.

Dans le cadre du « dialogue critique », l'UE a également enjoint l'Iran de mettre fin au soutien des mouvements islamistes, accusés de terrorisme par l'UE et les États-Unis, bien que selon le point de vue de Téhéran il s'agissait de mouvements de résistance à Israël. Soulignons d'ailleurs qu'à ce propos, l'Iran, sous la présidence de Rafsandjani, s'est opposé au processus de paix alors que le principal mouvement palestinien (Al-Fath) avait accepté la paix avec Israël. Cette posture iranienne provoqua la colère de l'UE, des États-Unis ainsi que des pays arabes. La troisième condition du dialogue critique tenait à la non-prolifération des armes de destruction massive et, dans ce contexte, l'UE maintenait la pression afin que de tels équipements ne soient pas développés. Mais du côté iranien, il s'agissait de pouvoir répondre à toute menace qui aurait pu surgir dans l'avenir ; particulièrement dans un contexte marqué par l'hostilité des États-Unis. L'Iran estimait n'avoir d'autre choix que de se fournir en avions, chars et missiles auprès de pays tels que la Russie, la Chine et la Corée du Nord. Une autre condition liée aux relations avec l'UE résidait dans la levée de la fatwa décrétée par Khomeyni à l'encontre de Salman Rushdie pour «blasphème » envers le prophète. L'Iran refusa et fit, à son tour, pression sur l'UE afin que les Versets sataniques soient interdits de publication et de diffusion mais celle-ci refusa.

Le dialogue critique n'a pas véritablement abouti et en 1997, suite au verdict du tribunal de Berlin, l'UE suspendit ses relations avec l'Iran. Selon le journal le Monde : «l'UE [s'était] montrée soucieuse de réitérer sa réprobation à l'égard des actions terroristes dont l'une, le meurtre de quatre opposants kurdes à Berlin, en 1992, [avait] été commandité, selon la justice allemande, par le haut sommet de l'État iranien. À cette fin, elle a confirmé solennellement la suspension du dialogue critique qu'elle entretenait depuis 1992 avec le régime des mollahs $»^{3}$. L'affaire de Mykonos, relative à l'assassinat de dirigeants du parti démocrate, entraîna une crise profonde entre l'UE et l'Iran. Ainsi, les gouvernements européens décidèrent de convoquer leurs ambassadeurs en Iran pour faire le point sur ce sujet et il en résulta une crise diplomatique qui dura sept mois.

À la lumière des explications relatives à cette première période des relations entre l'UE et l'Iran, nous constatons que l'UE a tenté de mettre en œuvre une politique commune et cohérente. Ce dialogue a permis à l'UE de tester une « politique étrangère commune » marquée par l'objectif central de développer des relations économiques et politiques avec l'Iran. Mais la réalité politique iranienne a révélé la limite de la puissance normative européenne. L'examen des cinq conditions montre que sur les plans commercial et économique, les relations ont connu une évolution importante caractérisées par une hausse de la présence des entreprises européennes en Iran et la croissance des échanges commerciaux entre les deux parties. Mais les autres conditions de l'UE n'ont pas abouti aux résultats escomptés. Cette difficulté a révélé que

\footnotetext{
${ }^{1}$ VAN ENGELAND-NOURAI, A. (2005), «Le rôle des droits de l'homme dans les relations entre l'Union européenne et l'Iran », Les Cahiers de l'Orient, ${ }^{\circ} 79$, p. 118.

${ }^{2}$ CORDESMAN, A. (1997), Iran: Dilemmas of dual containement, New York, Westview Press, p. 72.

${ }^{3}$ LEMAITRE, P. (1997), «L'Europe gèle le « dialogue critique » avec l'Iran mais ne prend pas de sanctions économiques », Le Monde, le 2 mai 1997, https://www.lemonde.fr/archives/article/1997/05/02/1-europe-gele-ledialogue-critique-avec-l-iran-mais-ne-prend-pas-de-sanctions-economiques 3540827_1819218.html (consulté le 15 janvier 2021).
} 
les normes européennes dans le cadre du dialogue critique s'opposaient aux valeurs politiques, culturelles et juridiques du régime iranien. En conséquence, l'UE n'a pas réussi à influencer le comportement politique de l'Iran et ce trait a constitué un défi pour la diplomatie européenne.

\section{Deux approches différentes entre l'Union Européenne et les États-Unis sur l'Iran pendant le dialogue critique}

Au contraire des Européens qui ont opté pour un dialogue politique et une coopération économique avec l'Iran, les États-Unis ont choisi une attitude d'isolement et de boycott dans le cadre d'une politique de « double endiguement » qui visait à la fois les gouvernements iranien et irakien. Cela correspond à une différence de visions entre l'UE et les États-Unis. L'UE entretient une approche libérale des relations internationales, basée sur le respect du droit international, le respect des droits fondamentaux, la négociation, la coopération économique et commerciale. Les États-Unis défendent une conception néo-réaliste, fondée sur la maximisation de l'intérêt national, leur sécurité et leur puissance : «Il est temps, écrit Robert Kagan, de cesser de faire comme si Européens et Américains partageaient la même vision du monde, ou même comme s'ils vivaient sur la même planète. L'Europe est en train de renoncer à la puissance ou, pour dire la chose autrement, elle s'en détourne au bénéfice d'un monde clos fait de lois et de règles, de négociation et de coopération transnationale. Elle pénètre dans un paradis post historique de paix et de relative prospérité, concrétisation de ce qu'Emmanuel Kant nomme la 'paix éternelle'. De leur côté, les États-Unis restent prisonniers de l'histoire, exerçant leur puissance dans le monde anarchique décrit par Hobbes ${ }^{1}$. Selon l'approche constructiviste, il existe trois sortes de cultures anarchiques ${ }^{2}$, l'UE se réclame de la culture anarchique kantienne, alors que les États-Unis relèvent de la culture anarchique hobbesienne.

L'objectif principal du «double endiguement » consistait à exercer une pression sur l'Iran afin qu'il renonce à son hostilité à l'égard d'Israël, au terrorisme et à son opposition au processus de paix : « [1] a politique de l'administration Clinton au sujet de l'Iran, entre 19931995, peut se résumer dans la poursuite d'une politique de double endiguement destinée à affaiblir les États iranien et irakien $»^{3}$. Cette politique fut complétée par un autre embargo économique et, en 1996, par la loi d'Amato qui prévoyait des sanctions contre toutes les compagnies pétrolières, même non-américaines, qui investiraient au-delà de 40 millions de dollars par an dans les deux pays, qualifiés d'États voyous par l'Amérique : l'Iran et la Libye. La portée extraterritoriale de cette loi a provoqué l'opposition unanime des pays de l'UE : «L'Europe reste fermement opposée à la législation des États-Unis qui a des effets extraterritoriaux, notamment à la loi d'Amato. Une telle législation est contraire au droit international $»^{4}$. Durant le dialogue critique, les Européens se sont démarqués des États-Unis en résistant à leur politique hégémonique, malgré la pression de ces derniers qui accusaient l'UE de faiblesse envers l'Iran, l'UE n'a pas cessé de poursuivre une politique indépendante.

2) L'Union Européenne et l'Iran pendant la présidence de Khatami (1997-2005) : une période marquée par une amélioration des rapports entre ces deux acteurs et par un demisuccès pour la puissance normative de l'UE

La victoire de Mohammad Khatami à l'élection présidentielle de 1997 a contribué à une amélioration relative des rapports irano-européens, dans la mesure où le nouveau président s'est démarqué des conservateurs du régime en appliquant une politique d'ouverture dans les

\footnotetext{
${ }^{1}$ KAGAN, R. (2004), La puissance et la faiblesse : Les États-Unis et l'Europe dans le nouvel ordre mondial, Paris, éd. Hachette, coll. Pluriel, p. 9.

${ }^{2}$ BATTISTELLA, D. (2012), Théories des relations internationales, Paris, Sciences Po, p. 315.

${ }^{3}$ KEMP, G. (1998), « The United States, Iran and Irak: Containement or Engagement? », US Policy and Iran, Paris, Edition Ifri, p. 32.

${ }^{4}$ La déclaration de sir Leon Brittan, le 30 septembre 1997, Bruxelles, Source d'Europe, 31494.
} 
relations extérieures, notamment envers l'UE. Depuis son arrivée au pouvoir, une page de la diplomatie iranienne à l'égard de l'UE a été tournée. La volonté de sortir de la crise dans laquelle se trouvaient les deux acteurs était réciproque, mais l'Iran ne disposait pas d'autre choix que de mettre fin à ses contentieux avec l'UE pour régler des problèmes importants sur le plan interne, qui étaient insolubles sans une ouverture de la politique étrangère. Quelques mois après l'arrivée au pouvoir de Khatami, l'UE a révisé sa position en adoptant une attitude positive à l'égard du nouveau gouvernement. Ce changement était lié à la déclaration du président iranien qui voulait donner de lui une nouvelle image, différente de celle de ses prédécesseurs, à travers son discours sur le respect de la liberté, la restauration de la société civile ainsi qu'une politique étrangère fondée sur la détente, le dialogue avec l'Occident ${ }^{1}$ et le « dialogue des civilisations ». Un ministre Britannique, Robin Cook, déclara ainsi sur le sujet : « Nous sommes prêts à aider les premiers pas de la glasnost en Iran. Nous nous félicitons des signes émis par le président iranien qui vont dans le sens d'une modernisation de l'économie et de la société ».

Après la reprise du processus de normalisation euro-iranien en 1998, le dialogue critique céda la place au dialogue global (constructif) qui abordait aussi bien les thèmes politiques que stratégiques. Il prit la forme de réunions semestrielles entre la troïka européenne et son homologue iranien. Le dialogue engageait des négociations dans trois domaines: 1) les questions régionales (Irak, golfe Persique, Asie centrale, processus de paix au Proche-Orient ; 2) les domaines de coopération (drogue, réfugiés, énergie, commerce et investissement) ; 3) les questions générales (terrorisme, droits humains et prolifération des armes de destruction massive). Dans ce contexte inédit, le nouveau gouvernement iranien renonça à l'application de la fatwa contre Salman Rushdie. Ce changement d'attitude fut un succès pour la diplomatie européenne dans la mesure où elle avait réussi, d'une part, à mettre en œuvre une politique cohérente et, d'autre part, à s'imposer comme acteur dans cette affaire. Cet exemple démontre que la puissance normative de l'UE peut rencontrer dans certaines conditions un écho favorable en fonction de l'identité des acteurs politiques.

\section{La stratégie de l'Union Européenne à l'égard de l'Iran durant les mandats de Khatami}

La stratégie de l'UE s'est concentrée sur le développement des rapports économiques et politiques, notamment, à partir de 2001-2002, coïncidant avec le deuxième mandat de Khatami. Cette stratégie prenait en compte l'importance de l'Iran sur le plan géopolitique, énergétique et économique dans un contexte politique marqué par la victoire des « réformistes » dans les élections législatives, augmentant ainsi le poids de Khatami vis-à-vis des «conservateurs ». Cette nouvelle donne politique suscita de nouveaux espoirs pour les Européens. Un rapport du Parlement européen expose cette stratégie : «A) Considérant que, au sens d'une stratégie de politique étrangère en matière de prévention des conflits, l'intérêt de l'UE réside dans un développement de l'Iran en un facteur de stabilité dans la région. B) Considérant que l'UE peut aider l'Iran à renouer des relations de bon voisinage avec tous les pays de la région et contribuer effectivement au développement de la coopération régionale. C) Considérant qu'avec un volume annuel d'exportation de plus de 4 milliards d'euros, l'UE présente le principal partenaire commercial de l'Iran $»^{2}$. En décembre 2002, à la suite de certains progrès, des négociations entre l'UE et l'Iran débutèrent en vue de conclure un Accord de commerce et de coopération. La Commission européenne lança des discussions en parallèle avec les négociations sur le dialogue politique et la lutte contre le terrorisme. Normalement elles auraient dû aboutir à un accord contractuel. Mais, l'UE a conditionné la conclusion de celui-ci au respect des droits humains ainsi qu'aux autres conditions précédemment abordées, et la question n'a

\footnotetext{
${ }^{1}$ FIEDLER, R. (2018), op. cit., p. 295.

${ }^{2}$ GAHLER, M. (2018), Le rapport du parlement européen sur les relations entre l'UE et la République islamique, Bruxelles, le 26 novembre 2001, pp. 6-8.
} 
pas manqué de diviser l'UE. Certains considéraient qu'il fallait séparer le volet économique du volet politique, alors que d'autres estimaient les deux volets indissociables. Ce qui ne manqua pas de montrer à quel point la cohésion au sein des pays de l'UE était faible.

En dépit d'une ouverture relative dans les relations euro-iraniennes depuis l'arrivée au pouvoir de Khatami, la révélation des sites nucléaires iraniens entraina une crise importante qui influença le processus des négociations: «C'est dans cette atmosphère qu'un groupe d'opposants en exil, l'Organisation des Moudjahidin du Peuple d'Iran (OMPI), [révéla] en 2002 que l'Iran [était] en train de construire une usine d'enrichissement d'uranium par centrifugation près de la ville de Natanz ainsi qu'une usine de production d'eau lourde près de ville d'Arak, destinée à alimenter un réacteur à eau lourde dont le chantier [devait] s'ouvrir à proximité ${ }^{1}$. Depuis cet événement, le «dialogue nucléaire» est devenu prioritaire pour la troïka européenne, les autres dialogues étant subordonnés aux progrès de ces négociations relatives au nucléaire ${ }^{2}$.

Les négociations se déroulèrent de décembre 2002 à juin 2003, à Bruxelles et à Téhéran. En 2003, suite à la crise nucléaire, elles s'arrêtèrent provisoirement et, en 2005, les discussions relatives à l'Accord de Commerce et de Coopération (ACC) ont repris, mais une nouvelle fois, elles furent suspendues pour le même motif en automne de la même année. Les objectifs de l'ACC peuvent être décrits ainsi : l'établissement d'un régime contractuel pour gérer le commerce UE-Iran, suivant les règles de l'Organisation Mondiale du Commerce (OMC) ; soutien de l'Iran dans son adaptation aux règles de l'OMC ; développement d'une coopération plus étroite dans des domaines comme l'énergie, le transport, l'environnement, la culture, l'immigration et les réfugiés ; encouragement aux réformes, renforcement de l'État de droit et progression du respect des droits humains.

Durant le dialogue global, notamment après les attentats du 11 septembre 2001, la divergence entre l'UE et les États-Unis s'accentua. Si ces derniers optèrent pour le durcissement de leurs politiques à l'égard de l'Iran, plaçant celui-ci dans la liste des pays de « l'Axe du mal », l'UE choisit la voie du dialogue, en donnant la priorité au respect du droit international et à la négociation, afin de trouver une solution diplomatique aux problèmes, notamment à celui de la crise nucléaire. Cette attitude de l'UE fut assimilée à une stratégie de la carotte par opposition à celle du bâton, mais pour une partie des observateurs, la politique de l'UE à l'égard de Téhéran s'est révélée inefficace car par ces négociations, l'Iran a essayé de gagner du temps pour obtenir la technologie nucléaire. Néanmoins, il faut rappeler que, par la trö̈ka européenne et notamment par le rôle important joué par Javier Solana, Haut représentant pour la politique étrangère et de sécurité commune, l'UE a réussi à faire signer à l'Iran le protocole additionnel de l'Agence Internationale de l'Énergie Atomique (AIEA) le 29 novembre 2004. Mais la reprise de l'activité nucléaire de l'Iran en 2005 a de nouveau entraîné une crise importante dans les rapports euro-iraniens.

De ce fait, pendant les mandats de Khatami, malgré les progrès relatifs dans les relations entre l'UE et l'Iran en matière de politique étrangère et de coopération commerciale, la crise nucléaire a empêché la conclusion de l'ACC. Durant cette période, le président iranien s'est rendu dans plusieurs pays européens, notamment en France et en Allemagne, moteurs au sein de l'UE, et a, de la sorte, obtenu une certaine reconnaissance. Au cours de cette période, une partie des normes européennes a rencontré un écho favorable auprès des « réformateurs » du système iranien. En ce qui concerne la crise nucléaire, l'UE a utilisé sa capacité d'influence sur certains acteurs iraniens afin d'amener l'Iran à la signature du protocole additionnel de l'AIEA, le 29 novembre 2004. Mais il n'a pas été ratifié par le Parlement iranien. Cette situation a

\footnotetext{
${ }^{1}$ NICOULLAUD, F. (2016), «La fin d'un bras de fer avec la communauté internationale ? Retour sur douze années de négociations nucléaires », Iran le retour, Questions internationales, $\mathrm{n}^{\circ}$ 7, La documentation française, p. 22.

${ }^{2}$ DUFAYS, N. (2012), op. cit., p. 425.
} 
montré que le changement des acteurs politiques iraniens a modifié la position de l'UE et que, par conséquent, la capacité d'influence politique et économique de l'UE s'est accrue pendant quelques années.

3) Les rapports entre l'Union Européenne et l'Iran sous la présidence d'Ahmadinejad (2005-2013) : une période marquée par la dégradation des rapports entre l'UE et l'Iran et par le renforcement de la position régionale de l'Iran au Moyen-Orient

Depuis l'arrivée au pouvoir de Mahmoud Ahmadinejad en juin 2005, la politique étrangère de l'Iran a subi des changements importants non sans conséquences sur les rapports euro-iraniens. Sa nouvelle politique étrangère s'est caractérisée par quatre axes majeurs : une hostilité croissante à l'égard d'Israël, un anti-américanisme avéré, une volonté d'accroître sa puissance au Moyen-Orient et une velléité d'obtenir la technologie nucléaire en résistant à la pression des États-Unis et de l'UE. Cette politique s'est concrétisée par le contexte régional qui a contribué à la montée en puissance de l'Iran.

Depuis juin 2005, les rapports euro-iraniens se sont poursuivis dans le cadre des conditions précédentes, mais deux problèmes ont marqué ces relations. D'abord, la reprise des activités nucléaires iraniennes au début d'août 2005 : « [1]es Européens ont cherché à obtenir de l'Iran une renonciation à toute maîtrise du cycle du combustible nucléaire et une ratification du protocole additionnel du TNP en échange d'offre de coopération dans les domaines du nucléaire civil, de l'énergie et d'un engagement de l'UE à soutenir la candidature iranienne à l'OMC. La négociation a toutefois été compromise par la décision du nouveau président Ahmadinejad de relancer l'enrichissement d'uranium en août $2005 »^{1}$. Ensuite, la déclaration d'Ahmadinejad à l'encontre de l'État hébreu qui, selon le président iranien, devait être rayé de la carte. Cette attitude provocatrice a engendré une protestation de l'UE à l'égard de l'Iran.

\section{Les effets de la crise nucléaire sur l'avenir des relations entre l'Union Européenne et l'Iran}

La reprise des activités nucléaires iraniennes a entraîné une crise importante avec l'UE. Pour trouver une solution diplomatique à ce problème, les Européens ont, en août 2005, proposé à l'Iran une offre globale sur les questions nucléaires, commerciales et de sécurité régionale, mais elle fut qualifiée d'inacceptable et d'insultante et rejetée en tant que telle. Dès lors, l'Iran a remis en marche le processus de conversion dans l'usine d'Ispahan. En 2006, après l'échec des négociations prévues par le «package » du groupe P5+1, la visite de Kofi Annan à Téhéran (5 septembre 2006) et les rencontres de Javier Solana durant le mois de septembre avec son homologue Ali Laridjani, le numéro 2 du programme nucléaire iranien a présenté une contreproposition : créer un consortium mené par l'entreprise française Areva pour accompagner l'enrichissement d'uranium. Mais les Européens l'ont rejetée.

Le 23 décembre 2006, le Conseil de sécurité de l'ONU a adopté la résolution 1737 qui a donné un délai de deux mois à l'Iran pour suspendre son programme d'enrichissement d'uranium. Malgré cet ultimatum, Téhéran est passé outre et, depuis le début de 2007, l'UE a adopté les sanctions décrétées par la résolution 1737. Ces sanctions concernent essentiellement l'interdiction de transfert de technologie nucléaire et balistique, la restriction de déplacement de personnes liées au programme nucléaire et le gel des avoirs de ces dernières. En effet, l'objectif principal de la politique de sanction, relevant de la diplomatie coercitive, consistait à affaiblir le gouvernement iranien afin qu'il renonce à son projet nucléaire. En dépit des sanctions envisagées par le Conseil de sécurité et l'UE, l'Iran a poursuivi son programme d'enrichissement et Mahmoud Ahmadinejad insista sur le droit légitime de son pays à produire l'énergie nucléaire dans le cadre de l'article 4 du Traité sur la Non-prolifération des Armes

\footnotetext{
${ }^{1}$ PETITEVILlE, F. (2006), La politique internationale de l'Union européenne, Sciences Po, p. 57.
} 
Nucléaires (TNP) ${ }^{1}$. Les pourparlers entre le négociateur iranien (M. Djalili qui a remplacé A. Laridjani) et J. Solana en 2008 n'ont pas abouti à des solutions acceptables pour les deux parties. Selon le gouvernement iranien, l'UE fut influencée par les États-Unis et Israël dans sa démarche.

Dans cette situation, force fut de constater que, d'une part, les négociations entre l'UE et l'Iran et, d'autre part, entre l'Iran et l'AIEA ont été dans l'impasse dans la mesure où l'Iran n'a pas renoncé à son projet. En outre, le directeur de l'Organisation de l'énergie atomique d'Iran « M. Aghazadeh a confirmé en novembre 2008 que l'Iran avait installé cinq mille centrifugeuses à Natanze $»^{2}$. Ainsi, l'Iran a envoyé des signaux de fermeté aux Européens et aux Américains dans un contexte politique marqué par l'arrivée au pouvoir d'Obama qui a réitéré son opposition au projet nucléaire iranien tout en exprimant sa volonté de dialoguer avec les dirigeants iraniens ${ }^{3}$. Malgré l'échec des négociations, l'UE a rejeté l'option militaire pour régler le problème iranien, estimant qu'un recours armé embraserait la région et entraînerait une crise internationale majeure ${ }^{4}$. C'est pourquoi, en dépit de l'intensification de la politique de sanction depuis 2010 à l'égard de l'Iran par l'UE, celle-ci a toujours insisté sur le dialogue et la solution diplomatique.

Les événements du 11 septembre ont bouleversé les relations internationales. La politique étrangère américaine s'est durcie et la décision d'inclure l'Iran dans « l'Axe du mal » ${ }^{5}$ marqua la rupture des relations entre les deux pays. En 2002, Washington accusa l'Iran de financer les terroristes d'Al-Qaeda. Depuis l'intervention états-unienne en Irak, les rapports sont entrés dans une phase critique, marquée par l'accentuation des menaces de la part de Washington, et la tension n'a cessé de croître à travers les déclarations officielles. Depuis la découverte d'un site clandestin d'enrichissement d'uranium, les États-Unis ont demandé à l'ONU de prendre des sanctions contre l'Iran. La nouvelle donne politique, marquée par l'arrivée de Barak Obama à la présidence des États-Unis en 2009, a ouvert la voie à une nouvelle politique caractérisée par le respect et l'engagement diplomatique vis-à-vis de Téhéran. Le 20 mars 2009, l'administration Obama s'est déclarée «attachée à une diplomatie incluant l'ensemble des questions qui se [présentaient à elle], en vue de nouer des liens constructifs entre les États-Unis, l'Iran et la communauté internationale (...) ce processus n'avancera pas grâce aux menaces $»^{6}$. En effet durant l'année 2009, l'administration américaine s'est dit prête au développement d'une «politique de la main tendue» en affichant des signes d'assouplissement ${ }^{7}$; cette offre de conciliation a toutefois été rejetée par Téhéran la même année $^{8}$. Avec l'arrivée d'Ahmadinejad, et sa réélection en 2009, la position des États-Unis et de l'UE à l'égard de l'Iran a changé. Deux nouveaux problèmes majeurs sont apparus. D'une part la relance du projet nucléaire et, d'autre part, les déclarations ouvertement antisionistes du président. Dès lors, les positions européenne et américaine se sont progressivement rapprochées.

\footnotetext{
${ }^{1}$ ZARIFIAN, J. (2015), « Le dossier nucléaire iranien et la question du rapprochement États-Unis-Iran », Politique américaine, $\mathrm{n}^{\circ} 26$, p. 34.

${ }^{2}$ Mehr News (site web iranien) : www.mehrrnews.com/fa/ (26.11.2008).

${ }^{3}$ EIFFLING, V. (2013), «Les États-Unis face à la question nucléaire iranienne : un nœud gordien perpétuel ? », dans NAHAVANDI, F. (dir.), L'Iran dans le monde, Paris, l'Harmattan, p. 54.

${ }^{4}$ BONIFACE, P. (2019), Comprendre le monde, Paris, Armand Collin, p. 273.

${ }^{5}$ LAROCHE, J. (2011), La brutalisation du monde : du retrait des États à la décivilisation, Québec, Liber, pp. 7677.

${ }^{6}$ MICHEL, L. (2009), «La refonte de la stratégie de défense américaine », Revue Internationale et Stratégique, $\mathrm{n}^{\circ} 76, \mathrm{pp} .147-154$.

7 MIKHAÎL, B. (2010), «Une diplomatie du pragmatisme aux effets limités au Moyen-Orient?», Revue Internationale et Stratégique, $\mathrm{n}^{\circ} 77$, p. 145.

${ }^{8}$ LESNES, C. (2013), «La politique étrangère de Barack Obama : la tentation du repli ? », dans BADIE, B. et VIDAL, D. (dir.), Puissances d'hier et de demain, La Découverte, p. 101.
} 


\section{Le changement de stratégie de l'Union Européenne à l'égard de l'Iran depuis 2010}

Depuis juin 2010, l'UE a mis en œuvre une nouvelle politique à l'égard de l'Iran, concrétisée par une série de sanctions unilatérales relevant de la politique de l'arme économique : l'UE a fait pression sur le gouvernement iranien afin qu'il accepte ses conditions. Avant cette date, la politique de l'UE consistait à négocier dans le cadre d'un dialogue critique (de 1992-1997) et d'un dialogue global (depuis 1998) afin d'aboutir à la normalisation de leurs relations politiques et à la conclusion de l'ACC. En décembre 2002, la Commission européenne a lancé les négociations sur l'ACC, mais depuis 2005, elles sont suspendues en raison de la reprise des activités nucléaires iraniennes. Cet Accord présente une importance stratégique pour l'économie iranienne dans le sens où il devrait lui permettre d'accéder aux marchés européens et faciliter l'adhésion à l'OMC. Pour la première fois dans les rapports euro-iraniens, nous avons constaté une convergence entre l'UE et les États-Unis sur le dossier iranien alors que, dans le passé, leurs approches divergeaient sensiblement. Le changement de politique européenne s'explique par le choix du régime iranien en faveur d'un accès à l'énergie nucléaire mis en doute par l'UE quant à la vocation pacifique de ce projet. C'est pourquoi depuis 2010, elle a mis en œuvre des sanctions économiques afin d'exercer une pression sur le régime iranien et le ramener à la table des négociations, «L'Union européenne a décidé de ne plus acheter de pétrole iranien à partir de juillet $2012 »^{1}$. Les positions des États-Unis et de l'UE convergeaient donc sur la question iranienne alors que la Russie et la Chine n'avaient pas la même perception sur ce sujet.

La politique de la Russie à l'égard du projet iranien s'est démarquée des approches américaine et européenne, et ce pour plusieurs raisons. En 1995 la Russie s'est opposée à l'embargo décrété par Clinton et a accepté de construire la centrale nucléaire de Boucher. Les compagnies Statoil et surtout Gazprom commencèrent de leur côté à participer à des contrats d'exploitation du pétrole et du gaz iranien. À peine la première guerre du Golfe était-elle terminée que les Russes ont profité des possibilités de partenariat et depuis la coopération n'a cessé de se renforcer. Dans la crise du nucléaire, Moscou a d'abord privilégié la solidarité avec les États-Unis pour des raisons économiques et politiques évidentes mais à partir de 2006, Moscou s'est distingué dans son attitude face à Téhéran. La visite de Vladimir Poutine le 16 octobre 2007 a marqué un tournant majeur et a débouché sur plusieurs accords et sur la livraison de carburant nucléaire pour la centrale de Boucher. En 2008, la Russie a cessé de soutenir les sanctions contre Téhéran. Après les innombrables échecs d'accord entre les cinq membres permanents du Conseil de sécurité de l'ONU plus l'Allemagne («P5+1») et Ahmadinejad, l'Iran a été condamné par trois résolutions pour ses refus de suspendre son enrichissement en uranium et d'apporter des éclaircissements sur le caractère non militaire de ses activités passées et présentes. La résolution 1696 du 31 juillet 2006 enjoignait l'Iran de suspendre ses activités d'enrichissement et prévoyait, en cas de refus, d'envisager des sanctions qui autoriseraient des mesures économiques prévoyant un recours à la force, en accord avec l'article 47 du chapitre VII de la charte de l'ONU. Comme toujours, la Chine a insisté sur la solution diplomatique. Selon Qin Gang, le porte-parole du Ministère des Affaires étrangères de la Chine en 2010, c'est la manière la plus appropriée pour trouver une solution répondant aux préoccupations de toutes les parties. La Chine s'est opposée à toute sanction relative au pétrole dans la mesure où elle est fortement dépendante de pays producteurs tels que l'Iran dont elle est, par ailleurs, le premier partenaire commercial ${ }^{2}$.

Deux mois après la dernière résolution onusienne, et peu de temps après les États-Unis, l'UE a décidé unilatéralement de durcir les sanctions à l'encontre de l'Iran, à travers le secteur gazier et pétrolier, soit un domaine de haut enjeu stratégique pour l'Iran car, bien qu'il soit

${ }^{1}$ THERME, C. et KHAZANEH, R. (2012), « Le développement du programme nucléaire iranien : entre aspects techniques et questions politiques », Maghreb-Machrek, $\mathrm{n}^{\circ} 212$, p. 115.

${ }^{2}$ CABESTAN, J-P. (2015), op. cit., pp. 496-497. 
classé quatrième producteur mondial de brut, il devait importer $40 \%$ de son essence, faute de capacités de raffinage. Par conséquent, l'UE, sur les conseils de l'AIEA, a décidé d'attaquer son point faible en interdisant nouveaux investissements, transferts de technologie et assistance technique. En outre, les personnalités affiliées aux Gardiens de la révolution furent soumises à des sanctions individuelles. Ces mesures eurent pour effets immédiats la suspension complète des activités de Total (le 18 octobre 2010) et la fermeture d'un gisement gazier dans la mer du Nord, détenu à parts égales par la filiale britannique BP et la compagnie nationale du pétrole iranien (NIOC) $)^{1}$. De leurs côtés, la Russie et la Chine, considérées comme « (...) des alliés économiques de l'Iran (...) se sont prononcés hostiles à toute sanction dirigée contre le régime des mollahs $»^{2}$. La continuation de la politique de sanctions a eu des effets importants sur l'économie iranienne, et en partie a influencé la position de l'Iran dans ses négociations avec le groupe 5+1 pour aboutir à l'accord de Genève en 2013.

\section{4) L'Union Européenne et l'Iran depuis l'arrivée au pouvoir de Hassan Rohani en 2013 ; une période caractérisée par des négociations multilatérales entre l'Iran et le groupe P5+1 qui a abouti à l'Accord de 2015, et par le retrait des États-Unis de ce dernier en 2018}

En 2013, Hassan Rohani a été élu président de la République du régime iranien. Depuis son arrivée au pouvoir, le nouveau président a mis, d'une part, l'accent sur la résolution diplomatique et politique du dossier nucléaire iranien et, d'autre part, il a évité d'employer un discours radical à l'adresse des États-Unis et d'Israël. Par ailleurs, il a réaffirmé que le projet iranien n'avait pas une dimension militaire et a précisé que son pays était prêt à négocier avec la communauté internationale tout en réaffirmant le droit de l'Iran d'accéder au nucléaire civil. «En ce qui concerne la question épineuse de la diplomatie nucléaire, Hassan Rohani est un bon connaisseur du dossier. De ce fait, il pourra faire repartir les négociations $»^{3}$. Quant aux relations de l'Iran avec l'UE, il a mis l'accent sur la coopération et la négociation. L'arrivée au pouvoir de Hassan Rohani en 2013 a permis à l'UE de renforcer son rôle dans les négociations : " cette élection a permis au groupe de contact de rompre avec la politique d'intransigeance iranienne et entraîne le retour en force de la diplomatie européenne, dont les intérêts sont défendus par la Haute Représentante, Lady Ashton ${ }^{4} »$.

Dans un contexte régional marqué par la crise au Moyen-Orient, l'Iran a continué à soutenir le régime syrien, avec l'aide de la Russie et du Hezbollah. Cette intervention a empêché le renversement de Bachar el-Assad ${ }^{5}$ et a démontré le rôle majeur joué par l'Iran sur le plan régional. L'Iran a accepté de revenir à la table des négociations avec les grandes puissances et l'UE à partir de février 2013 et d'entrer dans une nouvelle période de discussions en vue de trouver une solution diplomatique avec le P5+1. Dans cette phase : «l'UE a repris possession du rôle de porte-parole et de conciliateur qui lui [avait] été attribué sous Solana ${ }^{6}$. Les tractations ont abouti, le 24 novembre 2013, à l'accord préliminaire de Genève qui fut un compromis entre l'Iran et le groupe P5+1, qui mit un terme à une crise de 10 ans : «La stratégie des membres du P5+1 a été de trouver dans un premier temps un accord provisoire pour servir

\footnotetext{
${ }^{1}$ Agence France Presse, le 26 octobre 2010.

2 BLACHER, P. (2006), Droit des relations internationales, Paris, Litec, p. 154.

3 DJALILI, M-R. (2013-2014), «Politique étrangère de la République islamique : le rôle du président », Confluences méditerranée, $\mathrm{n}^{\circ} 88$, Paris, l'Harmattan, p. 31.

${ }^{4}$ VIAUD, A. (2017), L'Union européenne face à la crise nucléaire iranienne, Belgique, Presses universitaires de Louvain, p. 127.

${ }^{5}$ BAYRAMZADEH, K. (2013), «La lutte pour l'hégémonie régionale dans les relations internationales : le cas du conflit syrien », Cahiers de Sciences politiques de l'ULG, Cahier n²7, disponible à l'adresse suivante : http://popups.ulg.ac.be/csp/ (consultée le 13 juillet 2020).

${ }^{6}$ VIAUD, A. (2017), op. cit., p. 128.
} 
de base de discussion commune $»^{1}$. Cet accord a fixé une période transitoire pour aboutir à une forme définitive, pour autant qu'un respect réciproque des engagements soit assuré.

Dans la continuité des négociations, le 14 juillet 2015, l'Iran et le P5+1 sont parvenus à signer un texte définitif qui a reconnu à l'Iran le droit d'utiliser l'énergie nucléaire de manière pacifique, à condition de respecter les engagements prévus par l'Accord. La conclusion du texte de Genève 2015 a contribué à l'amélioration des rapports entre l'Iran et l'UE. L'implication diplomatique de cette dernière dans le processus des négociations de 2003 à 2015 a favorisé son rôle d'acteur des relations internationales. Notre analyse démontre d'une part, la cohérence des pays membres de l'UE qui ont montré leur unité dans cette crise et, d'autre part, du rôle joué par le Haut représentant de l'UE pendant les différentes étapes des négociations.

Selon le texte de 2015 (JCPOA), l'Iran s'engage, pendant quinze ans, à ne pas enrichir l'uranium au-delà de $3.67 \%$ et à ne conserver sur son sol qu'au maximum 300 kilogrammes d'uranium légèrement enrichi. L'Iran ne pourra faire fonctionner plus de 5060 centrifugeuses de première génération pendant dix ans et s'engage à appliquer le protocole additionnel de l'AIEA ${ }^{2}$. Cet Accord a permis la levée des sanctions à partir du 16 janvier 2016. Progressivement, les entreprises européennes ont repris leurs activités et ont signé des contrats avec l'Iran : il s'agit notamment de Renault-Nissan, Airbus, Peugeot, Volkswagen, etc. Cet Accord a constitué un tournant dans la crise nucléaire iranienne bien que l'Arabie Saoudite et Israël s'y sont opposés. L'Arabie Saoudite, alliée stratégique des États-Unis au Moyen-Orient, a mis en cause Washington en lui reprochant de s'être rapproché de Téhéran au détriment de Ryad : « l'accord du 14 juillet aussitôt signé, quelques voix [se sont élevées] pour exprimer un vif mécontentement : le prince Bandar Bin Sultan a dénoncé ses conséquences sur le MoyenOrient $^{3}$ ». En ce qui concerne l'État hébreu, « c'est une erreur historique » déclara son Premier ministre, Benyamin Netanyahou. Les convergences entre ces deux pays étant liées à leur perception de la menace ${ }^{4}$ qui voit le projet nucléaire iranien comme un dilemme de sécurité. L'Arabie Saoudite et Israël ont exercé une pression sur les États-Unis afin qu'ils se retirent de l'Accord nucléaire et ont trouvé un écho favorable auprès du président Donald Trump qui réalisa ce vœu en 2018.

\section{C) Les impacts de l'arrivée au pouvoir de Donald Trump sur l'Accord nucléaire de 2015 (JCPOA) ; une période marquée par une dégradation des relations entre les États- Unis et l'Union Européenne}

Depuis l'arrivée au pouvoir de Donald Trump, la nouvelle politique des États-Unis se caractérise par l'isolationnisme, le retrait de plusieurs traités internationaux, en particulier l'Accord multilatéral portant sur le nucléaire iranien, le désengagement de plusieurs organisations internationales, l'unilatéralisme et le néomercantilisme. Cette nouvelle politique est en rupture avec celle d'Obama. Par ces différentes actions, "il rejette l'ordre multilatéral basé sur le compromis, la négociation, la coopération et le respect du droit international $»^{5}$. Selon Dario Battistella, « la vision mercantiliste est liée à l'approche réaliste de la politique internationale, synonyme d'état de guerre. En ce qui concerne le commerce, l'enrichissement n'est possible que si la balance extérieure d'un État est excédentaire, d'où des politiques commerciales multipliant les prohibitions et les barrières aux importations, les primes et les

\footnotetext{
${ }^{1}$ ROUSSELET, L. (2017), Négocier l'Atome : Les États-Unis et les négociations de l'accord sur le nucléaire iranien, Paris, l'Harmattan, p. 72.

${ }^{2}$ Voir le contenu complet de l'Accord dans l'article de NICOULLAUD, F. (2016), op. cit., pp. 28-29.

${ }^{3}$ MAKINSKY, M. (2016), «Iran-Arabie Saoudite : quel dialogue après l'accord nucléaire ?», Stratégique Orients, $\mathrm{n}^{\circ}$ 3, l'Harmattan, p. 33.

${ }^{4}$ LOISEAU, H. (2009), «Les approches contemporaines des relations internationales », dans PAQUIN, S. et DESCHENES, D. (dir.), Introduction aux relations internationales, Canada, Chenelière Education, p. 25.

${ }^{5}$ SANTANDER, S. et VLASSIS, A. (2020), «EU in Global Affairs: Constrained Ambition in an Unpredictable World? », European Foreign Affairs Review, vol. 25, nº 1, p. 15 (traduit par nos soins).
} 
subventions à l'exportation et les représailles à l'encontre des mesures prises par les autres États ${ }^{1} »$. La politique actuelle des États-Unis à l'égard de l'UE, de la Chine et de la Russie, est fortement liée à cette approche économique, et nous constatons la trace de cette vision dans différentes déclarations de D. Trump à l'adresse de la Russie, l'UE, l'Iran et la Chine.

\section{1) La stratégie de D. Trump à l'égard de l'Iran et ses conséquences sur l'Union Européenne}

Dans ce nouveau contexte, Donald Trump veut affaiblir la puissance commerciale de l'UE par l'imposition de sa loi extraterritoriale aux entreprises étrangères, y compris les entreprises européennes. Ces changements d'orientation de la politique étrangère des ÉtatsUnis contribuent à montrer que les relations internationales sont entrées dans une nouvelle période, marquée par l'affaiblissement de la puissance hégémonique des États-Unis et la transformation du rôle des pays comme la Chine et la Russie. Ces deux dernières sont devenues de grandes puissances et constituent un défi pour la puissance états-unienne. Selon J. Mearsheimer, «cette situation montre la grande difficulté de l'ordre international libéral et annonce son affaiblissement $»^{2}$. Pour comprendre la stratégie des États-Unis, il est crucial d'appréhender cette problématique à travers la transformation des rapports de forces régionales et mondiales. Les États-Unis s'opposent à la montée en force de l'Iran en tant que puissance régionale hégémonique au Moyen-Orient, en particulier dans le golfe Persique, car d'après les États-Unis, si l'Iran atteint cette position, le pays aura peut-être la possibilité de se projeter dans d'autres régions du monde. C'est pourquoi, «D. Trump a mis en place des politiques de la pression maximale sur l'Iran $»^{3}$. Selon Donald Trump, l'Accord de 2015 a favorisé l'Iran, et l'accès de celui-ci au stade « atomique » peut renforcer sa puissance hégémonique au MoyenOrient, ce qui est considéré comme une menace pour les intérêts stratégiques des États-Unis. Cette politique s'inscrit dans une stratégie globale qui consiste à empêcher que les puissances européennes et asiatiques se transforment en des puissances régionales hégémoniques ${ }^{4}$. Dans la perception de Donald Trump, l'Iran demeure un pays qui présente des menaces pour les alliés américains que sont l'Arabie Saoudite ${ }^{5}$ et Israël. De ce fait, le retrait des États-Unis de l'Accord de 2015 est lié à une politique multidimensionnelle mixant des aspects économiques, commerciaux, politiques, sécuritaires et stratégiques. Il faut aussi préciser que, depuis le retrait, l'Iran s'est rapproché de la Chine et de la Russie.

\section{2) La politique de l'Union Européenne face au retrait des États-Unis de l'Accord de 2015}

Pendant la période électorale, Donald Trump avait déjà annoncé que, sous sa présidence, les États-Unis se retireraient de l'Accord, et c'est ce qu'il a fait en 2018 en réinstaurant les sanctions contre l'Iran. Cette décision fut en contradiction avec les intérêts de l'UE et des pays signataires et souleva une vague de mécontentement et de protestation auprès des responsables de l'UE. Ces sanctions unilatérales américaines provoquèrent un contentieux international inédit auprès, notamment, des entreprises européennes ou chinoises ${ }^{6}$. L'UE a continué à défendre l'Accord et tenté de mettre en pratique des mesures commerciales permettant aux entreprises européennes de commercer avec l'Iran sans qu'elles soient sanctionnées par les

\footnotetext{
${ }^{1}$ BATTISTELlA, D. (2011), Paix et Guerres au XXI siècle, Paris, Sciences Humaines Editions, pp. 57-58.

${ }^{2}$ MEARSHEIMER, J. (2019), « Bound to Fail, The Rise and Fall of the Liberal International Order », Security, vol. 43, n 4, pp. 7-50 (traduit par nos soins).

${ }^{3}$ CIZEL, A. (2020), «L'obsession iranienne : les États-Unis au défi des (dès)équilibres régionaux », dans THERME, C. (dir), L'Iran et ses rivaux, Passés composés. p, 35.

${ }^{4}$ MEARSHEIMER, J. (2012), op. cit., pp. 40-42.

${ }^{5}$ KANDAL, M. (2018), «États-Unis-Arabie Saoudite, une alliance ambiguë », Questions internationales, Paris, La documentation française, $n^{\circ} 89$, pp. 82-83.

${ }^{6}$ HOURCADE, B. (2019), «L'ennemi iranien» dans BADIE, B. et VIDAL, D. (dir.), Fin du Leadership Américain ?, Paris, La Découverte, p. 198.
} 
États-Unis. Dans cette perspective, le 6 juin 2018, la Commission européenne lança la procédure d'activation de la loi dite «de blocage» afin de contourner les sanctions américaines ${ }^{1}$. Cet acte interdisait aux entreprises européennes de se conformer aux prescriptions américaines; dans le cas contraire, elles se verraient sanctionner par l'UE. Le mécanisme accordait donc une indemnisation aux entreprises touchées par la loi américaine mais il n'a pas abouti en raison de son caractère symbolique et n'a pas vraiment permis le contournement des sanctions américaines.

Dans la continuité de cette politique, l'UE a lancé une autre initiative pour reprendre le commerce avec l'Iran. En effet en 2019, elle a créé un nouveau mécanisme (Instex), fondé sur le principe du troc, et autorisant les entreprises européennes de commercer avec l'Iran en contournant les sanctions des États-Unis ${ }^{2}$. La mesure est entrée en phase opérationnelle en mars 2020 et a permis d'exporter du matériel médical vers l'Iran. Désormais, les entreprises européennes qui exporteront vers l'Iran seront créditées par l'Instex. Il faut préciser que la portée du mécanisme est limitée et ne concerne que quelques secteurs : le commerce des produits alimentaires, des médicaments et de fournitures humanitaires entre l'Iran et plusieurs pays européens. L'objectif principal de l'UE consiste à encourager l'Iran à ne pas quitter 1'Accord de 2015 et à respecter ses engagements à cet égard : " [q]uant aux Européens, ils tentent d'apaiser la situation à l'aide d'arguments diplomatiques et économiques $»^{3}$. Pour l'Iran ces mesures sont insuffisantes et n'apportent pas de solutions durables aux sanctions et il demande à l'UE de respecter ses engagements. Au regard de la situation actuelle, la solution de l'UE, par le mécanisme de l'Instex, ne concerne pour l'instant qu'une transaction dans le cadre d'une aide apportée par l'UE pour des motifs humanitaires et sanitaires dans le cadre de la pandémie du Covid 19, ce qui constitue un moyen de montrer au gouvernement iranien la différence de l'UE par rapport aux États-Unis. D'un point de vue politique, ce mécanisme prend une valeur symbolique et peut-être faudra-t-il attendre les prochaines élections aux États-Unis pour un changement éventuel de la politique de ceux-ci.

\section{Conclusion}

La présente étude avait pour objectif d'exposer la limite de puissance de l'UE dans le système international, et en particulier dans ses relations avec l'Iran. Après avoir analysé les différentes dimensions de cette puissance à travers plusieurs cas, nous nous sommes concentrés sur l'exemple du projet nucléaire iranien afin de mettre en exergue les divergences entre les États-Unis et l'UE sur le sujet, notamment depuis l'arrivée de Donald Trump à la MaisonBlanche. Pour aborder cette matière, nous avons mobilisé plusieurs concepts analytiques des Relations internationales : le concept de l'acteur, celui de la puissance douce (soft power) et celui de la puissance normative (normative power). Nous les avons utilisés afin d'examiner la capacité d'influence de l'UE dans le cadre de sa puissance normative à travers ses relations avec l'Iran et les États-Unis. Notre étude a montré que, depuis 1991, l’UE ambitionne un rôle important sur le plan des relations internationales. Dans cette perspective, elle participe à la médiation, à la gestion des crises, à l'instauration de la paix et à la démocratisation de plusieurs pays. Cependant, son rôle doit être mesuré en fonction du contexte, des conditions politiques et du facteur des rapports de force. Selon F. Petiteville, « l'UE demeure pourtant un acteur très 'conditionnel' de la résolution des conflits ${ }^{4}$. L'UE est une organisation régionale dont la puissance ne peut être comparée à celle d'un État. La puissance normative européenne trouve

\footnotetext{
1 Voir le site de référence sur les questionnes européennes (Tout l'Europe, comprendre l'Europe), (le 03/05/2019),(https://www.touteleurope.eu/actualite/accord-nucleaire-iranien-qu-est-ce-que-l-extraterritorialitedes-lois-americaines.html, Iran : que peut faire l'Europe face aux sanctions des Etats-Unis?.

${ }^{2}$ Ibid.

${ }^{3}$ HOURCADE, B. (2019), op. cit., p. 198.

${ }^{4}$ PETITEVILLE, F. (2016), op. cit., p. 130.
} 
un écho favorable dans les rapports extérieurs, en particulier avec les pays candidats à l'adhésion. Le cas des pays d'Europe orientale confirme cette perception devenue réalité dans le sens où c'est en acceptant les normes prévues par les critères de Copenhague qu'ils sont devenus membres de l'UE. Par ailleurs, on peut citer les pays des Balkans occidentaux, ou la Turquie, qui doivent réaliser des réformes structurelles afin de remplir les conditions d'adhésion. À travers ces cas, force est d'observer que l'UE peut être considérée comme un acteur de démocratisation dans une partie du monde. Mais dans certains cas, cette puissance normative rencontre des limites car les pays comme la Russie ou la Chine rejettent les normes européennes relatives à la question des droits humains. De surcroît, ils s'opposent à la conditionnalité des relations commerciales et économiques au respect de ces normes.

En ce qui concerne la limite de la puissance normative de l'UE à l'égard de l'Iran, nous avons examiné cette question à travers quatre périodes de leurs relations. 1) De 1992 à 1997 : l'UE a établi un dialogue critique soumis à cinq conditions. Durant cette période, nous avons observé une évolution en matières économique et commerciale. Mais la puissance normative s'est vue limitée par le refus iranien de reconnaître l'universalité des normes, en particulier celles relatives aux droits fondamentaux. 2) De 1998 à 2005 : cette période coïncide avec la présidence de Khatami qui se montra favorable à une partie des normes dans le cadre du dialogue global. On enregistra quelques progrès dans les rapports entre ces deux protagonistes. Cependant la réalisation des conditions du dialogue exigées par l'UE s'est heurté à la résistance des conservateurs du régime en Iran sous l'égide du guide de la Révolution. Par ailleurs, la reprise des activités nucléaires a empêché la conclusion d'un ACC entre l'UE et l'Iran. 3) 20052013 : avec l'arrivée au pouvoir d'Ahmadinejad en 2005, les relations entre l'UE et l'Iran sont entrées dans une phase de crise, et en dépit des négociations entre les représentants des deux parties, Téhéran a rejeté les conditions de l'UE qui mettait en doute la vocation pacifique du nucléaire iranien. Les conditions de l'UE concernant l'arrêt de l'enrichissement d'uranium ont été jugées inacceptables par le gouvernement iranien qui a mis en avant le principe de nonnégociabilité sur ce sujet. C'est pourquoi l'UE a changé sa stratégie à l'égard de l'Iran à partir de 2010 par l'application d'une diplomatie coercitive. Cette période coïncide aussi avec la montée en puissance de l'Iran à l'échelle régionale et cette ascension a joué un rôle dans le processus des négociations. Par conséquent, la crise nucléaire a complètement influencé le dialogue irano-européen et a marginalisé la question des droits humains. 4) 2013-2020 : en 2013 avec l'arrivée au pouvoir d'Hassan Rohani, l'UE a mobilisé toute sa capacité diplomatique afin de jouer un rôle de médiateur dans les négociations multilatérales entre l'Iran et le groupe P5+1. Durant cette période, les États-Unis et l'UE ont partagé la même approche pour reconnaître le droit de l'Iran au nucléaire civil. Ce changement politique a joué un rôle crucial dans la conclusion de l'Accord de 2015 qui fut un succès pour la " politique étrangère commune européenne ». Par ailleurs, les activités diplomatiques des représentants de l'UE auprès de la Russie et de la Chine ont permis de rapprocher les positions de ces acteurs avec celles des ÉtatsUnis. Cette évolution s'accorda à l'existence d'un intérêt commun auprès des acteurs concernés. Ce qui a permis à l'UE d'exploiter sa capacité d'influence politique et diplomatique dans le processus des négociations. Certes, les États-Unis ont pris le leadership dans ces négociations mais l'UE a joué un rôle complémentaire. Selon Clément Therme : «à partir de l'année 2007, nous assistons à l'alignement progressif des capitales européennes sur la ligne américaine. De plus, l'élection de Barack Obama se traduit par un revirement diplomatique de Washington qui surprend les Européens et les pousse vers une responsabilité formelle de la négociation mais sous la tutelle américaine $» 1$.

Par conséquent, cet Accord a montré que, lorsque la politique européenne présente une certaine cohérence, l'UE peut devenir un acteur des résolutions des crises et des conflits. Cet

${ }^{1}$ THERME, C. (2020), « Le nucléaire iranien vu de France », Confluences méditerranée, n 113, l’Harmattan, p, 106. 
Accord a permis, quelques mois plus tard, la levée progressive de l'embargo et la normalisation des relations avec l'Iran. Mais l'élection de Donald Trump a complètement changé la politique des États-Unis au sujet de l'Accord. En 2018, les États-Unis s'en sont retirés et ont imposé leur loi extraterritoriale aux entreprises étrangères en interdisant le commerce avec l'Iran. Malgré sa protestation, l'UE n'a pas pu empêcher que cette interdiction s'impose aux entreprises européennes. De ce fait, cette confrontation, diplomatique et commerciale, a révélé la limite de la puissance normative de l'UE et sa dépendance vis-à-vis de Washington.

\section{Bibliographie}

Agence France Presse, le 26 octobre 2010.

ARON, R. (1962), Paix et guerre entre les nations, Paris, Calmann-Lévy.

BADIE, B. (2019), L'Hégémonie contestée. Les nouvelles formes de domination internationale, Paris, Odile Jacob.

BATTISTELLA, D. (2011), Paix et Guerres au XXI siècle, Paris, Sciences Humaines Editions.

BATTISTELLA, D. (2012), Théories des relations internationales, Paris, Sciences Po.

BATTISTEllA, D., SMOUT, M-C., VENNESSON, P., PETITEVILlE, F. (2006), Dictionnaire des relations internationales, Paris, Dalloz.

BAYRAMZADEH, K. (2004), Les enjeux principaux des relations entre l'Iran et l'Europe de 1979 à 2003, Paris, l'Harmattan.

BAYRAMZADEH, K. (2013), «La lutte pour l'hégémonie régionale dans les relations internationales : le cas du conflit syrien », Cahiers de Sciences politiques de l'ULG, Cahier $\mathrm{n}^{\circ} 27$, disponible à l'adresse suivante : http://popups.ulg.ac.be/csp/ (consultée le 13 juillet 2020).

BLACHER, P. (2006), Droit des relations internationales, Paris, Litec.

BONIFACE, P. (2019), Comprendre le monde, Paris, Armand Collin.

CABASTAN, J-P. (2015), La politique internationale de la Chine, Paris, Sciences Po.

CIZEL, A. (2020), «L'obsession iranienne: les Etats-Unis au défi des (dès)équilibres régionaux », in Clément Therme, L'Iran et ses rivaux, Passés composés.

Communication de la Commission au Conseil et au Parlement européen, Relations EURépublique Islamique de l'Iran, le 7 février 2001.

CORDESMAN, A. (1997), Iran: Dilemmas of dual containment, New York, Westview Press.

DEVIN, G. (2013), Sociologie des relations internationales, Paris, La Découverte. 
DJALILI, M-R. (2013-2014), «Politique étrangère de la République islamique : le rôle du président », Confluences méditerranée, $\mathrm{n}^{\circ} 88$, Paris, 1'Harmattan.

DUCHENE, F, (1972), «Europe's role in world peace », in Richard Mayen (ed.), Europe tomorrow. Sixteen Europeans look ahead, London,

DUFAYS, N. (2012), «Les relations de l'Union européenne avec la République islamique de l'Iran : enjeux, perspectives et perceptions », dans MAKINSKY, M. (dir.), L'Iran et les grands acteurs régionaux et globaux, Paris, L'Harmattan.

EIFFLING, V. (2013), «Les États-Unis face à la question nucléaire iranienne : un nœud gordien perpétuel ? », dans NAHAVANDI, F. (dir.), L'Iran dans le monde, Paris, l'Harmattan.

FIEDLER, R. (2018), «Iran and the European Union after the Nuclear Deal », CES Working Papers, Alexandru Ioan Cuza University of Iasi, Centre for European Studies, Iasi, vol. 10, Issue 3.

GAHLER, M. (2018), Le rapport du parlement européen sur les relations entre l'UE et la République islamique, Bruxelles, le 26 novembre 2001.

HOURCAD, B. (2019), «L'ennemi iranien» dans BADIE, B. et VIDAL, D. (dir.), Fin du Leadership Américain?, Paris, La Découverte.

JUPILLE, J. and CAPORASO, J. (1998), « States, Agency and Rules: The European Union in Global Environmental Politics » in RHODES, C. (ed.), The European Union in the World Community, Boulder, Colorado, Lynne Rienner.

KAGAN, R. (2004), La puissance et la faiblesse : Les États-Unis et l'Europe dans le nouvel ordre mondial, Paris, éd. Hachette, coll. Pluriel.

KANDAL, M. (2018), «États-Unis-Arabie Saoudite, une alliance ambiguë », Questions internationales, Paris, La documentation française, $\mathrm{n}^{\circ} 89$.

KEMP, G. (1998), « The United States, Iran and Irak: Containment or Engagement? », US Policy and Iran, Paris, Edition Ifri.

La déclaration de sir Leon Brittan, le 30 septembre 1997, Bruxelles, Source d'Europe, 31494.

LAÏDI, Z. (2009), «L'Europe, puissance normative internationale », dans DEHOUSSE, R., Politiques européennes, Paris, Presse de Sciences Po.

LAROCHE, J. (2011), La brutalisation du monde : du retrait des États à la décivilisation, Québec, Liber.

LEFEBVERE, M. (2011), La politique étrangère européenne, Paris, PUF.

LEMAITRE, P. (1997), « L'Europe gèle le « dialogue critique » avec l'Iran mais ne prend pas de sanctions économiques », Le Monde, le 2 mai 1997, https://www.lemonde.fr/archives/article/1997/05/02/l-europe-gele-le-dialogue-critique-avec-liran-mais-ne-prend-pas-de-sanctions-economiques_3540827_1819218.html (consulté le 15 janvier 2021). 
LESNES, C. (2013), «La politique étrangère de Barack Obama : la tentation du repli ? », dans BADIE, B. et VIDAL, D. (dir.), Puissances d'hier et de demain, La Découverte.

LIKA, L. (2016), «La pénétration turque dans les Balkans occidentaux : quels défis pour le projet d'élargissement de l'UE ?», dans SANTANDER, S. (dir.), Concurrences régionales dans un monde multipolaire émergent, Bruxelles, P.I.E. Peter Lang.

LOISEAU, H. (2009), «Les approches contemporaines des relations internationales », dans PAQUIN, S. et DESCHENES, D. (dir.), Introduction aux relations internationales, Canada, Chenelière Education.

MAKINSKY, M. (2016), «Iran-Arabie Saoudite : quel dialogue après l'accord nucléaire ?», Stratégique Orients, ${ }^{\circ} 3$, l'Harmattan.

MANNERS, I. (2002), « Normative Power Europe: A contradiction in Terms? », Journal of Common Market Studies, vol. 40, $\mathrm{n}^{\circ} 2$.

MEARSHEIMER, J. (2014), The Tragedy of Great Power Politics, USA, University of Chicago.

MEARSHEIMER, J. (2019), «Bound to Fail, The Rise and Fall of the Liberal International Order », Security, vol. 43, n 4.

Mehr News (site web iranien) : www.mehrnews.com/fa/ (26.11.2008).

MERLE, M. (1988), Sociologie des relations internationales, Paris, Dalloz.

MICHEL, L. (2009), «La refonte de la stratégie de défense américaine », Revue Internationale et Stratégique, $\mathrm{n}^{\circ} 76$.

MIKHAÎL, B. (2010), «Une diplomatie du pragmatisme aux effets limités au MoyenOrient ? », Revue Internationale et Stratégique, $\mathrm{n}^{\circ} 77$.

MORGENTHAU, H. (1948), Politics Among Nations. The struggle for Power and Peace, New York, Knopf.

NICOULLAUD, F. (2016), «La fin d'un bras de fer avec la communauté internationale ? Retour sur douze années de négociations nucléaires », Iran le retour, Questions internationales, $\mathrm{n}^{\circ} 7$, La documentation française.

NYE, J. (1990), Bound to lead. The Changing Nature of American Power, New York, Basic Books Publishers.

PAQUIN, S. (2009), «L'économie politique internationale et la mondialisation », dans PAQUIN, S. et DESCHÈNES, D. (dir.), Introduction aux relations internationales. Théories, pratiques et enjeux, Montréal, Chenelière.

PETITEVILLE, F. (2002), «L'Union européenne, un acteur international 'global' », Revue internationale et stratégique, $\mathrm{n}^{\circ} 43$. 
PETITEVILLE, F. (2006), La politique internationale de l'Union européenne, Sciences Po.

PETITEVILLE, F. (2016), «L'Union européenne, acteur conditionnel de la résolution des conflits », dans BAZIN, A. et TENENBAUM, C. (dir.), L'Union européenne et la paix, Paris, Presses de Siences Po.

ROSENEAU, J. (1990), Turbulence in World Politics. A Theory of Change and Continuity, Princeton, Princeton University Press.

ROUSSELET, L. (2017), Négocier l'Atome : Les États-Unis et les négociations de l'accord sur le nucléaire iranien, Paris, l'Harmattan.

SANTANDER, S. (2016) (dir.), Concurrences régionales dans un monde multipolaire émergent, Bruxelles, P.I.E. Peter Lang.

SANTANDER, S. VLASSIS, A. (2020), «EU in Global Affairs: Constrained Ambition in an Unpredictable World? », European Foreign Affairs Review, vol. 25, $\mathrm{n}^{\circ} 1$.

SANTANDER, S., VLASSIS, A. (2018), «L'UE, une puissance commerciale bousculée », Diplomatie, $\mathrm{n}^{\circ} 47$.

SCANDELLA, J. (2005), «L'Union européenne et l'Iran : entre institutionnalisation et suspension des relations », Les Cahiers de l'Orient, $\mathrm{n}^{\circ} 79$.

THERME, C. et KHAZANEH, R. (2012), «Le développement du programme nucléaire iranien : entre aspects techniques et questions politiques », Maghreb-Machrek, n 212.

THERME, C. (2020), « Le nucléaire iranien vu de France », Confluences méditerranée, $\mathrm{n}^{\circ} 113$, l'Harmattan.

VAN ENGELAND-NOURAI, A. (2005), «Le rôle des droits de l'homme dans les relations entre l'Union européenne et l'Iran », Les Cahiers de l'Orient, $\mathrm{n}^{\circ} 79$.

VIAUD, A. (2017), L'Union européenne face à la crise nucléaire iranienne, Belgique, Presses universitaires de Louvain.

WANG, Y. (2009), «The Identity Dilemmas of EU Normative Power: Observations from Chinese Traditional Culture », in GERRITS André (ed.), Normative Power Europe in a Changing World: A Discussion, The Hague, Netherlands, Clingedael European Papers $\mathrm{n}^{\circ} 5$.

ZARIFIAN, J. (2015), « Le dossier nucléaire iranien et la question du rapprochement ÉtatsUnis-Iran », Politique américaine, $\mathrm{n}^{\circ} 26$. 


\title{
Les nouveaux accords commerciaux conclus par l'Union Européenne
}

\author{
Philippe Vincent ${ }^{1}$
}

\section{Résumé}

Suite au blocage des négociations commerciales internationales au sein de l'Organisation Mondiale du Commerce (OMC), l'Union Européenne (UE) a conclu des accords commerciaux dits de «nouvelle génération» avec un certain nombre de partenaires. Le champ d'application de ces accords est beaucoup plus ambitieux que le seul commerce des marchandises auquel se limitaient les accords commerciaux précédemment conclus par l'Union. Il couvre en effet également le commerce des services, la propriété intellectuelle et les investissements internationaux. L'insertion de ceux-ci dans les nouveaux accords a fait l'objet de deux demandes d'avis à la Cour de Justice de l'Union Européenne (CJUE). Dans le premier, elle a déclaré que l'Union n'était pas compétente pour conclure seule un accord contenant des dispositions relatives aux investissements autres que directs et au règlement des différends relatifs aux investissements. Dans le second, elle a confirmé que le mécanisme de règlement des différends entre investisseurs et État d'accueil ne porte pas atteinte au principe de l'autonomie du droit de l'Union, et n'affecte pas le principe de la compétence exclusive de la Cour pour interpréter le droit européen.

Mots-clés : Union Européenne ; Politique Commerciale Commune ; Accords Commerciaux Internationaux; droit des investissements internationaux ; Organisation Mondiale du Commerce

\footnotetext{
${ }^{1}$ Philippe Vincent est professeur à l'Université de Liège, Département de Droit, UR CITÉ.
} 


\section{Introduction}

L'Union Européenne (UE) a conclu ces dernières années de nombreux accords commerciaux avec des partenaires éloignés, tels la Corée du Sud, le Vietnam, Singapour, le Canada et le Japon. Cet empressement pourrait paraître étrange, dans la mesure où existe depuis 1995 une institution internationale, l'Organisation Mondiale du Commerce (OMC), chargée précisément de la libéralisation des échanges internationaux. Comment expliquer les velléités européennes d'aller au-delà des règles de l'OMC dans leurs relations avec leurs partenaires commerciaux ? Après avoir rappelé l'évolution de la pratique européenne en matière de conclusion d'accords internationaux $(\S 1)$ et le blocage auquel les négociations internationales sont confrontées à l'heure actuelle $(\S 2)$, nous analyserons les accords actuels $(\S 3)$.

\section{La pratique européenne en matière de conclusion d'accords internationaux}

Plusieurs bases juridiques existent dans les traités européens pour conclure des accords internationaux. Certains rentrent dans le cadre de la politique commerciale commune, dont la définition a connu une évolution constante depuis 1957. D'autres accords sont dits « d'association », car ils mettent en place des institutions communes entre les partenaires.

\subsection{Les accords conclus dans le cadre de la Politique Commerciale Commune (PCC)}

Dès 1957, les États membres de la Communauté Économique Européenne (CEE) ont voulu doter celle-ci d'une politique commerciale commune (article $113 \mathrm{CEE}$, devenu $133 \mathrm{TCE}$ puis 207 TFUE). Celle-ci implique, outre l'adoption d'un tarif douanier commun pour l'ensemble des États membres et de mesures de défense commerciale (législation antidumping...), la conclusion d'" accords tarifaires et commerciaux relatifs aux échanges de marchandises et de services et les aspects commerciaux de la propriété intellectuelle » (article $207 \S 1^{\text {er }}$ TFUE).

Le champ d'application de la PCC n'a cessé de s'étendre depuis 1957. Alors que la Communauté ne disposait initialement que d'une compétence exclusive limitée aux accords relatifs au seul commerce des marchandises, celle-ci fut étendue en 2000 au commerce des services et à la protection de la propriété intellectuelle (article 133 TCE). Depuis le Traité de Lisbonne, l'Union est également compétente exclusivement pour conclure des accords relatifs aux investissements avec ses partenaires, moyennant certaines nuances sur lesquelles nous reviendrons par la suite ${ }^{1}$.

Rappelons qu'en vertu de l'article 207 § 3 TFUE, la Commission dispose du droit d'initiative pour l'initiation de négociations commerciales, pour lesquelles elle doit obtenir l'autorisation du Conseil. Une fois cette autorisation obtenue, la Commission négocie seule avec son ou ses partenaire $(s)^{2}$, dans le cadre des directives que le Conseil peut lui adresser ${ }^{3}$, en devant faire régulièrement rapport sur l'état d'avancement des négociations au comité spécial désigné par le Conseil pour l'assister dans sa tâche et au Parlement européen. Ces rapports réguliers ont été considérés comme nécessaires (et suffisants) par les rédacteurs du TFUE pour assurer un contrôle démocratique de l'avancement des négociations commerciales. Des observateurs ont toutefois insisté sur le secret entourant certaines négociations, notamment

\footnotetext{
${ }^{1}$ Cf. $§ 3.4 .2$.

${ }^{2}$ La Commission dispose de pouvoirs parfois qualifiés d'exorbitants dans le cadre de ces négociations. Elle peut par exemple décider de les suspendre sans avoir à se justifier. Vu l'intervention du Conseil et du Parlement européen en fin de processus, elle a toutefois intérêt à les tenir informés de l'évolution des négociations, sous peine de s'exposer à un rejet en fin de procédure (comme ce fut le cas, par exemple, pour l'accord commercial anticontrefaçon (ACTA), rejeté par le Parlement européen en juillet 2012.

${ }^{3}$ Celles-ci peuvent par ailleurs évoluer au fur et à mesure de l'avancement des négociations.
} 
celles de l'Accord Économique et de Commerce Global (AECG) avec le Canada, et les négociations avortées avec les États-Unis dans le cadre du partenariat transatlantique.

Si l'accord est signé par la Commission, le Conseil doit autoriser cette signature, et il intervient avec le Parlement européen (depuis le traité de Lisbonne) pour l'adoption de la décision finale de conclusion de l'Accord.

La compétence communautaire ne devint exclusive que le $1^{\mathrm{er}}$ janvier 1970, afin de laisser aux États membres le temps de coordonner progressivement leurs relations commerciales avec les pays tiers. L'ancien article 113 CEE a permis à la Communauté de conclure des accords commerciaux avec une vingtaine d'États dans les années $1970^{1}$. Il forme également la base juridique des règlements mettant en place le Système des préférences tarifaires généralisées (SPG) par lequel la Communauté (et maintenant l'Union) accorde des avantages tarifaires non réciproques aux pays du Sud.

\subsection{Les accords d'association}

Parallèlement à l'article 113 CEE, l'article 238 CEE (devenu 310 TCE puis 217 TFUE) permet à l'Union de conclure des accords d'association "caractérisé(s) par des droits et obligations réciproques, des actions en commun et des procédures particulières» (article 217 TFUE) avec ses partenaires. Ces accords vont plus loin que de simples accords commerciaux de libre-échange. Ils prévoient généralement la mise en place d'institutions, notamment un «conseil d'association $»^{2}$ qui peut se voir doté du pouvoir de prendre des décisions obligatoires ${ }^{3}$. Le concept $\mathrm{d}^{\prime}$ " accord d'association » a évolué avec le temps.

\subsubsection{Les accords d'association de première génération}

Les accords d'association de première génération furent conclus avec les premiers candidats à l'adhésion : la Grèce en $1961^{4}$, la Turquie en $1963^{5}$, Malte en $1970^{6}$ et Chypre en $1972^{7}$. Ils visaient à établir une véritable union douanière entre ces États ${ }^{8}$ et la Communauté, dans la perspective d'une adhésion ultérieure. Ils mettaient également en place une structure institutionnelle dotée du pouvoir de prendre des décisions obligatoires afin de faciliter les futures adhésions.

\subsubsection{Les accords de deuxième génération}

Les accords d'association de deuxième génération furent conclus avec des partenaires privilégiés situés sur d'autres continents, dans une perspective non plus d'adhésion future mais de coopération au développement. Rentre dans cette catégorie la Convention de Yaoundé, conclue entre la Communauté et les anciennes colonies belges et françaises d'Afrique en $1963^{9}$

\footnotetext{
${ }^{1}$ Espagne (JOCE 1970, L 182/1) ; Israël (JOCE 1970, L 183/1) ; Autriche (JOCE 1972, L 300/2) ; Suède (JOCE 1972, L 300/97) ; Suisse (JOCE 1972, L 300/189) ; Islande (JOCE 1972, L 301/2) ; Portugal (JOCE 1972, L 301/165) ; Norvège (JOCE 1973, L 171/1) ; Finlande (JOCE 1973, L 238/1); Inde (JOCE 1974, L 82/1); Sri Lanka (JOCE 1975, L 247/2) ; Pakistan (JOCE 1976, L 168/1) ; Bangladesh (JOCE 1976, L 319/1).

${ }^{2}$ Parfois qualifié de « Conseil des ministres » ou de « Conseil de coopération ».

${ }^{3}$ Voy. par exemple la décision 1/98 du Conseil d'association CE-Turquie du 25 février 1998 concernant le régime de commerce des produits agricoles.

${ }^{4} J O C E \mathrm{n}^{\circ} 26$ du 18 février 1963, p. 296.

${ }^{5} J O C E \mathrm{n}^{\circ} 27$ du 29 décembre 1964, p. 3685.

${ }^{6}$ JOCE 1971, L 61/1.

${ }^{7}$ JOCE 1973, L 133/1.

${ }^{8}$ L'union douanière avec la Turquie ne fut toutefois mise en place que le $1^{\text {er }}$ juillet 1996 . Encore ne concerne-telle que partiellement les produits agricoles.

${ }^{9} J O C E \mathrm{n}^{\circ} 93$ du 11 juin 1964, p. 1430.
} 
et prolongée en $1969^{1}$, année où la CEE conclut également des accords d'association avec les anciennes colonies britanniques d'Afrique de l'est ${ }^{2}$, le Maroc ${ }^{3}$ et la Tunisie ${ }^{4}$.

Ces accords se contentaient de mettre en place des préférences non réciproques entre la Communauté et les pays bénéficiaires. Interrogée sur cet écart par rapport au principe de réciprocité qui devait théoriquement caractériser les accords d'association, la Cour de Justice de la Communauté Européenne (CJCE) répondit dans son arrêt Bresciani ${ }^{5}$ que « le déséquilibre dans les obligations assumées par la Communauté vis-à-vis des États associés... est dans la logique même du caractère spécifique de la Convention (de Yaoundé) » ${ }^{6}$.

\subsubsection{Les accords de troisième génération}

Les accords «européens », dits de troisième génération, furent signés à partir de 1991 entre la Communauté et les pays d'Europe centrale et orientale (Hongrie, Pologne, Tchécoslovaquie, Bulgarie et Roumanie). Leur objectif était clairement de préparer l'adhésion de ces États à la Communauté, par la création de zones de libre-échange au bout d'une période transitoire de 10 ans, et la mise en place de coopérations dans les domaines économique, financier et éducatif.

D'autres accords de troisième génération furent conclus sous la formes d' «accords euro-méditerranéens » entre 1998 et 2006 avec la Palestine ${ }^{7}$, la Tunisie ${ }^{8}$, le Maroc ${ }^{9}$, Israë ${ }^{10}$, la Jordanie $^{11}$, l'Égypte ${ }^{12}$, l'Algérie ${ }^{13}$ et le Liban ${ }^{14}$. Ceux-ci prévoyaient l'instauration d'une zone de libre-échange sur une période transitoire de 12 ans (à l'exception d'Israël avec lequel les échanges étaient déjà libéralisés), ainsi que la mise en place d'un dialogue régulier en matière de sécurité, et d'une coopération économique, sociale, financière, sociale, culturelle et en matière d'éducation.

Entrent également dans cette catégorie les «Accords de Partenariat Économique» (APE) conclus à partir de 2000 entre la Communauté et les États d'Afrique, Caraïbes et Pacifique (ACP) dans le cadre de la Convention de Cotonou ${ }^{15}$, les « Accords de Stabilisation et d'Association » (ASA) conclus avec la Macédoine du Nord, la Serbie, la Bosnie-Herzégovine, le Monténégro, l'Albanie et le Kosovo ${ }^{16}$, ainsi que les " accords de libre-échanges complets et approfondis » conclus en 2014 avec la Géorgie ${ }^{17}$, la Moldavie ${ }^{18}$ et l'Ukraine ${ }^{19}$.

\footnotetext{
${ }^{1}$ JOCE 1970, L 282/1.

${ }^{2} J O C E$ 1970, L 282/54.

${ }^{3}$ JOCE 1969, L 197/1.

${ }^{4}$ JOCE 1969, L 198/2.

${ }^{5}$ CJCE, arrêt Bresciani du 5 février 1976, aff. 87/75, Rec. 1976, p. 18.

${ }^{6}$ Point 23 de l'arrêt.

${ }^{7}$ JOCE 1997, L 187/1.

${ }^{8}$ JOCE 1998, L 97/1.

${ }^{9}$ JOCE 2000, L 70/1.

${ }^{10}$ JOCE 2000, L 147/1.

${ }^{11}$ JOCE 2002, L 129/1.

${ }^{12}$ JOCE 2004, L 304/38.

${ }^{13}$ JOCE 2006, L 173/1.

${ }^{14}$ JOCE 2006, L 143/1.

${ }^{15} \mathrm{~L}$ 'accord de Cotonou fut conclu suite à la condamnation par l'Organe de règlement des différends de l'OMC dans le cadre de l'affaire de la banane du régime préférentiel non réciproque mis en place dans la Convention de Lomé. Voy. à ce sujet VINCENT, P. (2003), «L'entrée en vigueur de la convention de Cotonou », Cahiers de Droit européen, pp. 157-176.

${ }^{16}$ JOUE 2015, L 290/4.

${ }^{17}$ JOUE 2014, L 261/4.

${ }^{18}$ JOUE 2014, L 260/4.

${ }^{19}$ JOUE 2014, L 161/3.
} 
1.3 La notion $d^{\prime}$ « accord mixte $»^{1}$

L’Union (comme la Communauté avant elle) est compétente pour conclure seule en son nom propre les accords ne contenant que des dispositions concernant des secteurs où elle dispose de compétences exclusives, et dont elle assurera seule le financement. À partir du moment où l'accord projeté contient des dispositions empiétant sur les compétences des États membres, ou si le financement sera assumé (ne serait-ce qu'en partie) par ceux-ci, l'accord est dit «mixte $»^{2}$. Cela implique que les États membres seront parties à l'accord aux côtés de l'Union, et que par conséquent ils devront également le signer et le ratifier ${ }^{3}$. Cela implique dès lors « une coopération étroite entre les institutions de l'Union et les États membres, tant dans le processus de négociation et de conclusion que dans l'exécution des engagements assumés $»^{4}$.

\subsection{La notion d' « application provisoire »}

Les accords commerciaux mixtes peuvent connaître une « application provisoire ». Cela signifie que les articles concernant des matières pour lesquelles l'Union est seule compétente entreront en vigueur dès que la procédure européenne de conclusion de l'accord sera achevée. L'entrée en vigueur définitive de la totalité de l'accord n'aura lieu que lorsque les États membres l'auront tous ratifié.

\subsection{Le cadre juridique des relations commerciales de la Communauté en 1994}

Au moment de la création de l'OMC en 1994, les relations commerciales de la Communauté européenne avec ses partenaires étaient par conséquent de trois ordres :

- accords de libre-échange ${ }^{5}$ (ou d'union douanière) avec ses partenaires proches : pays européens et Israël (et plus tard méditerranéens et $\mathrm{ACP}^{6}$ ) ;

- préférences non réciproques avec les pays du Sud, par le biais de la Convention de Lomé pour les États $\mathrm{ACP}^{7}$ et le SPG ;

- absence d'accord commercial avec ses partenaires industrialisés (États-Unis, Canada, Japon, Australie et Nouvelle-Zélande, auxquels viendront s'ajouter en 1998 la Corée du Sud, Hongkong et Singapour suite à leur exclusion du bénéfice du SPG).

Les relations avec cette troisième catégorie de partenaires allaient s'opérer exclusivement dans le cadre de l'OMC. Pour rappel, le champ d'application de celle-ci s'étend, au-delà du commerce des marchandises, au commerce des services et à la protection de la propriété intellectuelle. Le Built-in Agenda agréé au moment de la conclusion de l'Accord instituant l'OMC prévoyait une poursuite des négociations à partir de 2000, afin d'approfondir les concessions ${ }^{8}$ et la libéralisation des échanges. Par ailleurs, deux accords spécifiques en matière de libéralisation accrue du commerce des services financiers et des télécommunications furent conclus en 1997 et 1998. Le multilatéralisme paraissait triomphant à ce moment. Il n'était par conséquent nullement nécessaire d'envisager la conclusion d'accords commerciaux

\footnotetext{
${ }^{1}$ Voy. à ce sujet BOURGEOIS J., DEWOST, J-L, et GAIFFE, M-A (éds.) (1997), La Communauté européenne et les accords mixtes. Quelles perspectives? Bruges, Collège d'Europe ; HELISKOSKI, J. (2001) Mixed Agreements as a Technique for Organizing the International relations of the European Community and its Member States, La Haye, Kluwer Law International.

${ }^{2}$ CJCE, avis 1/78 du 4 octobre 1979, Rec. 1979, p. 2871, § 60.

${ }^{3}$ Ce qui entraîne implicitement un droit de veto de chaque État membre sur l'accord, comme on a failli le constater au moment de la signature de l'accord avec le Canada en 2017.

${ }^{4}$ CJUE, délibération 1/78 du 14 novembre 1978, Rec. 1978, p. 2151.

${ }^{5}$ Dits de « première génération ».

${ }^{6}$ Ainsi que le Mexique et le Chili.

${ }^{7}$ Jusqu'à la mise en place des accords de partenariat économique dans le cadre de la convention de Cotonou.

${ }^{8}$ Notamment en matière de commerce des services.
} 
globaux avec les partenaires industrialisés de la Communauté. Ceux-ci auraient fait double emploi avec les négociations OMC. Seuls des accords ponctuels allaient être conclus ${ }^{1}$.

L'un des secteurs pour lesquels l'OMC n'avait que des compétences extrêmement limitées était celui de la réglementation internationale des investissements. Cette lacune aurait dû être comblée par les négociations entamées au sein de l'Organisation de Coopération et de Développement Économiques (OCDE) pour la conclusion d'un accord multilatéral sur les investissements ${ }^{2}$.

En 1999, lors de son audition devant le Parlement européen avant sa nomination au poste de commissaire européen au commerce, Pascal Lamy introduisit le terme de "mondialisation maitrisée ${ }^{3}$. Celle-ci impliquait (entre autres) la préférence donnée au multilatéralisme par rapport au bilatéralisme ${ }^{4}$, l'inclusion de matières périphériques au commerce dans les négociations commerciales internationales ${ }^{5}$, le soutien à l'Organe de Règlement des Différends (ORD) de l'OMC et à l'augmentation du nombre de membres de celle-ci ${ }^{6}$. Elle allait cependant se heurter très rapidement au nouveau cadre des relations commerciales internationales.

\section{Les mutations de l'économie mondiale au tournant du XXI ${ }^{\mathrm{ème}}$ siècle}

L'économie mondiale a connu un certain nombre de changements fondamentaux au tournant du XXI ${ }^{\text {ème }}$ siècle. Les négociations internationales sont en effet caractérisées par un blocage, qui s'est marqué pour la première fois à l'occasion de la conférence ministérielle de l'OMC de 1999. Par ailleurs, son centre de gravité fait l'objet d'un basculement vers la zone Asie-Pacifique et les pays émergents.

\subsection{Le blocage des négociations internationales}

L'OMC est, depuis 1995, l'instance multilatérale compétente pour la libéralisation des échanges internationaux de marchandises et de services, ainsi que pour la protection des droits de propriété intellectuelle liés au commerce. On lui doit notamment la mise en place d'un organe de règlement des différends dont l'efficacité est reconnue par l'ensemble des participants de la scène commerciale internationale ${ }^{7}$, même si les États-Unis se sont ingéniés à le torpiller en bloquant la nomination de nouveaux membres au sein de l'Organe d'appel permanent, de sorte que celui-ci est totalement inopérant depuis le 10 décembre 2019.

L'OMC elle-même autorise la conclusion d'Accords Commerciaux Régionaux (ACR) entre ses membres, moyennant le respect de certaines conditions ${ }^{8}$. Ceux-ci ont un succès

\footnotetext{
${ }^{1}$ Voy. par exemple les accords conclus en matière de concurrence avec les États-Unis (JOCE 1995, L 95/45) et le Canada (JOCE 1999, L 175/49) ; l'accord sur le commerce du vin conclu entre les États-Unis et l'Union (JOUE 2005, L 301/19)...

${ }^{2}$ Cf. $\S 2.2$.

${ }^{3}$ Pour un commentaire, voy. MEUNIER, S. (2008) « L'Union européenne et l'OMC : la mondialisation maîtrisée à l'épreuve », in BOISMENU, G. et PETIT, I. (éds.), L'Europe qui se fait. Regards croisés sur un parcours inachevé, Paris, Éditions de la Maison des sciences de l'homme, pp. 211-222.

${ }^{4}$ Pourtant, à ce moment, l'Union européenne était en train de négocier la Convention de Cotonou avec les États ACP et les accords euro-méditerranéens, les négociations avec le MERCOSUR commençant quant à elles en 2000. ${ }_{5}^{5}$ Notamment les matières de Singapour (cf. $§ 2.1$ ), la protection de l'environnement et celle des droits sociaux des travailleurs.

${ }^{6}$ À l'heure actuelle, l'OMC compte 168 membres.

${ }^{7}$ Au 13 mars 2020, 595 différends lui avaient été soumis.

${ }^{8}$ Les États désireux d'établir entre eux un accord d'intégration économique régionale doivent suivre une procédure spécifique prévue par l'article XXIV, $\S \S 5$ à 7, du GATT, ainsi que par le Mémorandum d'accord sur l'interprétation de l'article XXIV du GATT, adopté en 1994. Ils doivent notifier leur décision au Comité des accords commerciaux régionaux, dépendant du Conseil du commerce des marchandises. Celui-ci désignera un groupe de travail, dont la mission sera de vérifier le respect des conditions suivantes :
} 
grandissant. Au 17 janvier 2020, 303 ACR étaient en vigueur, alors qu'ils n'étaient que 230 en décembre 2008 et 35 en $1994^{1}$. Plus de $80 \%$ de ses accords sont bilatéraux, et le nombre d'unions douanières est négligeable. Enfin, le critère de proximité géographique, qui a caractérisé pendant longtemps les ACR, n'est plus qu'anecdotique à l'heure actuelle, comme on aura l'occasion de le voir.

Pour comprendre la volonté de l'Union et de ses partenaires commerciaux de conclure des accords bilatéraux malgré l'existence d'un cadre multilatéral, il faut se rappeler la situation actuelle, avec les échecs récents des tentatives de réglementation internationale d'un certain nombre de secteurs intéressant particulièrement les pays industrialisés.

\subsubsection{Le blocage des négociations au sein de l'OMC}

La première Conférence ministérielle organisée après l'entrée en vigueur de l'Accord instituant l'OMC eut lieu à Singapour du 9 au 13 décembre 1996. À cette occasion, la Communauté européenne introduisit des propositions concernant certaines questions horizontales, qui allaient être qualifiées de "matières de Singapour ». Il s'agissait de la concurrence, de la facilitation des échanges, des investissements et des marchés publics. La Communauté et certains de ses partenaires espéraient que des accords multilatéraux seraient adoptés afin de faire entrer ces matières dans le corpus juridique de l'OMC. Trois groupes de travail (sur la concurrence, les rapports entre commerce et investissements et la transparence dans les marchés publics) furent mis en place à l'issue de la Conférence ${ }^{2}$. Les pays du Sud, échaudés par l'adoption de l'Accord sur les aspects relatifs au commerce des droits de propriété intellectuelle, marquèrent toutefois une réticence certaine à l'inclusion de nouveaux secteurs dans les négociations.

La Conférence ministérielle de Seattle de 1999, dont l'objectif était le lancement d'un « cycle du Millénaire » chargé d'approfondir la libéralisation des échanges internationaux, fut un échec complet, en raison de la mobilisation de la société civile internationale et de la détermination de plus en plus grande des pays du Sud à ne plus se voir arracher de concessions sans contrepartie importante. Cet échec incita les membres industrialisés à apporter une

\footnotetext{
- la suppression des droits de douane et des autres réglementations commerciales restrictives doit concerner «l'essentiel des produits originaires des territoires constitutifs de l'accord ». Le désarmement ne doit par conséquent pas nécessairement être total, afin de permettre une certaine souplesse aux négociateurs et le maintien de certaines protections pour des secteurs jugés d'intérêt capital pour l'une des parties. Le contrôle du respect de cette condition doit faire l'objet d'un examen au cas par cas ;

- la suppression des obstacles au commerce doit être réciproque ;

- un calendrier et un plan pour l'établissement de l'accord « dans un délai raisonnable » doivent être prévus. En vertu du Mémorandum, ce délai raisonnable ne devrait pas dépasser 10 ans, sauf dans des cas exceptionnels ( 33 du Mémorandum);

- la mise en place d'un accord d'intégration économique régionale ne peut avoir pour conséquence d'opposer des obstacles nouveaux au commerce avec les pays tiers. Cela implique que l'incidence moyenne des droits de douane et des autres réglementations commerciales ne peut être plus rigoureuse que ne l'étaient ceux en vigueur sur le territoire des États membres avant l'entrée en vigueur de l'accord (art. XXIV, § 5, du GATT).

Pour la mise en place d'une union douanière, qui implique la substitution du territoire douanier des États membres par un territoire commun, une condition supplémentaire doit être remplie. Les droits de douane et les réglementations commerciales de l'union applicables aux rapports avec les États tiers doivent être « identiques en substance », ce qui implique la mise en place d'un tarif douanier commun et d'une politique commerciale commune. Une certaine souplesse a été reconnue dans l'interprétation de cette disposition.

Le cas échéant, le groupe de travail fera des recommandations aux États membres. Dans la plupart des cas, le rapport se contente toutefois d'exposer les points de vue opposés des membres du groupe de travail, sans proposer de recommandations. La non-compatibilité d'un accord d'intégration économique régionale avec le texte du GATT ne peut dès lors être contestée que par le biais du mécanisme de règlement des différends. On notera qu'il n'est nullement nécessaire que les États membres de l'accord aient une frontière commune.

${ }^{1}$ Source : OMC.

$2 \S \S 20$ et 21 de la Déclaration ministérielle adoptée à l'issue de la Conférence de Singapour (doc. WT/MIN(96)/DEC).
} 
attention plus grande aux revendications du Sud. Il fut ainsi décidé que le cycle de négociations qui s'ouvrirait à l'occasion de la Conférence ministérielle suivante, celle de Doha, qui eut lieu du 9 au 13 novembre 2001, serait qualifié de «cycle du développement ».

À l'occasion de la Conférence de Doha, il fut décidé que les négociations sur les matières de Singapour ne devaient être entamées qu'après la Conférence ministérielle de 2003, et à condition qu'une décision en ce sens soit adoptée par consensus à l'occasion de celle-ci' .

La Conférence ministérielle de 2003, organisée à Cancun, se conclut toutefois à nouveau par un échec. Une vingtaine de pays du Sud gros exportateurs de produits agricoles, auxquels se joignirent la Chine et l'Inde, formèrent une coalition connue sous le nom de « G20+ ». Ces pays réclamaient la suppression (ou à tout le moins la réduction) des mesures de soutien accordées par les pays développés à leurs agriculteurs avant d'accepter l'ouverture de négociations sur de nouveaux secteurs ${ }^{2}$. En fin de compte, l'UE accepta d'abandonner ses propositions concernant les liens entre commerce et investissements, commerce et concurrence et la transparence dans les marchés publics. Cette concession fut actée à l'occasion de la Conférence ministérielle de Hongkong de 2005.

Les négociations au sein de l'OMC n'en sont pas moins bloquées depuis 2003. Le désaccord persistant entre les membres sur la réduction des mesures de soutien agricole a eu pour conséquence qu'aucune avancée n'a été constatée en termes de libéralisation du commerce des marchandises et des services, ni en matière de réglementation des aspects relatifs au commerce des droits de propriété intellectuelle depuis lors. Les seuls pas en avant furent l'accord sur la facilitation des échanges adopté à l'issue de la Conférence ministérielle de Bali de 2013, ainsi que le «paquet de Nairobi », adopté à la suite de celle de 2015, qui prévoyait la suppression des subventions agricoles à l'exportation et quelques mesures adoptées en faveur des Pays les Moins Avancés (PMA) producteurs de coton. Le peu de succès remporté par les négociations dans le cadre du cycle de Doha explique le recours par les grandes puissances commerciales à des initiatives bilatérales, voire régionales.

\subsubsection{L'échec de l'Accord Multilatéral sur les Investissements (AMI)}

À l'heure actuelle, environ $3000^{3}$ accords bilatéraux de promotion et de protection des investissements existent, la plupart conclus entre un partenaire industrialisé et un partenaire du $\mathrm{Sud}^{4}$. À côté d'eux, un certain nombre d'accords multilatéraux, tels la Charte de l'énergie et l'Accord de Libre-échange Nord-Américain (ALENA) contiennent des dispositions relatives à la protection des investissements (et au règlement des différends investisseurs/États). En 1995, les gouvernements des États membres de l'OCDE décidèrent d'entamer la négociation d'un traité international, l'AMI, dont l'objectif était d'établir un large cadre multilatéral pour l'investissement international comportant des normes élevées de libéralisation des régimes et de protection de l'investissement, et doté de procédures efficaces de règlement des différends. Les négociations eurent lieu dans le plus grand secret pendant trois ans.

\footnotetext{
${ }^{1} \S \S 20$ à 27 de la Déclaration ministérielle adoptée à l'issue de la Conférence de Doha (doc. WT/MIN (01)/DEC/1). Pour un commentaire, voy. VINCENT, P. (2003), « Les résultats de la quatrième Conférence ministérielle de l'OMC - vers un cycle du développement ?», Revue belge de droit international, pp. 111-130.

${ }^{2}$ Les différences apparentes d'agendas entre les pays agro-exportateurs et les autres, ainsi que les risques de dislocation du Groupe suite à des négociations bilatérales avec des promesses de concessions mineures de la part des pays du Nord risquaient de faire échouer le G20+. Celui-ci survécut jusqu'à la fin de de la Conférence de Cancún, pour plusieurs raisons. En premier lieu, les leaders du Groupe (Brésil, Chine et Inde) ne montrèrent jamais le moindre signe de discorde entre eux (ce qui aurait immanquablement eu un effet domino sur le reste du groupe). En second lieu, les parties s'arrangèrent pour déposer des propositions de négociations qui satisfaisaient l'ensemble d'entre elles malgré leurs agendas différents, en stipulant expressément qu'il ne serait demandé aucune augmentation des contingents tarifaires et aucune réduction tarifaire aux pays en développement.

${ }^{3}$ Le plus ancien accord actuellement en vigueur est la convention conclue entre la République fédérale allemande et le Pakistan en 1959.

${ }^{4}$ Pour la liste des accords conclus par la Belgique, voy. http://investmentpolicyhub.unctad.org/IIA/CountryBits/19
} 
Alertée, la société civile commença à exercer des pressions sur les gouvernements participants afin qu'ils interrompent ces négociations. Les principales craintes concernaient la limitation de la souveraineté des États en matière de protection de l'environnement, des droits sociaux des travailleurs et des industries culturelles ${ }^{1}$. Les négociations furent interrompues en mai 1998 et définitivement arrêtées en décembre de la même année ${ }^{2}$.

La question des investissements apparaît fondamentale à l'heure actuelle. Les entreprises multinationales sont demanderesses de sécurité juridique, afin d'éviter que les bénéfices qu'elles comptent retirer de leurs investissements soient mis en péril par des réglementations nationales, et de pouvoir avoir accès à des procédures rapides de règlement des différends, contournant les systèmes judiciaires nationaux considérés à tort ou à raison comme lents et souvent corrompus.

Les perspectives d'évolution au niveau multilatéral sont dès lors à l'heure actuelle bloquées. Face à cette situation, un certain nombre de membres ont préféré recourir à la voie bilatérale pour poursuivre la libéralisation des échanges et réglementer entre eux certaines matières de Singapour. Les nouveaux accords commerciaux conclus par l'UE entrent dans cette mouvance.

\subsection{Le basculement du centre de gravité de l'économie mondiale}

La montée en puissance des pays émergents est impressionnante depuis le début du $\mathrm{XXI}^{\text {ème }}$ siècle. Alors qu'ils ne représentaient que $10 \%$ du Produit Intérieur Brut (PIB) mondial en 1990, leur part a triplé pour atteindre $30 \%$ en 2015. Parmi ceux-ci, la Chine, premier exportateur mondial de produits industriels depuis 2010, se détache largement. Toutefois, les pays du Sud-est asiatique (Corée du Sud, Singapour, Taïwan...) et les autres puissances émergentes (Brésil, Russie, Inde et Afrique du Sud) ne sont pas en reste et représentent des puissances commerciales avec lesquelles il faut désormais compter ${ }^{3}$.

\section{Les nouvelles stratégies de l'UE}

Rappelons qu'en 1999, le commissaire Pascal Lamy avait introduit le concept de «mondialisation maitrisée ». Celle-ci impliquait que les échanges internationaux devaient se dérouler dans un cadre multilatéral, les pouvoirs de l'OMC devant être renforcés ${ }^{4}$, tandis que la Communauté allait y promouvoir ses propres normes et valeurs (notamment les matières dites de Singapour, ainsi que les normes environnementales et sociales). Cette priorité donnée aux négociations multilatérales avait comme conséquence logique un moratoire sur la négociation de nouveaux accords commerciaux bilatéraux ${ }^{5}$.

\subsection{La Stratégie de Lisbonne}

À l'occasion du Conseil européen de Lisbonne de mars $2000^{6}$, les États membres adoptèrent la «Stratégie ${ }^{7}$ de Lisbonne », qui devait permettre à la Communauté de faire face aux défis du début du XXI ${ }^{\text {ème }}$ siècle. Celle-ci avait pour objectif de faire de l'UE« l'économie

\footnotetext{
${ }^{1}$ Voy. la résolution du Parlement européen du 11 mars 1998 sur la question.

${ }^{2}$ Voy. à ce sujet SHAHRJERDI, P. (1998), «L'AMI ou le projet mort-né de l'OCDE », Actualité et droit international, http://www.ridi.org/adi/199811a5.html (consultée le 10 juin 2020).

${ }^{3}$ Voy. à ce sujet ZACHARIE, A. et WINTGENS (dir.) (2018), Le décentrage du monde. L'impact des émergents sur la gouvernance mondiale, Bruxelles, Le bord de l'eau.

${ }^{4}$ Voy. à ce sujet ABDELAL, R. et MEUNIER, S. (2010), « Managed globalization : Doctrine, practice and promise », Journal of European Public Policy, pp. 350-367.

${ }^{5}$ Les négociations déjà entamées, notamment celles avec les pays ACP et le MERCOSUR n'étaient cependant pas affectées par ce moratoire.

6 Pour le texte des conclusions adoptées à l'issue du Conseil, voy.
} http://www.europarl.europa.eu/summits/lis1_fr.htm

${ }^{7}$ Ou l'Agenda. 
de la connaissance la plus compétitive et la plus dynamique du monde d'ici à 2010, capable d'une croissance économique durable accompagnée d'une amélioration quantitative et qualitative de l'emploi et d'une plus grande cohésion sociale ».

Dans le cadre de cette stratégie, l'aspect « Relations commerciales externes » allait bien évidemment jouer un rôle fondamental. L'échec de la Conférence ministérielle de Cancun de 2003, la rapide croissance économique des pays émergents et la décision des États-Unis de recourir à la voie bilatérale plutôt qu'au multilatéralisme ${ }^{1}$ allaient sonner le glas de la «mondialisation maitrisée ». En 2004, la Commission Barroso I est mise en place. Le Britannique Peter Mandelson devient commissaire au commerce en remplacement de Pascal Lamy, qui dirigera l'OMC de 2005 à 2013.

Confronté au blocage du multilatéralisme, la philosophie du nouveau commissaire va être radicalement différente de celle de son prédécesseur. En septembre 2005, la Commission européenne publia une étude intitulée Commerce et compétitivité2. L'année suivante, en octobre 2006, elle émit un nouveau document intitulé Une Europe compétitive dans une économie mondialisée $e^{3}$.Insistant toujours sur la nécessité du multilatéralisme et la poursuite du programme de Doha, cette communication marque toutefois un tournant dans la politique de l'UE, en indiquant qu'afin de faciliter l'accès des entreprises européennes aux marchés des États tiers, l'Union devait s'orienter vers le bilatéralisme et conclure des accords commerciaux plus complets, au champ d'application plus large que les accords de libre-échange « classiques » négociés précédemment, et qui devaient mettre l'accent sur les droits de propriété intellectuelle, les services, les investissements, les marchés publics et la concurrence ${ }^{4}$.Par ailleurs, la communication insistait sur la nécessité pour les pays émergents, considérés comme des «passagers clandestins »du système commercial international ${ }^{5}$, d'ouvrir leurs marchés, caractérisés par des barrières élevées aux échanges. Parmi les partenaires commerciaux avec lesquels la conclusion d'accords était prioritaire figuraient l'Association des Nations de l'Asie du Sud-Est (ASEAN), la Corée du Sud, le Marché Commun du Sud (MERCOSUR), l’Inde, la Russie, le Conseil de Coopération du Golfe (CCG) et la Chine.

\subsection{La Stratégie « Europe $2020 »$}

La récession entamée en 2008 , loin de mener à des politiques protectionnistes comme l'avait fait celle de 1929, incita les grandes puissances commerciales à se lancer dans la négociation d'accords commerciaux extrêmement ambitieux, afin de relancer la croissance économique $^{6}$. Une nouvelle Commission est mise en place en 2009, le Belge Karel de Gucht devenant le nouveau commissaire au commerce.

\footnotetext{
${ }^{1}$ Conclusion d'un accord de libre-échange avec la Jordanie en 2001, l'Australie, le Chili et Singapour en 2004, les pays d'Amérique centrale en 2005, Bahreïn, le Maroc et le Sultanat d'Oman en 2006... Pour un commentaire, voy. DEBLOCK, C. (2010), « Le bilatéralisme commercial des États-Unis », in REMICHE, B., et RUIZ-FABRI, H. (2010), Le commerce international entre bi- et multilatéralisme, Bruxelles, Larcier, pp. 115-173.

${ }^{2}$ Présentée à l'occasion du $5^{\text {e }}$ Symposium de la Commission sur l'accès au marché, organisé à Bruxelles le 19 septembre 2005.

${ }^{3}$ Doc. COM(2006)567.

${ }^{4}$ On remarque immédiatement qu'il s'agit des deux secteurs pour lesquels l'OMC dispose de compétences, mais qu'elle ne peut mettre en œuvre en raison du blocage des négociations, et des matières de Singapour. Leur champ d'application devant couvrir des matières non traitées par l'OMC, ces accords sont souvent qualifiés d' "OMC+ ». ${ }^{5}$ En raison du fait qu'ils profitaient de la libéralisation des échanges internationaux tout en maintenant eux-mêmes des barrières élevées aux échanges, arguant de leur qualité de pays en développement (voy. à ce sujet ELGSTRÖM, O. (2007), «Outsiders perceptions of the European Union in international trade negociations », Journal of Common Market Studies, pp. 949-967.

${ }^{6}$ On fait ici notamment référence aux projets de Partenariat transpacifique et de Partenariat économique régional global.
} 
Le 3 mars 2010, la Commission publia une communication intitulée Europe 2020. Une stratégie pour une croissance intelligente, durable et inclusive ${ }^{1}$ dans laquelle elle proposait à l'Union de fixer un certain nombre de grands objectifs ${ }^{2}$. La communication subséquente de novembre 2010 Commerce, croissance et affaires mondiales - La politique commerciale au cour de la stratégie Europe $2020^{3}$ a insisté à nouveau sur la place du commerce mondial dans le cadre de la stratégie «Europe $2020 »$. Les documents Trade : a key source of growth and jobs for the EU de $2013^{4}$ et Le commerce pour tous d'octobre 2015 ont encore renforcé cette approche $^{5}$. Si le rôle de l'OMC est souligné et que sa relance est souhaitée, ces textes insistent sur la nécessité de conclure de nouveaux accords de libre-échange allant au-delà du simple commerce des marchandises, et concernant des partenaires avec lesquels aucun accord n'avait été conclu précédemment, ajoutant notamment les États-Unis et le Japon aux États déjà mentionnés en $2006^{6}$.

Alors qu'elle était jusqu'au début des années 2000 l'un des principaux champions de l'approche multilatérale des relations commerciales internationales, l'UE a depuis opéré un changement complet de paradigme, étant devenue (même si le soutien à l'OMC reste la position théorique) le principal négociateur d'accords commerciaux bilatéraux avec ses partenaires.

\subsection{Les accords négociés}

La liste des négociations engagées par l'Union est longue. Les nouveaux accords sont qualifiés de «nouvelle génération » car ils vont bien au-delà du démantèlement des seules barrières douanières dont se contentaient les accords de libre-échange classiques.

Le premier accord dit « de nouvelle génération » a été conclu en octobre 2010 avec la Corée du Sud ${ }^{7}$. Il est entré en vigueur provisoirement le $1^{\text {er }}$ juillet 2011 et définitivement en décembre 2015. Son champ d'application était plus ambitieux que tous les accords commerciaux conclus jusqu'alors par l'Union. Il contenait en effet des dispositions relatives à la libéralisation du commerce des marchandises et des services, à l'élimination de certaines barrières non tarifaires, à la protection de certaines indications d'origine. Il ne contenait par contre aucune disposition relative à la protection des investissements.

Par la suite, des accords semblables ont été conclus avec les pays andins (Pérou, Colombie et Équateur) ${ }^{8}$, les pays d'Amérique centrale (Costa Rica, El Salvador, Guatemala, Honduras, Nicaragua, Panama $)^{9}$. D'autres accords, plus ambitieux car contenant des dispositions sur la protection des investissements, furent ensuite conclus avec le Canada ${ }^{10}$,

\footnotetext{
${ }^{1}$ Doc. $\operatorname{COM}(2010) 2020$.

${ }^{2}$ Réduction du chômage et de la pauvreté ; augmentation du budget investi dans la R\&D ; réduction des émissions de gaz à effet de serre...

${ }^{3}$ Doc. $\operatorname{COM}(2010) 619$.

4 Contribution de la Commission au Conseil européen des 7-8 février 2013 (disponible en ligne : http://eu2013.ie/media/eupresidency/content/documents/130207-Commission-Contribution-on-Trade-toEC.pdf).

${ }^{5}$ Doc. COM(2015) 497. Pour un commentaire, voy. HERVE, A. (2017), « La Commission affiche les nouvelles orientations de sa politique commerciale dans la communication « Le commerce pour tous - Vers une politique de commerce et d'investissement plus responsable », Revue trimestrielle de droit européen, pp. 137-140.

${ }^{6} \mathrm{La}$ communication prenait acte par ailleurs de l'impossibilité de conclure un accord birégional avec l'ASEAN, et annonçait le lancement de négociations sur une base purement bilatérale avec Singapour, la Malaisie et le Vietnam.

${ }^{7}$ JOUE 2011, L 127/1. Il fut par ailleurs le premier accord commercial à être adopté par le Parlement européen, conformément à la nouvelle procédure mise en place par le Traité de Lisbonne.

${ }^{8}$ JOUE 2012, L 354/1 pour la Colombie et le Pérou ; JOUE 2016, L 356/1 pour l'adhésion de l'Équateur à l'accord. ${ }^{9}$ JOUE 2012, L 346/3.

${ }^{10}$ JOUE 2017, L 11/1. Pour un commentaire, voy. les six articles qui lui ont été consacrés dans la Revue des affaires européennes 2017/2, pp. 201-262, et VINCENT, P. (2016), «Le Comprehensive Economic Trade Agreement (CETA) », Revue de droit du commerce international et des transports, pp. 498-521.
} 
Singapour ${ }^{1}$, le Vietnam ${ }^{2}$ et le Japon ${ }^{3}$.Les négociations de l'accord avec les pays du MERCOSUR ont été achevées le 28 juin 2019. Des négociations sont en cours avec le Chili, la Tunisie, l'Indonésie, les Philippines, l'Australie et la Nouvelle-Zélande, tandis que celles avec le Maroc, la Thaïlande, la Malaisie, les Philippines, le Myanmar et l'Inde sont au point mort à $l^{\prime}$ 'heure actuelle ${ }^{4}$. Après l'abandon des négociations du Partenariat transatlantique de commerce et d'investissement (TTIP) entre l'Union et les États-Unis d'Amérique, de nouvelles négociations ont commencé en mai 2019 avec ces derniers. Elles ne concerneront cependant que la mise en place d'une zone de libre-échange limitée aux marchandises industrielles ${ }^{5}$. Des accords avec la Chine et le Myanmar limités aux questions liées aux investissements sont également en cours de négociations.

\subsection{Brève analyse du contenu des accords}

Il ne saurait évidemment être question de décrire ici de façon exhaustive l'ensemble des dispositions contenues dans tous les accords de nouvelle génération conclus par l'Union. Seuls les points les plus importants ${ }^{6}$ seront abordés dans le cadre restreint de cette contribution.

\subsubsection{Les dispositions communes aux différents accords conclus}

a) Le commerce des marchandises

a1 - La mise en place d'une zone de libre-échange

Les nouveaux accords mettent tous en place une zone de libre-échange, conforme aux exigences de l'article XXIV de l'Accord Général sur les Tarifs Douaniers et le Commerce (GATT), entre les parties. Pour les produits industriels, une grande partie des positions tarifaires $^{7}$ font l'objet d'une libéralisation immédiate, dès l'entrée en vigueur provisoire de l'accord concerné ${ }^{8}$. Pour les secteurs sensibles (notamment l'automobile), un calendrier de désarmement tarifaire (portant sur 3 à 20 ans suivant les produits et les pays) ${ }^{9}$ est prévu. Pour les produits agricoles, secteur traditionnellement extrêmement sensible ${ }^{10}$, le désarmement

\footnotetext{
${ }^{1}$ JOUE 2018, L 189/2.

${ }^{2}$ JOUE 2016, L 329/6.

${ }^{3}$ JOUE 2018, L 330/1.

4 Pour la liste des négociations en cours, voy.
} http://trade.ec.europa.eu/doclib/docs/2006/december/tradoc 118238.pdf

${ }^{5}$ Voy. la décision du Conseil du 9 avril 2019 autorisant l'ouverture de négociations avec les États-Unis pour un accord sur l'élimination des tarifs douaniers sur les produits industriels.

${ }^{6}$ Aux yeux tout à fait subjectifs de l'auteur...

${ }^{7}$ Chaque marchandise fait l'objet d'un classement dans les tarifs douaniers des États. Celui-ci permet de déterminer le droit de douane applicable. À l'heure actuelle, la plupart des États ont recours au Système harmonisé de désignation et de codification des marchandises (SH), adopté en 1983 au sein du Conseil de coopération douanière, devenu en 1994 l'Organisation mondiale des douanes (OMD). Celui-ci distingue plus de 5000 positions, réparties en 96 chapitres et 21 sections.

${ }^{8}$ Rappelons que, pour les matières relevant de la compétence exclusive de l'Union, la ratification des États membres n'est pas nécessaire. La libéralisation du commerce des marchandises eut dès lors lieu dès que la procédure législative propre à l'Union fut achevée.

${ }^{9}$ Un délai de 7 ans est par exemple prévu pour le démantèlement des droits de douane canadiens portant sur les navires.

${ }^{10}$ On rappellera par exemple le contentieux du bœuf aux hormones et celui des OGM, qui opposèrent (notamment) le Canada et l'Union au sein de l'OMC. 
tarifaire ne sera pas total ${ }^{1}$. Il ne concernera qu'un peu plus de $85 \%^{2}$ des positions tarifaires respectives des partenaires, avec parfois la fixation de contingents tarifaires ${ }^{3}$ (par exemple dans le cas de l'accord avec le MERCOSUR) ${ }^{4}$. Autre secteur extrêmement sensible, les mesures de soutien interne octroyées par les partenaires à leurs agriculteurs ne sont pas concernées par les accords.

\section{a2 - Les mesures sanitaires et phytosanitaires}

Un chapitre particulièrement attendu des accords était bien entendu celui relatif aux mesures sanitaires et phytosanitaires (SPS), en raison des litiges qui avaient opposé le Canada et l'Union à leur sujet au sein de $1^{\prime} \mathrm{OMC}^{5}$, et des craintes de la population européenne de voir réapparaitre des produits alimentaires de qualité douteuse (par exemple de la viande bovine traitée aux hormones) dans les rayons des magasins suite à l'entrée en vigueur des accords.

L'accord avec la Corée du Sud est peu intrusif. Il se contente de renvoyer à l'accord SPS, prévoyant simplement une coopération entre les parties pour l'élaboration de recommandations et de normes internationales ${ }^{6}$. Les accords avec le Canada et le Japon, par contre, vont beaucoup plus loin en édictant la reconnaissance mutuelle des normes sanitaires et phytosanitaires des parties, dans la mesure où « la Partie exportatrice démontre de façon objective à la partie importatrice qu'avec sa mesure le niveau approprié de protection SPS dans la Partie importatrice est atteint $»^{7}$. Les principes et directives permettant de déterminer l'équivalence devront être déterminés ultérieurement ${ }^{8}$. Une série de mesures font déjà l'objet d'une reconnaissance ${ }^{9}$.L' accord avec Singapour, enfin, est à mi-chemin entre les deux positions puisqu'il dispose que les Parties «peuvent» reconnaître les mesures sanitaires et phytosanitaires appliquées par l'autre, sans contrainte ${ }^{10}$.

À première vue, le texte des accords apparaît plus protecteur de la santé des consommateurs que l'accord SPS de l'OMC, où la partie importatrice doit faire la preuve scientifique du caractère insuffisant d'une norme internationale pour pouvoir adopter une norme plus sévère. Il ne faut toutefois pas oublier que les parties confirment dans les accords leurs obligations découlant de l'accord SPS. Autrement dit, lorsque le Canada, par exemple, souhaitera exporter à destination de l'Union des produits alimentaires présentant, selon celleci, des dangers pour la santé humaine, elle ne sera pas obligée de reconnaître la norme canadienne si le Canada ne "démontre pas de façon objective » l'innocuité de la marchandise

\footnotetext{
${ }^{1}$ Le maintien de droits de douane dans le cadre d'une zone de libre-échange est tout à fait compatible avec l'article XXIV du GATT, qui dispose que l'élimination des droits de douane doit concerner « l'essentiel des produits originaires des territoires constitutifs de l'accord $»$.

${ }^{2}$ Les chiffres donnés varient évidemment d'un accord à l'autre. Nous renvoyons le lecteur à la lecture des différentes annexes aux accords pour une vue précise de la libéralisation des échanges entre l'Union et ses partenaires.

${ }^{3}$ Un contingent tarifaire fixe une quantité de marchandises pouvant être importée à droit nul (ou réduit), toute quantité dépassant le contingent fixé étant taxée au taux normal.

${ }^{4}$ L'accord actuel prévoit par exemple un contingent tarifaire de 99.000 tonnes de bœuf par an taxées au taux préférentiel de 7,5\% (en lieu et place d'un droit fixe de 12,80\% combiné à un droit variable de 176,80 €/100 kg), ainsi que des contingents tarifaires à droit nul sur 180.000 tonnes de sucre, 180.000 tonnes de volaille, 25.000 tonnes de viande de porc, 650.000 tonnes d'éthanol, 60.000 tonnes de riz et 45.000 tonnes de miel, concessions jugées exorbitantes par les agriculteurs européens (voy. par exemple l'article « UE-Mercosur : que contient l'accord jugé « inacceptable » par les agriculteurs français ? » paru dans le Sud-Ouest du 29 juin 2019).

${ }^{5}$ Cf. supra, note 14.

${ }^{6}$ Article 5.6 de l'accord avec la Corée du Sud.

${ }^{7}$ Article 5.6 de l'accord avec le Canada ; article 6.14 de l'accord avec le Japon.

${ }^{8}$ Annexe 5-D de l'accord avec le Canada.

${ }^{9}$ Annexe 5-E de l'accord avec le Canada.

${ }^{10}$ Article 5.14 de l'accord avec Singapour.
} 
exportée. Mais le Canada disposera toujours du droit de contester le refus d'importation devant l'ORD.

Un comité de gestion mixte est mis en place dans l'accord avec le Canada. Composé de représentants des secteurs commerciaux et réglementaires des États parties. Ce comité est notamment chargé de «discuter à un stade précoce de tout changement ou proposition de changement concernant une mesure SPS envisagée ${ }^{1}$. L'intervention de ce comité pose problème à certains, dans la mesure où il est composé pour moitié de représentants de secteurs économiques ayant vraisemblablement intérêt à l'adoption de mesures SPS laxistes. Dans le texte de l'accord, il n'apparaît que comme un forum de discussion, la prise de décision revenant aux autorités des Parties. Certains observateurs craignent cependant que ce comité ne prenne une importance grandissante dans le processus d'adoption des mesures SPS, qu'il rende des avis tendant à une réduction de la protection de la santé des consommateurs et que ces avis soient suivis, entraînant un affaiblissement de cette protection ${ }^{2}$. Tout ceci relève certes en grande partie du procès d'intention. L'existence du risque ne peut cependant être niée.

Il est à noter que le principe de précaution n'est pas repris dans le texte de l'accord avec le Canada, ce qui peut apparaître étrange quand on connaît l'importance qui lui est reconnue au sein de l'Union.

\section{a3 - La collaboration réglementaire}

Les accords contiennent des dispositions relatives aux règlements techniques susceptibles d'avoir un impact sur les échanges entre les parties. L'accord avec la Corée du Sud est le moins intrusif. Il se contente d'inciter les parties à se fournir mutuellement toutes informations sur l'objectif, le fondement juridique et la motivation des nouveaux règlements techniques.

L'accord avec le Canada va beaucoup plus loin ${ }^{3}$. Son objectif est en effet «(d') améliorer les conditions de la compétitivité et de l'innovation, y compris en cherchant à assurer la compatibilité, la reconnaissance d'équivalence et la convergence des réglementations » (article 21.5). Si l'accord insiste sur le respect de l'autonomie normative des parties (article 21.4), des voix se sont élevées pour dénoncer un risque d'harmonisation par le bas des réglementations techniques protectrices des consommateurs, et par conséquent le risque que des marchandises ne remplissant pas les critères actuels pénètrent par la suite sur le territoire de l'Union. On rappellera ici l'absence assez inexplicable de toute référence au principe de précaution dans le texte de l'accord.

a4 - Le commerce électronique

Tous les accords contiennent des dispositions relatives au commerce électronique.

b) Le commerce des services

Les accords de nouvelle génération contiennent tous des dispositions relatives à la libéralisation du commerce des services entre les parties. Celles-ci entendent aller plus loin que ce qui est prévu à l'heure actuelle dans le cadre de l'Accord Général sur le Commerce des

\footnotetext{
${ }^{1}$ Article 5.14, $\S 3$ b) de l'accord avec le Canada.

2 Voy. par exemple le lien suivant : http://www.no-transat.be/sites/default/files/dossiers-presse/2016-03-17_ttip_ceta_la_grande braderie sanitaire.pdf.

${ }^{3}$ Voy. à ce sujet HERVE, A. (2017), « La loi du marché - Réflexions sur la coopération réglementaire instaurée par l'AECG », Revue des affaires européennes, pp. 235-251.
} 
Services (AGCS) de l'OMC. Vu le blocage actuel des négociations dans ce secteur ${ }^{1}$, l'inclusion de dispositions relatives à une poursuite de la libéralisation du commerce des services dans les accords de nouvelle génération était une évidence.

Le chapitre 10 de l'accord avec le Canada contient l'une des avancées les plus importantes de l'accord. Il est consacré à l'admission et au séjour temporaire des personnes physiques à des fins professionnelles. Chaque partie autorise sur son territoire l'admission temporaire de personnes physiques à des fins professionnelles. Cette admission est cependant limitée au personnel clé d'une entreprise ${ }^{2}$, aux fournisseurs de services contractuels ${ }^{3}$, aux professionnels indépendants et aux visiteurs en déplacement d'affaire de courte durée (article $10.2 \S 2$ ). L'exigence de visa n'étant toutefois pas considérée comme une entrave à celle-ci (article $10.2 \S 3$ ), ni l'octroi d'un permis de travail, dont la durée pourra être limitée à 3 ans $^{4}$. L'immigration définitive sort par ailleurs du champ d'application de l'accord, de même que le déplacement de personnes cherchant à accéder au marché du travail de l'autre partie (article $10.2 \S 2$ in fine). Une importante liste d'exceptions est par ailleurs reprise dans l'annexe 10 -B de l'accord.

Ces dispositions constituent une avancée indéniable par rapport à la situation des parties au sein de l'OMC. Dans le cadre de l'AGCS, le mode 4 de prestation de services, qui concerne le détachement temporaire de travailleurs sur le territoire de l'État d'accueil, doit faire l'objet de concessions au cas par cas. Le principe, ici, est l'autorisation automatique, sauf les exceptions limitativement énumérées en annexe. Même si celles-ci restent nombreuses, le changement de paradigme est fondamental par rapport à la situation antérieure. La circulation des travailleurs et des prestataires de services serait grandement facilitée après l'entrée en vigueur de l'accord.

c) La propriété intellectuelle

La question de la propriété intellectuelle intéressait particulièrement l'UE dans les différentes négociations, notamment au niveau des appellations d'origine contrôlée et des droits d'auteur.

\section{c1 - La question des appellations d'origine protégées}

Des négociations ont été entamées au sein de l'OMC, conformément à l'article 23 :4 de 1'Accord ADPIC (Aspects des Droits de Propriété Intellectuelle qui touchent au Commerce), afin d'établir un registre international des appellations d'origine de vins et spiritueux. Un certain nombre de membres, notamment l'UE, ont déposé des propositions afin que des appellations d'origine d'autres marchandises (fromages, salaisons...) soient également incorporées dans le registre $^{5}$. Certains pays, notamment le Canada, y sont opposés. Ils craignent que leurs citoyens ayant apporté de leur pays d'origine des méthodes de fabrication et des noms de produits et les

\footnotetext{
${ }^{1}$ Aussi bien dans le cadre de l'OMC que dans celui de l'Accord sur le commerce des services négocié par 23 membres de l'OMC entre mars 2013 et novembre 2016, date du retrait des États-Unis des négociations, qui sont suspendues depuis.

${ }^{2}$ Définis comme les cadres supérieurs, les spécialistes et les stagiaires diplômés (article 10.1).

${ }^{3}$ Définis comme les personnes physiques travaillant pour une entreprise n'ayant pas d'établissement sur le territoire de l'autre Partie mais ayant conclu un contrat nécessitant à titre temporaire la présence de ses employés sur le territoire de l'autre Partie.

${ }^{4}$ Sauf pour les stagiaires et les investisseurs, où la durée du permis peut être limitée à un an (article 10.7 § 5).

${ }^{5}$ Voy. notamment la proposition de l'UE du 14 juin 2005, doc. OMC TN/IP/W/11.
} 
ayant utilisés de bonne foi soient accusés d'usurpation ${ }^{1}$. À l'heure actuelle, les négociations sont au point mort ${ }^{2}$.

À défaut d'obtenir une solution multilatérale à la question, l'UE a insisté pour qu'elle soit incorporée dans les négociations des accords de nouvelle génération. Celles-ci ont abouti à un jugement de Salomon : sur environ 1500 appellations d'origine protégées européennes, 145 seront protégées grâce à l'accord avec le Canada ${ }^{3}, 169$ avec le Vietnam ${ }^{4}, 205$ suite à l'accord avec le Japon ${ }^{5}, 355$ dans le projet d'accord avec le MERCOSUR... À ceux qui s'offusquent du petit nombre d'appellations concernées répondent ceux qui se réjouissent qu'au moins un certain nombre d'appellations européennes seront maintenant protégées au Canada, au Vietnam et au Japon...

c2 - La question des droits d'auteur des artistes et exécutants

L'AECG avec le Canada représente une avancée majeure dans le domaine des droits d'auteur, dans la mesure où il reconnait aux artistes et exécutants (et non plus aux seuls auteurscompositeurs) le droit d'autoriser ou d'interdire la diffusion de son œuvre par le moyen des ondes radioélectriques, ainsi que le droit de bénéficier d'une partie des rémunérations versées par les utilisateurs, l'autre partie revenant aux producteurs (article 20.8).

d) Les marchés publics

Autre sujet brûlant en raison d'absence d'avancée au sein de l'OMC, la question des marchés publics a été longuement débattue à l'occasion des négociations des accords de nouvelle génération.

Certains accords se contentent de renvoyer à l'accord sur les marchés publics conclus dans le cadre de l'OMC $^{6}$. D'autres prévoient que l'ouverture des marchés publics des Parties se fera selon le régime des concessions : seuls les marchés repris dans les annexes aux accords seront ouverts aux entreprises de l'autre Partie ${ }^{7}$.

\subsubsection{La délicate question de la protection des investissements}

Si tous ces accords entrent dans la catégorie de « Nouvelle génération », en raison de leur champ d'application plus large que le simple commerce des marchandises, seuls les accords conclus avec Singapour, le Vietnam et le Canada contiennent des dispositions relatives à la protection des investissements.

La question des investissements est très sensible, principalement en ce qui concerne la mise en place de mécanismes d'arbitrage chargés de trancher les litiges s'élevant entre les investisseurs et leur État d'accueil ${ }^{8}$.Beaucoup d'observateurs craignent une perte de souveraineté des États obligés d'accepter le recours à l'arbitrage plutôt qu'à leurs juridictions nationales. Par ailleurs, les différents accords prévoient qu'un traitement «juste et équitable ${ }^{9}$ doit être réservé aux investisseurs internationaux. Aucune définition n'est donnée

\footnotetext{
${ }^{1}$ Pour une synthèse des arguments des deux parties, voy. les docs. OMC WT/GC/W/546 et TN/C/W/25 du 18 mai 2005.

2 Voy. doc. OMC TN/IP/23 du 3 décembre 2015.

${ }^{3}$ Annexe 20-A à l'accord.

${ }^{4}$ Annexe 12-A à l'accord.

${ }^{5}$ Annexe 14-B à l'accord.

${ }^{6}$ Article 10.1 de l'accord avec le Japon.

${ }^{7}$ Article 19.2 § 4 de l'accord avec le Canada ; article 9.2 et annexes 9-A à 9-G de l'accord avec Singapour ; article 9.2 et annexes 9-A et 9-B de l'accord avec le Vietnam.

${ }^{8}$ Ces mécanismes sont qualifiés d'ISDS, Investor-State Dispute Settlement.

${ }^{9}$ Le traitement « juste et équitable » est la norme dans les traités de protection des investissements. Voy. à ce sujet SCHILL, S.W. (2006), Fair and Equitable Treatment under Investment Treaties as an Embodiment of the Rule of
} 
de ce concept. Seuls sont cités (par exemple dans l'accord conclu avec le Canada) des comportements qui constituent autant de violations de cette obligation :

- un déni de justice dans les procédures pénales, civiles ou administratives ;

- une violation fondamentale du principe de l'application régulière de la loi, y compris une violation fondamentale de la transparence, dans les procédures judiciaires et administratives ;

- un cas d'arbitraire manifeste ;

- une discrimination ciblée basée sur des motifs manifestement illicites, comme le sexe, la race ou les croyances religieuses ;

- un traitement abusif des investisseurs, tel que la coercition, la contrainte et le harcèlement ;

- un manquement à tout autre élément de l'obligation d'accorder un traitement juste et

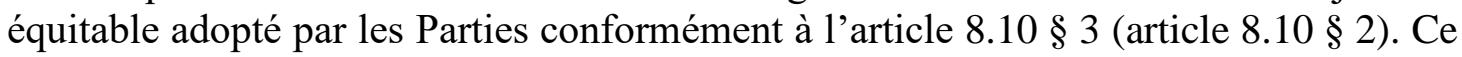
dernier reconnaît au comité des services et de l'investissement le droit de formuler des recommandations et de soumettre celles-ci au Comité de l'accord pour décision.

Ces différents éléments apportent de l'eau au moulin de ceux qui critiquent l'insertion de telles dispositions dans les nouveaux accords conclus par l'Union.

La signature et la ratification des accords contenant des dispositions relatives à la protection des investissements, notamment celui avec le Canada, a fait l'objet de vifs débats au sein des parlements des États membres. Rappelons qu'un certain nombre de parlements régionaux et communautaires belges n'ont accepté d'autoriser la signature par la Belgique de l'accord avec le Canada que moyennant le dépôt d'une demande d'avis auprès de la Cour de Justice de l'Union Européenne (CJUE) à propos de la légalité du mécanisme de règlement des différends investisseurs/État contenu dans l'accord ${ }^{1}$.

Une première demande d'avis avait été adressée à la CJUE à propos de la compétence de l'Union à conclure seule un accord ${ }^{2}$ contenant des dispositions relatives au règlement des différends entre investisseurs et États d'accueil. Dans son avis 2/15 du 16 mai $2017^{3}$, celle-ci a édicté que :

«L'accord de libre-échange entre l'Union européenne et la République de Singapour relève de la compétence exclusive de l'Union, à l'exception des dispositions suivantes, qui relèvent d'une compétence partagée entre l'Union et les États membres :

- les dispositions de la section A (Protection des investissements) du chapitre 9 (Investissements) de cet accord, pour autant que celles-ci se rapportent aux investissements entre l'Union et la République de Singapour autres que directs ;

- les dispositions de la section B (Règlement des différends entre investisseurs et États) de ce chapitre 9 , et

- les dispositions des chapitres $1^{\mathrm{er}}$ (Objectifs et définitions générales), 14 (Transparence), 15 (Règlement des différends entre les parties),16 (Mécanisme de médiation) et 17 (Dispositions institutionnelles, générales et finales) dudit accord, pour autant que

\footnotetext{
Law, IILJ Working Paper, et TUDOR, I. (2008), The Fair and Equitable Treatment Standard in the International Law of Foreign Investment Oxford, Oxford University Press.

${ }^{1}$ Question à laquelle la Cour a répondu positivement dans son avis 1/17 du 30 avril 2019, Rec. 2019, p. 341.

${ }^{2}$ In casu l'accord conclu avec Singapour.

${ }^{3}$ CJUE, avis 2/15 du 16 mai 2017. Pour un commentaire, voy. FLAESCH-MOUGIN, C. (2017), « La nature des compétences externes de l'Union européenne à la lumière des avis $2 / 15$ et 3/15 de la Cour de Justice de l'Union européenne », Revue trimestrielle de droit européen, p. 600 ; HERVE, A. (2017), « Les accords de libre-échange de l'Union européenne seront-ils les mêmes après l'avis 2/15?», Revue trimestrielle de droit européen, p. 617 ; HERVE, A. (2017), « L'avis 2/15 de la Cour de Justice - Et maintenant que faire du partage de compétences entre l'Union et ses États? , Cahiers de droit européen, pp. 694-735.
} 
celles-ci se rapportent aux dispositions dudit chapitre 9 et dans la mesure où ces dernières relèvent d'une compétence partagée entre l'Union et les États membres ».

Le texte de l'avis était clair : malgré l'élargissement constant du concept de «politique commerciale commune ", l'Union n'était pas compétente pour conclure seule un accord contenant des dispositions relatives aux investissements autres que directs et au règlement des différends relatifs aux investissements.

À partir de ce moment, l'Union a poursuivi la négociation de ses accords commerciaux externes de deux manières :

- dans le cas de Singapour, du Vietnam et du Japon, la Commission a scindé les pourparlers, négociant séparément un accord de libre-échange (basé sur l'article 207 TFUE, il concerne tous les secteurs de la politique commerciale commune, c'est-à-dire, au-delà du commerce des marchandises, celui des services et la propriété intellectuelle ; il pourra par conséquent être signé et conclu par la seule Union) et un accord de protection des investissements. Ce dernier prend la forme d'un accord mixte, qui devra à la fois être ratifié par l'Union et ses États membres, conformément à l'avis $2 / 15$. Cette manière de procéder, qui évite les incertitudes liées au caractère mixte de l'ensemble de l'accord négocié et des positions que les parlements nationaux pourraient adopter, devrait vraisemblablement se généraliser ${ }^{1}$;

- dans le cas du Canada, la Commission a négocié un AECG contenant des dispositions relatives aux investissements, en partant dès le départ du point de vue que l'accord serait mixte (ce qui a entraîné des difficultés en Belgique ${ }^{2}$ ). Suite à la pression de la société civile, la Commission européenne a proposé la mise en place dans le cadre de l'AECG d'un système d'arbitrage inédit, par la création d'un véritable Tribunal arbitral ${ }^{3}$ composé de 15 membres : 5 ressortissants d'États membres de l'Union, 5 ressortissants canadiens et 5 ressortissants d'États tiers, désignés pour un mandat de 5 ans, renouvelable une fois. Ils doivent être indépendants des États, une partie à un litige pouvant demander au Président de la Cour Internationale de Justice (CIJ) de rendre une décision sur la nomination d'un membre soupçonné de conflit d'intérêt. Afin d'éviter un renouvellement complet du Tribunal au bout de 5 ans, il est prévu que les mandats de 7 membres tirés au sort auront une durée de 6 ans. Les affaires seront toujours instruites par une chambre de 3 membres composée de façon tripartite, et présidée par le membre ressortissant d'un État tiers. Les membres sont rémunérés par les Parties, chacune devant assumer la moitié des rétributions. Les audiences du tribunal sont publiques. Il est également institué un Tribunal d'appel, sur le modèle de l'Organe d'appel permanent de l'OMC. À terme, l'ambition de la Commission est de mettre en place un mécanisme comparable compétent pour l'ensemble des accords de protection des investissements conclus par l'Union avec ses partenaires, voire un tribunal arbitral multilatéral ${ }^{4}$.

La légalité du mécanisme mis en place dans le cadre de l'AECG avec le Canada ayant été questionnée par la Région wallonne, la Belgique a déposé le 6 septembre 2017 auprès de la

\footnotetext{
1 Il faut cependant noter que la conclusion d'un accord de protection des investissements ne sera pas systématiquement proposée aux partenaires commerciaux de l'Union. L'Australie et la Nouvelle-Zélande, par exemple, ne négocient qu'un accord de libre-échange.

${ }^{2}$ Voy. à ce sujet HERVE, A. (2017), «Les résistances des États membres au développement des relations conventionnelles de l'Union européenne : quels enseignements tirer de la conclusion de l'accord de libre-échange UE-Canada et de l'accord d'association UE-Ukraine ? », Revue trimestrielle de droit européen, pp. 119-123.

${ }^{3}$ Mieux connu sous l'acronyme ICS (International Court System).

${ }^{4}$ Recommandation relative à l'ouverture de négociations au niveau multilatéral visant à mettre en place un tribunal multilatéral pour le règlement des différends en matière d'investissements, $\operatorname{COM}(2017) 493$.
} 
CJUE une demande d'avis au sujet de sa compatibilité avec « la compétence exclusive de la CJUE de fournir une interprétation définitive du droit de l'Union ». Le 30 avril 2019, la CJUE a confirmé que le mécanisme ne portait pas atteinte au principe de l'autonomie du droit de l'Union, et n'affecte pas le principe de la compétence exclusive de la Cour pour interpréter le droit européen. La Cour énonce dans son avis que le mécanisme d'arbitrage ne peut concerner d'autres normes de droit que celles contenues dans l'AECG, et que « L'AECG contient des clauses privant lesdits tribunaux de toute compétence pour remettre en cause les choix démocratiquement opérés au sein d'une Partie à cet accord en matière, notamment, de niveau de protection de l'ordre public, de la sécurité publique, de la moralité publique, de la santé et de la vie des personnes et des animaux ou de préservation de l'innocuité alimentaire, des végétaux, de l'environnement, du bien-être au travail, de la sécurité des produits, des consommateurs ou encore de droits fondamentaux $»^{1}$. Plus aucun obstacle juridique ne s'oppose dès lors à l'entrée en vigueur de l'accord. Il faudra néanmoins obtenir la ratification de tous les États membres, ce qui implique le vote de normes d'assentiment par tous les parlements concernés, notamment le parlement wallon. Ce vote étant loin d'être acquis, il n'est pas exclu que des années s'écoulent avant l'entrée en vigueur complète de l'AECG avec le Canada.

Du point de vue pratique, le choix entre un AECG et un accord de libre-échange couplé à un accord de protection des investissements présente une différence fondamentale : dans le premier cas, l'accord étant mixte, la signature de l'ensemble des États membres est nécessaire pour sa conclusion. Dans le second cas, les deux accords (l'accord de libre-échange relevant de la politique commerciale commune et l'accord de protection des investissements étant mixte) entreront en vigueur séparément après l'accomplissement des formalités nécessaires (le Conseil statuant à la majorité qualifiée pour la conclusion de l'accord de libre-échange).

Comme le souligne très judicieusement Marianne Dony, « (...) une réflexion devra être menée sur la valeur ajoutée d'un chapitre relatif à la protection des investissements, qui est la seule exception au caractère exclusif de la compétence de l'Union pour conclure des accords commerciaux de nouvelle génération, et qui, par ailleurs, fait partie des chapitres les plus polémiques $»^{2}$. Les multinationales, concernées au premier chef, ne sont évidemment pas de son avis. Soucieuse de ne plus voir se reproduire les difficultés liées à la conclusion de l'Accord Économique et Commercial Global (CETA), l'Union préférera vraisemblablement avoir dorénavant recours à la négociation de deux accords séparés.

\subsection{Les autres dispositions}

Les nouveaux accords contiennent une série de dispositions relatives aux questions environnementales ${ }^{3}$ et sociales, et au développement durable ${ }^{4}$. Chaque partie peut réglementer le travail et l'environnement de la manière qu'elle juge appropriée ou nécessaire, en garantissant des niveaux élevés de protection ${ }^{5}$. Aucun mécanisme de sanction n'est cependant mis en place par les différents accords, même si un mécanisme de règlement des différends spécifique est instauré.

Ce mécanisme de règlement des différends a fait l'objet d'une mise en œuvre à l'égard de la Corée du Sud. Le 17 décembre 2018, la Commission européenne entama une procédure à l'encontre des autorités de Séoul pour non-respect des engagements de celles-ci en matière de respect des droits des travailleurs (notamment la liberté d'association et la reconnaissance du

\footnotetext{
${ }^{1}$ Avis $1 / 17$ du 30 avril 2019, Rec. 2019, p. 341.

${ }^{2}$ DONY, M. (2017), « Quel avenir pour la politique commerciale de l'Union européenne ?», Revue trimestrielle de droit européen, p. 199.

${ }^{3}$ L'accord conclu avec le Japon et le projet d'accord avec le MERCOSUR prévoient par exemple que les parties s'engagent à respecter l'accord de Paris sur le climat. Les autres accords (notamment l'AECG avec le Canada, sont muets sur la question, ce qui a fait l'objet de critiques acerbes.

${ }^{4}$ Chapitre 12 de l'accord avec Singapour.

${ }^{5}$ Voy. par exemple les articles 23.3 et 23.4 de l'AECG avec le Canada.
} 
droit de négociation collective) et pour ne pas avoir ratifié quatre conventions de l'Organisation Internationale du Travail (OIT) concernant notamment la liberté d'association ${ }^{1}$ et l'abolition du travail forcé ${ }^{2}$. En l'absence de résultat des négociations bilatérales, le Conseil a fait savoir aux autorités sud-coréennes qu'il demandait l'établissement d'un panel d'experts chargé de trancher le litige ${ }^{3}$. Les pouvoirs de ce panel sont cependant limités : il est en effet chargé de rendre un rapport, les parties «s'effor(çant) de tenir compte des avis ou recommandations formulés (dans celui-ci). La mise en œuvre des recommandations du groupe d'experts est supervisée par le Comité 'Commerce et développement durable' (mis en place par l'accord) (article $13.5 \S 2$ de l'accord UE-Corée du Sud). Le même mécanisme est prévu dans l'ensemble des accords de nouvelle génération. Aucune contre-mesure ne peut par conséquent être prise par une partie estimant que l'autre ne respecte pas ses obligations en matière de normes environnementales ou sociales, ou de développement durable.

La question de la protection de l'environnement est également à l'ordre du jour des négociations entre l'Union et le MERCOSUR. Après que les parties aient atteint un accord de principe le 28 juin $2019^{4}$, le président Emmanuel Macron annonça le 23 août 2019 à l'occasion du sommet du G7 à Biarritz que la France ne ratifierait pas cet accord, estimant que le président Jair Bolsonaro avait menti sur ses engagements en matière d'environnement suite à son inaction face aux incendies ravageant l'Amazonie ${ }^{5}$.

\subsection{Les critiques des accords}

Les critiques vis-à-vis des accords de nouvelle génération n'ont pas manqué. En premier lieu, on a reproché un manque de transparence dans les négociations. Les directives de négociations de l'accord avec le Canada n'ont été publiées (et de façon partielle) que le 15 décembre 2015, plus d'un an après la fin des négociations, tandis que celles de l'accord avec le Japon n'ont jamais été rendues publiques. Par ailleurs, les parlementaires européens se sont plaints des difficultés qu'ils rencontraient à consulter les rapports remis régulièrement par la Commission sur l'avancement des négociations.

En deuxième lieu, on en a déjà parlé, de nombreuses voix (notamment au sein du parlement wallon) se sont élevées pour critiquer le mécanisme de règlement des différends investisseurs/États prévu par l'accord avec le Canada, et les renoncements à la souveraineté des États qu'il contient ${ }^{6}$.

En troisième lieu, des voix plus nombreuses encore s'élèvent pour dénoncer les risques que font courir pour l'économie européenne (notamment son agriculture) la libéralisation des échanges avec des partenaires commerciaux dont les coûts de production sont sensiblement inférieurs aux européens. L'accord avec le MERCOSUR fait l'objet d'une critique quasi unanime du monde agricole ${ }^{7}$.

En dernier lieu, le peu de place réservé à la protection de l'environnement, aux droits sociaux des travailleurs, aux droits humains, au principe de précaution et au développement durable, alors que l'UE aurait pu profiter de son statut de superpuissance commerciale pour imposer à ses partenaires leur inscription dans les accords conclus et, par là même, l'exportation

\footnotetext{
${ }^{1}$ Conventions OIT 87 et 98.

${ }^{2}$ Conventions OIT 29 et 105.

${ }^{3}$ Lettre du 4 juillet 2019 (https://trade.ec.europa.eu/doclib/docs/2019/july/tradoc_157992.pdf).

${ }^{4}$ Voy. le communiqué de presse du 28 juin 2019 (http://trade.ec.europa.eu/doclib/press/index.cfm?id=2039).

${ }^{5}$ Le Monde du 23 août 2019.

${ }^{6}$ En témoigne l'initiative citoyenne « Stop CETA » (tout comme l'initiative « Stop TTIP »). Pour un commentaire (concernant essentiellement cette dernière), voy. DELCOURT, C. (2015), « L'action extérieure de l'Union, terrain d'expérimentation d'une première controverse juridique opposant la commission aux organisateurs d'une initiative citoyenne », Revue trimestrielle de droit européen, p. 220.

${ }^{7}$ Voy. supra, note 91.
} 
de ses valeurs, soulève de nombreuses questions et inquiétudes parmi la population ${ }^{1}$. Seul le business importerait à l'Union. La négociation d'accords de protection des investissements avec la Chine et le Myanmar est d'ailleurs de nature à renforcer cette impression.

\section{Conclusion}

À l'heure actuelle, le cadre des relations commerciales de l'Union a fondamentalement changé par rapport à celui qui était en vigueur en 1994 au moment de l'entrée en vigueur de l'OMC. L'Union a conclu des accords avec 71 partenaires, tandis que le SPG ne concerne plus que 70 États $^{2}$. Les relations commerciales avec les autres pays se font dans le cadre des règles de $\mathrm{l}^{\prime} \mathrm{OMC}{ }^{3}$.

L'échec du multilatéralisme commercial a ouvert une boîte de Pandore dans laquelle la plupart des États, tant émergents qu'industrialisés, se sont engouffrés. La Chine, qui s'est longtemps prévalue de son statut de pays en développement pour tirer profit de la libéralisation des échanges internationaux sans devoir faire (trop) de concessions ${ }^{4}$, s'est lancée dans l'aventure du bilatéralisme, négociant des accords avec le CCG, l'Australie, la Norvège, l'Inde, la Corée du Sud, le Japon, les pays de l'ASEAN, le Pakistan, le Chili, le Pérou, la NouvelleZélande, Singapour, le Costa Rica, l'Islande, la Suisse...5. L'Inde n'est pas restée en reste, négociant des accords avec l'Afghanistan, les pays de l'ASEAN, le Bhoutan, le Chili, le Japon, le Népal, Singapour, le Sri Lanka et la Corée du Sud ${ }^{6}$.Les États-Unis ont, depuis l'accession au pouvoir de Donald Trump, fait machine arrière sur la plupart des traités bilatéraux ou multilatéraux restreints qu'ils étaient en train de négocier ${ }^{7}$ et n'hésitent pas à appliquer des surcharges tarifaires unilatérales lorsqu'ils estiment (tout aussi unilatéralement) que leurs partenaires commerciaux (notamment l'UE) ne respectent pas les règles du jeu commercial international $^{8}$.

L'UE, quant à elle, multiplie les accords. Ceux-ci se heurtent à l'opposition d'une partie de l'opinion publique, qui y voit des instruments mis exclusivement au service des multinationales pour réaliser des profits, parfois au détriment de la santé des consommateurs, et de graves risques d'atteinte à la souveraineté des États, en raison de la mise en place de

\footnotetext{
1 JACQUEMART, K. (2017), «TTIP, CETA : accords de nouvelle génération, nouvelles menaces pour la démocratie ? », Revue internationale et stratégique, pp. 111-120.

${ }^{2}$ Contre 128 en 1994.

${ }^{3}$ Cela concerne notamment les États-Unis, la Chine, la Russie, l'Inde, l'Australie, la Nouvelle-Zélande, les pays du Mercosur, les pays du Golfe, l'Azerbaïdjan, le Belarus, Cuba, le Gabon, la Libye et la Thaïlande. Cette longue liste explique pourquoi seuls $40 \%$ des échanges de l'Union ont lieu dans le cadre d'accords commerciaux préférentiels, plus de la moitié étant effectués par quatre pays (Japon : $8 \%$; Suisse : $7 \%$; Turquie : 4,1\%; Norvège : 3,4 \%) ; cf. Report of the Commission to the European Parliament, the Council, the European Economic and Social Committee and the Committee of Regions on the implementation of Free Trade Agreements, 1 January 2017 - 31 December 2017, p. 8 (chiffres actualisés par l'auteur suite à l'entrée en vigueur de l'accord avec le Japon).

${ }^{4}$ Voy. à ce sujet LI, M. (2011). « Rising from within: China's search for a multilateral world and its implications for sino-relations », Global Governance, pp. 331-351.

${ }^{5}$ Pour la liste des accords conclus par la Chine, voy. http://www.china.org.cn/business/node_7233287.htm. Pour un commentaire, voy. notamment SNYDER, F. (2010), « Les accords commerciaux régionaux de la Chine et le droit de l'OMC », in REMICHE, B. et RUIZ-FABRI, H. (2010) (éds.), Le commerce international entre bi-et multilatéralisme, Bruxelles, Larcier, pp. 41-114.

6 Pour la liste des accords conclus par l'Inde, voy. https://commerce.gov.in/InnerContent.aspx?Type=InternationalTrademenu\&Id=32.

7 À l'exception de l'ALENA, renégocié en 2018 et rebaptisé Accord Canada-États-Unis-Mexique (ACEUM), et des négociations d'accords de libre-échange classiques avec l'UE, le Royaume-Uni et le Japon.

${ }^{8}$ Pour une analyse de l'impact de l'arrivée au pouvoir de Donald Trump sur la politique commerciale commune, voy. SOLAL-AROUET, J. et TERSEN, D. (2017), « Trump et l'avenir de la politique commerciale européenne », Politique étrangère, 2017/1, pp. 85-97.
} 
mécanismes de règlement des différends en matière d'investissements internationaux échappant à l'ordre juridique national des États hôtes. On n'oubliera pas non plus l'argument de l'ineptie de conclure des accords commerciaux avec des partenaires lointains alors qu'il est plus qu'urgent de réduire l'empreinte carbone des moyens de transport utilisés pour transporter ces marchandises.

Il est encore trop tôt pour tirer des conclusions sur les avantages et les inconvénients de ces accords. Seule l'analyse de l'arrivée ou non sur le territoire européen de produits alimentaires potentiellement nocifs, l'harmonisation ou non à la baisse de mesures de protection de l'environnement ou des travailleurs, les décisions prises par les organes de règlement des différends en matière d'investissement... permettra de tirer un bilan sur la politique européenne d'ouverture des marchés.

\section{Bibliographie}

ABDELAL, R. et MEUNIER, S. (2010), «Managed globalization : Doctrine, practice and promise », Journal of European Public Policy, pp. 350-367.

BOURGEOIS J., DEWOST, J-L, et GAIFFE, M-A (éds.) (1997), La Communauté européenne et les accords mixtes. Quelles perspectives? Bruges, Collège d'Europe.

DEBLOCK, C. (2010), «Le bilatéralisme commercial des États-Unis », in REMICHE, B., et RUIZ-FABRI, H. (2010), Le commerce international entre bi- et multilatéralisme, Bruxelles, Larcier, pp. 115-173.

DELCOURT, C. (2015), «L'action extérieure de l'Union, terrain d'expérimentation d'une première controverse juridique opposant la commission aux organisateurs d'une initiative citoyenne », Revue trimestrielle de droit européen, p. 220.

DONY, M. (2017), «Quel avenir pour la politique commerciale de l'Union européenne ?», Revue trimestrielle de droit européen, p. 199.

ELGSTRÖM, O. (2007), « Outsiders perceptions of the European Union in international trade negociations », Journal of Common Market Studies, pp. 949-967.

FLAESCH-MOUGIN, C. (2017), «La nature des compétences externes de l’Union européenne à la lumière des avis $2 / 15$ et $3 / 15$ de la Cour de Justice de l'Union européenne », Revue trimestrielle de droit européen, p. 600.

HELISKOSKI, J. (2001) Mixed Agreements as a Technique for Organizing the International relations of the European Community and its Member States, La Haye, Kluwer Law International.

HERVE, A. (2017), «Les résistances des États membres au développement des relations conventionnelles de l'Union européenne: quels enseignements tirer de la conclusion de l'accord de libre-échange UE-Canada et de l'accord d'association UE-Ukraine ? », Revue trimestrielle de droit européen, pp. 119-123.

HERVE, A. (2017), «La Commission affiche les nouvelles orientations de sa politique commerciale dans la communication «Le commerce pour tous - Vers une politique de 
commerce et d'investissement plus responsable », Revue trimestrielle de droit européen, pp. $137-140$.

HERVE, A. (2017), « Les accords de libre-échange de l'Union européenne seront-ils les mêmes après l'avis 2/15 ?», Revue trimestrielle de droit européen, p. 617.

HERVE, A. (2017), « La loi du marché - Réflexions sur la coopération réglementaire instaurée par l'AECG », Revue des affaires européennes, pp. 235-251.

HERVE, A. (2017), «L'avis 2/15 de la Cour de Justice - Et maintenant que faire du partage de compétences entre l'Union et ses États ? », Cahiers de droit européen, pp. 694-735.

JACQUEMART, K. (2017), «TTIP, CETA : accords de nouvelle génération, nouvelles menaces pour la démocratie ? », Revue internationale et stratégique, pp. 111-120.

LI, M. (2011). « Rising from within: China's search for a multilateral world and its implications for sino-relations », Global Governance, pp. 331-351.

MEUNIER, S. (2008) «L'Union européenne et l'OMC : la mondialisation maîtrisée à l'épreuve », in BOISMENU, G. et PETIT, I. (éds.), L'Europe qui se fait. Regards croisés sur un parcours inachevé, Paris, Éditions de la Maison des sciences de l'homme, pp. 211-222.

SCHILL, S.W. (2006), Fair and Equitable Treatment under Investment Treaties as an Embodiment of the Rule of Law, IILJ Working Paper $n^{\circ} 6$.

SHAHRJERDI, P. (1998), «L'AMI ou le projet mort-né de l'OCDE », Actualité et droit international, http://www.ridi.org/adi/199811a5.html (consultée le 10 juin 2020).

SNYDER, F. (2010), «Les accords commerciaux régionaux de la Chine et le droit de l'OMC », in REMICHE, B. et RUIZ-FABRI, H. (2010) (éds.), Le commerce international entre bi- et multilatéralisme, Bruxelles, Larcier, pp. 41-114.

SOLAL-AROUET, J. et TERSEN, D. (2017), « Trump et l'avenir de la politique commerciale européenne », Politique étrangère, pp. 85-97.

TUDOR, I. (2008), The Fair and Equitable Treatment Standard in the International Law of Foreign Investment Oxford, Oxford University Press.

VINCENT, P. (2003), «L'entrée en vigueur de la convention de Cotonou », Cahiers de Droit européen, pp. 157-176.

VINCENT, P. (2003), « Les résultats de la quatrième Conférence ministérielle de l'OMC - vers un cycle du développement ? », Revue belge de droit international, pp. 111-130.

VINCENT, P. (2016), «Le Comprehensive Economic Trade Agreement (CETA)», Revue de droit du commerce international et des transports, pp. 498-521.

ZACHARIE, A. et WINTGENS S. (dir.) (2018), Le décentrage du monde. L'impact des émergents sur la gouvernance mondiale, Bruxelles, Le bord de l'eau. 


\title{
Politique commerciale extérieure : quel rôle pour les assemblées parlementaires ? Le cas des États-Unis et de l'Union Européenne
}

\begin{abstract}
Vincent Bricart $^{1}$

\section{Résumé}

Depuis le début des années 2010, une série de nouveaux accords ou de processus de négociations commerciaux entre de grands blocs géographiques ont émergé dans le monde. L’Union Européenne (UE) et les États-Unis ont à ce titre joué un rôle de premier plan dans ces initiatives et dans leurs proliférations. Face à l'impact grandissant de la globalisation sur le quotidien des citoyens, les assemblées législatives tendent à s'impliquer progressivement dans ces processus diplomatiques et à gagner en importance et en visibilité dans leur fonction vis-à-vis de ces accords. Si bien qu'aujourd'hui, toute personne s'intéressant de près ou de loin à l'étude des accords commerciaux ne peut plus ignorer le rôle qu'y jouent les parlements des États impliqués dans ces processus. Les négociations du Partenariat Transatlantique de Commerce et d'Investissement (TTIP), de l'Accord Économique et Commercial Global (CETA) et de l'Accord de Partenariat Transpacifique (TPP) représentent ainsi de bons indicateurs du rôle, des atouts et des limites que les interventions d'un parlement dans un processus de négociation peuvent rencontrer en fonction du contexte politique ou institutionnel et de l'appui de l'opinion publique. Le Parlement européen et le Congrès américain constituent respectivement des assemblées législatives relativement puissantes, représentant un nombre de citoyens conséquent et ayant d'importantes prérogatives constitutionnelles ou institutionnelles en matière commerciale, mais évoluant dans des cadres significativement différents. Via leurs outils institutionnels et à travers des pressions formelles et informelles de la part de ces deux pouvoirs législatifs, les exécutifs se retrouvent souvent contraints de prendre en compte certaines revendications des parlementaires faisant voix aux revendications d'une partie de la société civile. À défaut, le risque de voir une négociation échouer faute de ratification de l'accord par le pouvoir législatif est important. Néanmoins, l'influence du pouvoir législatif n'est pas la même pour chaque négociation et le contexte de celle-ci va dès lors jouer un rôle important pour en déterminer l'amplitude et la visibilité d'une assemblée dans ces différents processus.
\end{abstract}

Mots-clés : Accords-commerciaux ; UE ; États-Unis ; TTIP ; TPP ; CETA

\footnotetext{
${ }^{1}$ Vincent Bricart est assistant-doctorant. Diplômé d'un master en Science Politique à l'Université de Liège (ULiège) en Belgique, il travaille actuellement comme chercheur au sein du Center for International Relations Studies (CEFIR).
} 


\section{Introduction}

Au cours de la décennie qui vient de s'écouler, on a pu voir s'accroître un phénomène qui n'est pas neuf, mais qui se veut de plus en plus fréquent dans les relations diplomatiques qu'entretiennent les démocraties libérales occidentales entre elles : la mise en place de vastes accords commerciaux de libre-échange. En une dizaine d'années, on a pu voir émerger toute une série de nouveaux accords ou de processus de négociations entre de grands blocs géographiques. L'augmentation de manière répétée de ces accords s'inscrit dans des stratégies tant à buts économiques que politiques pour les démocraties occidentales qui cherchent à s'adapter à la mondialisation et à y faire face. Parallèlement à ces accords, on a pu également constater un fait relativement nouveau dans les relations internationales post-guerre froide de ces mêmes États : l'implication croissante des assemblées parlementaires et de leurs membres dans le processus de négociation et de conclusion des traités commerciaux internationaux.

De manière générale, l'étude des relations internationales se base en premier lieu sur l'analyse des interactions entre les différents exécutifs ainsi qu'entre leurs corps diplomatiques respectifs. L'examen du rôle des assemblées parlementaires dans les relations internationales est dès lors resté pendant longtemps minoritaire parmi les chercheurs car ces institutions ont des compétences et responsabilités en matière de politique extérieure à priori plus restreintes que les autres pouvoirs de par leur vocation à traiter en premier lieu des matières internes à un État. Ainsi, les rares attributions dont elles disposent dans ce domaine se limitent principalement à une activité de contrôle et d'avalisation de l'action de l'exécutif plutôt qu'à une intervention concrète dans les relations internationales avec les autres Nations. Cependant, depuis quelques années, on assiste à un regain d'intérêt des analystes politiques pour l'étude du rôle des parlementaires sur les affaires extérieures de leur État. Face à l'impact grandissant de la globalisation sur la vie quotidienne, les assemblées législatives tendent ainsi à s'impliquer progressivement dans les processus diplomatiques avec parfois des conséquences importantes pour ces derniers. À ce titre, les accords internationaux constituent l'exemple le plus évident où la participation parlementaire se montre importante et où son impact est le plus visible.

La présente analyse aura dès lors pour objectif de démontrer comment cette influence se manifeste aujourd'hui à travers plusieurs terrains d'étude. D'une part, l'Union européenne (UE) et le Parlement européen seront analysés à travers les négociations du Partenariat Transatlantique de Commerce et d'Investissement ou en anglais Transatlantic Trade and Investment Partnership (TTIP) et de l'Accord Économique et Commercial Global (CETA), d'autre part les États-Unis et le Congrès américain seront étudiés à travers le prisme des pourparlers du TTIP et de l'Accord de Partenariat Transpacifique ou en anglais Trans-Pacific Partnership (TPP). L’UE et les États-Unis ont été choisis ici car les deux entités politiques figurent parmi les plus grands espaces économiques et démocratiques du monde. Par ailleurs, elles disposent d'assemblées législatives relativement puissantes, représentant un nombre de citoyens conséquent et ayant d'importantes prérogatives constitutionnelles en matière commerciale. Elles ont cependant une organisation, des compétences, une histoire et un mode de fonctionnement différent qui rendent l'analyse comparative particulièrement pertinente. Le choix d'analyser les accords commerciaux de manière générale se base quant à lui principalement sur le fait que ces derniers constituent des processus diplomatiques intenses, prenant place sur une certaine durée, ayant un impact important sur la vie quotidienne des citoyens et surtout dans lesquels les assemblées législatives ont le plus de marge de manœuvre en politique étrangère. Enfin, les cas spécifiques étudiés ont été sélectionnés pour leurs natures et caractéristiques similaires ainsi que pour la concomitance ou proximité de leurs différentes phases de négociation. 


\section{Tour d'horizon des compétences respectives en matière de politique étrangère a. Caractéristiques structurelles : Le Parlement européen versus le Congrès américain}

Avant de passer au cœur du sujet de cette recherche, il est utile de réaliser une comparaison entre deux caractéristiques structurelles du Parlement européen et du Congrès américain : à savoir, le «droit d'initiative législative » et les «commissions parlementaires ». Aux États-Unis, les parlementaires américains sont les seuls à pouvoir initier une proposition législative ce qui a pour conséquence de pousser le président à négocier avec les parlementaires pour qu'une loi soit introduite. Cela donne de facto un pouvoir et une influence importante à ces derniers. ${ }^{1}$ Dans 1 'UE, ce droit d'initiative parlementaire appartient exclusivement à la Commission européenne et non pas aux parlementaires. Néanmoins, le Parlement européen a le pouvoir de demander à la Commission de soumettre une proposition de « loi », sous la forme d'une directive ou d'un règlement. Par ailleurs, le pouvoir de codécision du Parlement européen ayant été considérablement accru depuis la réforme du Traité de Lisbonne, il dispose de la possibilité de refuser ou d'amender la très grande majorité des législations européennes ce qui le rend de facto beaucoup plus influent sur le devenir des législations ${ }^{2}$. Enfin, tout acte législatif doit faire l'objet d'un accord entre le Parlement et le Conseil. Dès lors, la capacité d'influence des deux assemblées, américaine et européenne, sur l'exécutif est à priori similaire ${ }^{3}$.

Parallèlement à cela, les commissions parlementaires, ou «committees » en anglais, jouent un rôle fondamental dans les deux institutions pour la rédaction de rapports d'enquête, d'analyse et d'évaluation des politiques de l'exécutif. Les parlementaires au sein de ces commissions ont une influence et une maitrise dans certains thèmes qui dépassent de loin celles des parlementaires lambda. Les committees jouent ainsi un rôle important pour influencer les débats parlementaires, les débats au sein de la société civile, ainsi que les discussions sur les différentes propositions de $10 i^{4}$. Par ailleurs, même si cela se réalise de manière moins fréquente au niveau du Parlement européen, les différentes assemblées ont toutes deux la possibilité d'auditionner les membres de leurs exécutifs pour leur poser des questions relatives à leurs politiques via ces commissions parlementaires. Elles ont ainsi la possibilité d'aborder en débat l'ensemble des sujets qui leur semblent importants et d'exprimer leur position sur tous les domaines relevant d'un intérêt à leurs yeux. Ce qui est très important pour la création de l'espace public européen et américain ainsi que pour la légitimation des politiques gouvernementales ${ }^{5}$. Les deux institutions peuvent donc être considérées comme des parlements très puissants de manière générale même si, à l'instar de la majorité des parlements, cette puissance est moindre en matière de politique étrangère.

Il parait également important de noter qu'une coopération interparlementaire entre le Parlement européen et le Congrès américain existe depuis déjà plusieurs années. Les premières

\footnotetext{
${ }^{1}$ Article 1 , section 1 et 8, United States Constitution, signée à Philadelphie le 17 septembre 1787, modifiée le 7 mai 1992.

${ }^{2}$ Article 17, paragraphe 2 du Traité sur l'Union Européenne (TUE), signé à Maastricht le 7 février 1992, modifié le 13 décembre 2007 ; Article 225 et 289 du Traité sur le Fonctionnement de l'Union européenne (TFUE), signé à Rome le 25 mars 1957, modifié le 13 décembre 2007.

${ }^{3}$ BEAUSSIER, A.-L. et BENJABALLAH, S. (2014), « Comparer le Parlement européen et le Congrès américain. Un état des lieux théorique et méthodologique », Revue internationale de politique comparée, vol. $21, \mathrm{n}^{\circ} 3, \mathrm{pp} .9$ 30.

${ }^{4}$ WINZEN, T. (2011), « Technical or Political? An Exploration of the Work of Officials in the Committees of the European Parliament », The Journal of Legislative Studies, vol. 17, n 1, pp. 27-44 ; DAVID, C-P. (éd.) (2015), La politique étrangère des Etats-Unis : fondements, acteurs, formulation, Paris, Presses de Sciences Po, $3^{\text {ème }}$ édition, pp. 414-462.

${ }^{5}$ COSTA, O. (2014), « Que peut le Parlement européen ? », Pouvoirs, vol. 149, n 2, pp. 77-89 ; COURMONT, B. (2001), «Le Congrès et son poids dans la formulation de la politique étrangère américaine », Revue internationale et stratégique, vol. 42, $\mathrm{n}^{\circ} 2$, pp. 87-97.
} 
réunions bilatérales remontent à 1972 et leurs fréquences ont considérablement augmenté depuis deux décennies. Les contacts entre les deux institutions ne sont ainsi pas nouveaux et ils auraient plutôt tendance à être réguliers ${ }^{1}$. Deux éléments peuvent appuyer ce constat, d'une part le Parlement européen dispose d'un bureau de liaison permanent établi à Washington chargé d'entretenir des contacts avec le Congrès américain ${ }^{2}$. Il existe également une structure de dialogue unique entre les deux assemblées à travers laquelle les principaux contacts interparlementaires ont lieu, à savoir le Transatlantic Legislator Dialog (TLD) créé en 1999. Les deux assemblées se rencontrent ainsi en son sein officiellement deux fois par an, mais aussi de manière un peu plus informelle le reste du temps via des groupes de travail communs ou des vidéo-conférences dans le but d'améliorer les échanges, la communication et la compréhension mutuelle ${ }^{3}$.

\section{b. Le Parlement européen et la politique étrangère}

Les compétences du Parlement européen en matière de politique étrangère sont reprises dans le titre 5 du Traité sur le Fonctionnement de l'UE (TFUE). L'article 218 de ce dernier établit ainsi le pouvoir de co-approbation dont dispose l'institution concernant les accords internationaux portant sur des notions clés comme le commerce, l'agriculture et la sécurité intérieure. Il établit également le droit de l'institution à être informée à toutes les étapes de la procédure et de pouvoir saisir la Cour de Justice de l'Union Européenne (CJUE) sur la compatibilité d'un accord international avec les traités de l'UE'.

Parallèlement, la Commission européenne a le monopole pour négocier les accords commerciaux européens sur base d'un mandat préalablement accordé par le Conseil européen. Le rôle de l'assemblée se limite à l'approbation de l'accord négocié précédemment par la Commission. De manière indirecte, le Parlement européen a également le pouvoir d'auditionner les commissaires lorsque ceux-ci interviennent de manière directe ou indirecte sur la politique extérieure. Le haut représentant aux affaires externes a par ailleurs le devoir de consulter et d'informer régulièrement les parlementaires sur son action dans le cadre de la politique européenne de défense et de sécurité commune. Enfin, l'approbation du budget européen, et donc des ressources allouées à la politique extérieure de l'UE, fait-elle aussi partie des compétences du Parlement européen ${ }^{5}$.

Depuis 2009 et la mise en application du traité de Lisbonne, ces différents pouvoirs du Parlement européen ont fait l'objet de nombreuses études et analyses par les chercheurs. En matière de « politique étrangère européenne ${ }^{6}$, plusieurs auteurs ont ainsi affirmé, en se basant sur les compétences reprises dans les traités, que les pouvoirs de cette assemblée se limitent à

\footnotetext{
${ }^{1}$ JANČIĆ, D. (2016), «The Role of the European Parliament and the US Congress in Shaping Transatlantic Relations: TTIP, NSA Surveillance, and CIA Renditions », Journal of Common Market Studies, vol. 54, $\mathrm{n}^{\circ} 4$, pp. 896-912 ; Transatlantic Legislators' Dialogue (2019), «Transatlantic Legislators' Dialogue: Welcome », europa.eu, https://www.europarl.europa.eu/intcoop/tld/default_en.htm.

2 European Parliament (2020), «Bureaux de liaison dans votre pays », europa.eu, http://www.europarl.europa.eu/at-your-service/fr/stay-informed/liaison-offices-in-your-country.

3 Transatlantic Legislators' Dialogue (2019), "Transatlantic Legislators' Dialogue: Welcome », europa.eu, https://www.europarl.europa.eu/intcoop/tld/default_en.htm ; JANČIĆ, D. (2016), op. cit.

4 Article 218 du Traité sur le Fonctionnement de l'Union européenne (TFUE), signé à Rome le 25 Mars 1957, modifié le 13 Décembre 2007. ; Damen, D. (2019), «L’Union européenne et ses partenaires commerciaux », Fiches thématiques l'Union sur européenne, Novembre http://www.europarl.europa.eu/factsheets/fr/sheet/160/l-union-europeenne-et-ses-partenaires-commerciaux.

5 RIPOLL SERVENT, A. (2014), «The role of the European Parliament in international negotiations after Lisbon », Journal of European Public Policy, vol. 21, n 4, pp. 568-586 ; KEUKELEIRE, S., DELREUX, T. (2014), The Foreign Policy of the European Union, Londres, MacMillan Education UK, 2 ème edition, pp. 85-88. ${ }^{6}$ Le terme «politique étrangère » doit être ici nuancé car elle se divise étrangère entre la PESC, qui est restée intégralement intergouvernementale et dont le PE est totalement exclu, et la politique commerciale, compétence exclusive de l'Union où le PE est très impliqué, ce qui diffère avec la politique étrangère d'un État traditionnel.
} 
son pouvoir de codécision en matière du budget de l'Union et à son pouvoir d'approuver ou de rejeter l'adoption des accords internationaux, ce dernier trait s'apparentant à un droit de véto. Son implication dans la politique étrangère de l'UE est donc, selon eux, à priori très faible ${ }^{1}$. Néanmoins, la grande majorité des chercheurs mettent en avant l'extension importante des pouvoirs que le Parlement européen a connu depuis 2009. Pour les auteurs comme Ariadna Ripoll Servent, Karina L. Pasquariello Mariano et Bruno Theodoro Luciano, l'assemblée a réussi à s'imposer progressivement dans la politique étrangère de l'Union et à s'impliquer dans l'ensemble du processus de négociation et de décision en matière d'accord international ${ }^{2}$. Cette évolution a été rendue possible de par la menace que représentait son pouvoir de véto sur les différents accords négociés par la Commission européenne. Les parlementaires ont ainsi rendu essentielles la consultation et l'implication indirecte du Parlement dans les négociations pour la bonne conduite de ces dernières. À cette fin, l'assemblée a montré à plusieurs reprises qu'elle était prête à appliquer son droit de véto final si elle désapprouvait majoritairement un accord pour lequel elle aurait été trop peu consultée ${ }^{3}$. Cela a notamment été le cas pour les négociations $\mathrm{du}$ "SWIFT agreement ${ }^{4}$. Le Parlement a donc évolué pour devenir un acteur définissant en partie l'agenda politique des négociations de l'UE afin d'éviter le paradigme de la pensée unique.

En outre, grâce à une interprétation extensive de ses propres domaines de compétences, le Parlement a réussi à légitimer son droit d'être impliqué dans les négociations internationales dans des domaines plus variés que ce que prévoyaient les traités et a progressivement gagné en influence dans ces derniers. Enfin, grâce à son pouvoir d'audition, de résolution, d'interrogation et dans une moindre mesure grâce à son travail d'expertise et d'analyse sur les politiques et opérations de l'UE réalisé par les commissions parlementaires, le Parlement a réussi à créer un véritable dialogue avec la Commission européenne en matière de politique étrangère et a pu se greffer à l'ensemble des domaines de cette dernière ${ }^{5}$. Même si le degré d'implication varie fortement encore d'un sujet à l'autre et d'un accord à l'autre ${ }^{6}$. Son influence reste par ailleurs beaucoup plus importante en matière de politique commerciale que dans les autres domaines ${ }^{7}$.

Il est admis par les différents auteurs consultés que cette évolution du rôle du pouvoir législatif européen a été rendue possible car il y a eu une réelle volonté de la part des dirigeants européens de donner une légitimité à l'UE et à sa politique extérieure, notamment commerciale, en incluant davantage le Parlement ${ }^{8}$.

\footnotetext{
${ }^{1}$ KEUKELEIRE, S., DELREUX, T., op. cit. ; FROMAGE, D. (2018), « The European Parliament in the postcrisis era: an institution empowered on paper only? », Journal of European Integration, vol. 40, n 3, pp. 281-294. ${ }^{2}$ RIPOLL SERVENT, A., op. cit. ; PASQUARIELLO MARIONO, K. L. et THODORO LUCIONA, B. (2018), «The parliamentarization of EU trade policy: unveiling the European Parliament's involvement in EUMERCOSUR trade negotiations », European Politics and Society, vol. 20, n 5, pp. 591608.

${ }^{3}$ Ibid.

${ }^{4}$ European Parliament (2010), « SWIFT: European Parliament votes down agreement with the US », europa.eu, 11 février 2010, https://www.europarl.europa.eu/sides/getDoc.do?pubRef=-//EP//TEXT+IMPRESS+20100209IPR68674+0+DOC+XML+V0//EN

${ }^{5}$ RIDDERVOLD, M. et ROSÉN, G. (2016), « Trick and treat: how the Commission and the European Parliament exert influence in EU foreign and security policies », Journal of European Integration, vol. 38, ${ }^{\circ}$ 6, pp. 687-702; PASQUARIELLO MARIONO, K. L. et THODORO LUCIONA, B., op. cit.

${ }^{6}$ HUBER, K. (2015), « The European Parliament as an actor in EU border policies: its role, relations with other EU institutions, and impact », European Security, vol. 24, n 3, pp. 420-437; RIDDERVOLD, M. et ROSÉN, G., op. cit.

7 ROSÉN, G. (2017), «The impact of norms on political decision-making: how to account for the European Parliament's empowerment in EU external trade policy », Journal of European Public Policy, vol. 24, $\mathrm{n}^{\circ}$ 10, pp. 1450-1470.

${ }^{8}$ ROSÉN, G., op. cit. ; RIDDERVOLD, M. et ROSÉN, G., op. cit.
} 


\section{c. Le pouvoir du Congrès américain en politique étrangère}

Historiquement et dans une interprétation stricte de la Constitution américaine, le Congrès américain est supposé être l'institution prédominante en matière de politique extérieure du pays. Ainsi, selon l'article 1 section 8 et l'article 2 section 1, 2, 3 de la Constitution américaine, le Congrès a le pouvoir de réglementer le commerce avec les nations étrangères, de déclarer la guerre, de prévoir des sanctions politiques et économiques vis-à-vis des autres nations, etc. Le président par ailleurs est constitutionnellement obligé d'obtenir l'approbation du Sénat pour, entre autres, la ratification des traités internationaux, la nomination d'ambassadeurs et la nomination du secrétaire d'État. Enfin, le chef de l'État est obligé d'informer périodiquement le Congrès de l'évolution de la politique étrangère du pays ${ }^{1}$.

Sur le papier donc, le Congrès américain est très puissant pour l'orientation de la politique extérieure du pays. Cependant dans la pratique, comme l'on va le constater, les choses ont évolué pour donner progressivement un pouvoir prédominant au président et à son administration dans ce domaine.

L'analyse ne s'attardera pas ici sur la répartition des compétences de «hard power » des États-Unis car il est peu pertinent de vouloir les comparer avec les pouvoirs presque inexistants de l'UE en la matière. Il faut néanmoins retenir qu'aujourd'hui la mainmise du président sur ce domaine est presque absolue face à un Congrès disposant d'un pouvoir de contrôle plus que limité dans la pratique ${ }^{2}$.

Dans les matières civiles, les choses ont évolué depuis la ratification de la Constitution américaine. Tout comme le Parlement européen, le Congrès a le pouvoir de se prononcer sur n'importe quel sujet, politique étrangère comprise, mais ces interventions restent de simples déclarations sans effets concrets ${ }^{3}$. Les deux principaux pouvoirs officiels du Congrès se trouvent réellement au niveau d'une partie des traités internationaux et de la validation du budget annuel accordé à l'exécutif.

En matière d'accords internationaux, il existe dans le droit américain trois types de traités pouvant être mis en place aux États-Unis. Le degré d'implication du Congrès dans les négociations variera en fonction que l'on soit dans l'une ou l'autre procédure. Il existe d'une part le traité traditionnel dont le processus de ratification est extrêmement lourd et difficile à faire passer par le Congrès. Il faut ainsi l'accord de 2/3 des représentants au Sénat pour qu'un traité soit ratifié par l'institution. Il existe ensuite les «executive agreements », traités impliquant uniquement l'exécutif et ratifiés par le président dans les domaines de compétence relevant de ses prérogatives en tant que chef d'État. ${ }^{4}$ L'implication du Congrès est nulle dans cette procédure.

Enfin, la dernière stratégie de ratification d'un accord international est le « congressional-executive agreement ». Depuis 1974, le Congrès des États-Unis peut, s'il vote dans ce sens, accorder un mandat à l'exécutif pour une durée limitée permettant la mise en place d'une procédure exceptionnelle de ratification d'accords internationaux portant sur le commerce : la «trade promotion authority » (TPA) ou «fast track procedure ». Selon les modalités de cette dernière, les accords commerciaux sont négociés par le président et ils

\footnotetext{
1 Article 1 section 8 et l'article 2 section 1, 2 et 3, United States Constitution, signée à Philadelphie le 17 septembre 1787, modifiée le 7 mai 1992.

${ }^{2}$ BRICART, V. (2017), « Le Congrès américain et les pouvoirs de guerre : de la théorie à la pratique », CEFIR Working Paper, ${ }^{\circ}$ 3, pp. 1-19; ROEHRIG, T. et WESSEL, L. A. (2011), « Congress and U.S.-North Korean Relations: The Role of the Entrepreneur », Asian Affairs: An American Review, vol. 38, n 2, pp. 89-108.

${ }^{3}$ Article 1 , section 1 et 8 , United States Constitution, signée à Philadelphie le 17 septembre 1787, modifiée le 7 mai 1992.

${ }^{4}$ FORTMANN, M. (dir.) et MARTIN P. (dir.) (2013), Le système politique américain, Montréal, Les Presses de 1'Université de Montréal, $5^{\text {ème }}$ édition, pp. 421-426 ; KANDEL, M. (2016), « Le rôle du Congrès américain dans le processus de décision en politique étrangère : les accords de Dayton (1995) », Critique internationale, vol. 71, $\mathrm{n}^{\circ} 2$, pp. $109-127$.
} 
doivent répondre positivement aux critères et préoccupations définis dans des domaines spécifiques par le Congrès. Une fois l'accord conclu, les parlementaires ont ainsi l'occasion de se prononcer, 60 jours après l'introduction de la demande de ratification et avec un nombre de débats limité, pour décider à la simple majorité dans les deux chambres s'ils souhaitent approuver la ratification de l'accord commercial. La loi obtenue par ce dernier vote sera appelée le «congressional-executive agreement». Aucune demande d'amendement à l'accord commercial conclu par le président avec les autres parties n'est possible durant les débats entourant le vote. L'administration doit en contrepartie avoir respecté l'ensemble des objectifs de négociation définis par le Congrès dans le mandat qu'elle lui a accordé via la "trade promotion authority ». Elle doit par ailleurs accepter la présence de conseillers nommés par les deux chambres dans l'équipe de négociations et respecter les dispositions qui appellent à notifier et à consulter le Congrès aux étapes prévues par ce dernier. Si le Congrès considère que ces règles et objectifs n'ont pas été atteints, il pourra ainsi refuser de ratifier l'accord s'il est soumis à un vote ou forcer le président via des tractations en dehors du cadre législatif à en renégocier certaines parties avec les autres États avant de le soumettre au vote ${ }^{1}$. Techniquement, un mandat n'est pas nécessaire pour que l'exécutif entame ou même conclue des négociations commerciales avec une autre Nation, mais il est néanmoins requis dans les pratiques coutumières et légales américaines que le Congrès soit informé si un début de négociation est envisagé et il est admis que son implication via cette procédure est essentielle. D'une part pour l'expression de la compétence commerciale des deux chambres législatives dans ce domaine, ensuite pour que l'accord obtienne une légitimité démocratique, enfin pour garantir la bonne mise en œuvre de l'accord sur le territoire américain ${ }^{2}$.

En outre, le Congrès peut autoriser le représentant américain au commerce extérieur (USTR) à enquêter sur les pratiques commerciales déloyales d'une autre nation et à y répondre ${ }^{3}$.

Le Congrès américain reste par ailleurs très influent en matière de politique étrangère grâce à son vaste pouvoir d'enquête, d'audition et de supervision parlementaires conduit par ses commissions ${ }^{4}$. Ce pouvoir d'enquête et d'investigation des parlementaires américains peut parfois les conduire à prendre des initiatives diplomatiques exceptionnelles dans le but d'obtenir une meilleure compréhension des thèmes qu'ils étudient ainsi que pour établir des contacts à des degrés variés avec les différents acteurs impliqués, notamment en se rendant directement sur le terrain ${ }^{5}$.

Enfin, le Congrès américain dispose d'un grand levier pour influencer la politique extérieure notamment grâce à son pouvoir de validation du budget alloué à la politique étrangère du pays. Il dispose ainsi du pouvoir de refuser de financer ou de poursuivre le financement d'un projet ou d'une initiative si cette dernière ne lui convient pas. En relations internationales, ce pouvoir est d'autant plus important que certains traités internationaux nécessitent parfois des fonds importants, de même que la coopération technique et législative du Congrès pour leurs bonnes mises en application dans la législation américaine ${ }^{6}$.

\footnotetext{
${ }^{1}$ DEL MONTE, M. et PUCCIO, L. (2016). Rôle du Congrès des États-Unis dans les accords commerciaux, La procédure accélérée «Fast-Track procedure » (PE 577.999), Bruxelles, European Parliament Research Service ; JANČIĆ, D. (2016), op. cit. ; JANČIĆ, D. (2017), « TTIP and legislative-executive relations in EU trade policy », West European Politics, vol. 40, n 1, pp. 202-221.

${ }^{2}$ FERGUSSO, I.-F. (2015), « Trade Promotion Authority (TPA) and the Role of Congress in Trade Policy (RL33743) », Washington, Congressional Research Service; JANČIĆ, D. (2015), « Transatlantic Regulatory Interdependence, Law and Governance: The Evolving Roles of the EU and US Legislatures », Cambridge Yearbook of European Legal Studies, vol. 17, pp. 334-359.

${ }^{3}$ FERGUSSO, I.-F., op. cit.

${ }^{4}$ COURMONT, B., op. cit. ; JANČIĆ, D. (2015), op. cit.

${ }^{5}$ ROEHRIG, T. et WESSEL, L. A., op. cit. ; BERGBOWER, M. L. et SCHMITT, C. (2015), « Congressional Activism in the Foreign Policy Arena: A Case Study of the 1994 Rwandan Genocide », Democracy and Security, vol. 11, n 4, pp. 353-372 ; KANDEL, M., op. cit.

${ }^{6}$ COURMONT, B., op. cit.
} 


\section{2. Études des accords commerciaux}

Après avoir étudié la théorie entourant les compétences parlementaires en politique extérieure, il est temps d'analyser une série de cas pratiques dans l'optique de confirmer ou d'infirmer ces théories contingentes. Il faut cependant préciser que cette analyse se limitera à l'étude du respect et de l'application des compétences principales du Congrès et du Parlement européen en matière commerciale. Les éléments secondaires, mais importants, comme le rôle des partis politiques, l'influence des personnalités dirigeantes parlementaires, l'impact du pouvoir budgétaire et enfin l'influence des parlements nationaux ou des entités fédérées sur les accords commerciaux ne seront pas traités ici dans l'optique de ne pas perdre le fil conducteur de notre analyse.

\subsection{Le Parlement européen}

\section{a. TTIP}

Dès les premières phases de dialogue entre négociateurs, le Parlement européen a manifesté son souhait de s'impliquer dans le contenu des négociations du TTIP entre les ÉtatsUnis et l'UE. Ainsi durant l'année 2013, soit la première année des pourparlers, l'assemblée a rappelé rapidement à la Commission le rôle que les parlementaires devraient jouer et elle a également défini les objectifs, les priorités et les problématiques importantes auxquels il faudrait répondre afin que les futures négociations soient menées à bien. Cela s'est exprimé d'une part à travers sa résolution du 23 mai $2013^{1}$, mais également via ses différentes compétences d'information et d'enquête. Dans cette optique, l'audition de membres de la Commission européenne par 15 des 20 commissions parlementaires ou groupes de recherche différents a été cruciale pour maintenir au-devant de la scène ses demandes et pour faire évoluer les débats entourant les négociations ${ }^{2}$. Dans ces dernières, on peut y retrouver de nombreuses questions relatives à la transparence, ou plutôt au manque de transparence, des négociations entre la Commission et les négociateurs américains. Par ailleurs, l'assemblée a manifesté de sérieuses préoccupations concernant la nature du système de « règlement des différends entre un investisseur et un État » prévu par le traité. Les éléments connus de l'époque mettaient ainsi en avant une pratique juridique favorisant davantage les entreprises et étant contraire aux pratiques de règlements des différends en Europe. Elle a ainsi fait de la modification de ce système une condition sine qua non à sa ratification du traité ${ }^{3}$. Le Parlement a obtenu par ailleurs que soient mis en place des « gardes fous » portant sur certaines matières sensibles pour les consommateurs européens ${ }^{4}$.

\footnotetext{
${ }^{1}$ European Parliament, «EU trade and investment agreement negotiations with the US », Resolution, P7_TA (2013)0227, 23 May 2013.

${ }^{2}$ ROEDERER-RYNNING, C. (2017), « Parliamentary assertion and deep integration: the European parliament in the CETA and TTIP negotiations », Cambridge Review of International Affairs, vol. 30, n 5-6, pp. 507-526 ; European Parliament, «TTIP: Challenges and Opportunities for the Internal Market », Joint Public Hearing Committee on the Internal Market and Consumer Protection Committee on International Trade, http://www.europarl.europa.eu, 24 February 2015 ; Committees (2020), « Hearings », European Parliament Committees, https://www.europarl.europa.eu/committees/en/indexsearch.html?term=9\&query=TTIP ; European Parliament, «TTIP: What's in it for Europeans?», Public Hearing Committee on International Trade, DV $1053409 E N . d o c, 18$ March 2015.

${ }^{3}$ PUCCIO, L. (2016). Négociations UE/États-Unis sur le PTCI, Vue d'ensemble des questions en suspens (PE 586.606), Bruxelles, European Parliament Research Service ; JANČIĆ, D. (2016), op. cit.

${ }^{4}$ Ibid; European Parliament, «European Parliament's Recommendations to the European Commission on the Negotiations for the Transatlantic Trade and Investment Partnership (TTIP) », Resolution, P8_TA(2015)0252, 8 July 2015.
} 
Dans cette situation, la participation du Parlement européen est clairement visible et l'on constate également en regardant l'évolution du discours et des publications des représentants de la Commission européenne que les préoccupations de l'assemblée ont été largement prises en considération par ses négociateurs ${ }^{1}$. D'une part, à partir de 2015, notamment après la résolution du Parlement européen du 8 juillet dans laquelle il a exposé ses 69 préoccupations, recommandations et objectifs concernant le traité ${ }^{2}$, le contenu des négociations a été régulièrement publié et transmis aux parlementaires ${ }^{3}$. La publication de ces documents a rendu possible son contrôle et son évaluation par les parlementaires, ce qui leur a permis d'émettre des réserves sur différents points. Ensuite, face aux importantes critiques, le système de règlements des différends a été abandonné dans le traité et remplacé par un «tribunal de règlement des différends en matière d'investissement». Par ailleurs, une partie des revendications du Parlement ont été par la suite reprises dans la position officielle de la Commission pour les négociations ${ }^{4}$.

Pour bien comprendre ce qui a poussé et permis au Parlement européen de s'impliquer autant dans le processus de négociations, il faut prendre en compte l'extrême impopularité et inquiétude qui étaient ressentie par la société civile vis-à-vis de l'accord du TTIP ${ }^{5}$, notamment après la polémique entourant le système de règlement des différends en matière d'investissement. Ainsi fin 2014 la Commission Juncker, au fil de plusieurs sondages d'opinion ou de consultations populaires confirmant l'impopularité du TTIP et de son système de règlement des différends ${ }^{6}$, a fini par céder au besoin de transparence réclamé par le Parlement pour les négociations afin de lutter contre le caractère hautement impopulaire de l'accord. Pour Alina Alexoaei et Valentin Cojanu ce n'est donc pas la demande d'implication accrue du Parlement aux négociations commerciales qui poussa la Commission à réagir, mais bien la volonté de la nouvelle Commission Juncker de légitimer l'accord auprès de la société civile afin de faire face à la prolifération des discours de plus en plus nombreux de certains groupes politiques, au niveau européen ou au niveau des États, déclarant qu'ils n'allaient pas soutenir pas l'accord sans transparence au préalable. Via sa mauvaise campagne de communication autour du TTIP, la Commission a ainsi contribué à rendre nécessaire un contrôle législatif de

\footnotetext{
${ }^{1}$ European Commission (2015), «Dans un souci de transparence, la Commission européenne publie des textes juridiques concernant le TTIP », europa.eu, 7 janvier 2015, https://europa.eu/rapid/press-release IP-152980 fr.htm ; Malmström, C. (2014), «The Trade Commissioner and Parliament: A Vital Relationship », europa.eu, 3 décembre 2014, https://europa.eu/rapid/press-release_SPEECH-14-2348_en.htm ; European Commission (2015), «Présentation ce jour d'un rapport sur la consultation concernant la protection des investissements dans les négociations commerciales UE-Etats-Unis », europa.eu, 13 janvier 2015, https://europa.eu/rapid/press-release_IP-15-3201_fr.htm.

2 European Parliament, «European Parliament's Recommendations to the European Commission on the Negotiations for the Transatlantic Trade and Investment Partnership (TTIP) », Resolution, P8_TA(2015)0252, 8 July 2015.

3 European Commission (2016), «EU negotiating texts in TTIP », europa.eu, 14 juillet 2016, http://trade.ec.europa.eu/doclib/press/index.cfm?id=1230.

4 PUCCIO, L., op. cit.; European Commission (2016), «EU negotiating texts in TTIP», europa.eu, 14 juillet 2016, http://trade.ec.europa.eu/doclib/press/index.cfm?id=1230.

5 DUCOURTIEUX, C. (2016), «La galaxie hétéroclite des anti-TTIP », Lemonde, 16 septembre ; DUCOURTIEUX, C. (2016), «Les autorités peinent à convaincre les opinions publiques », Lemonde, 30 avril.

${ }^{6}$ European Commission. (2015). Online public consultation on investment protection and investor-to-state dispute settlement (ISDS) in the Transatlantic Trade and Investment Partnership Agreement(TTIP) (13.1.2015 SWD (2015) 3 final), Bruxelles, http://trade.ec.europa.eu/doclib/docs/2015/january/tradoc 153044.pdf ; European Commission (2014), « Online public consultation on investment protection and investor-to-state dispute settlement (ISDS) in the Transatlantic Trade and Investment Partnership Agreement (TTIP) », europa.eu, juillet 2014, http://trade.ec.europa.eu/consultations/index.cfm?consul_id=179 ; European Commission (2015), «Présentation ce jour d'un rapport sur la consultation concernant la protection des investissements dans les négociations commerciales UE-Etats-Unis », europa.eu, 13 janvier 2015, https://europa.eu/rapid/press-release IP-153201_fr.htm.
} 
l'accord ${ }^{1}$. Pour reprendre les propos de Christilla Roederer-Rynning « en exploitant le pouvoir de la mobilisation sociale, le Parlement européen n'a pas seulement concrétisé de manière concrète ses droits à une information complète découlant d'un traité. Il a également contribué, par son activisme juridique et constitutionnel, à ouvrir le processus décisionnel des négociations commerciales internationales et a obligé la Commission et le Conseil à accepter un degré de transparence accru $»^{2}$.

\section{b. CETA}

Les négociations pour le Comprehensive Economic and Trade Agreement (CETA) entre l'UE et le Canada ont débuté en mai 2009, quelques mois avant que les différentes réformes du traité de Lisbonne accordant un pouvoir de codécision au Parlement européen aient été entièrement mises en place. Ainsi, ce n'est que fin de la même année que le Parlement a entrepris d'exercer ses compétences en matière de contrôle et de supervision dans cette négociation commerciale. Néanmoins, du début des dialogues en 2009 jusqu'à la fin de ces derniers en 2014, le nombre d'interventions et de rapports parlementaires sur le CETA est resté relativement peu élevé si on le compare avec celui du TTIP. Par ailleurs, sur cette même période seule une commission parlementaire sur les 20 existantes s'est impliquée dans le contrôle du processus $^{3}$. Pour Chritilla Roederer-Rynning, si les interventions du Parlement européen sur les négociations ont été réelles, ces dernières étaient beaucoup moins communiquées au public que pour le TTIP, notamment en raison d'une certaine ignorance ou d'un désintérêt médiatique pour l'accord. Le Parlement lui-même avait souhaité se concentrer davantage sur le contrôle de l'action du Conseil et de la Commission plutôt que sur sa communication avec les citoyens européens et la société civile. Enfin, il a existé à l'époque parmi les parlementaires un sentiment partagé que le Canada était suffisamment proche culturellement et économiquement des pratiques européennes pour qu'il ne soit pas nécessaire de polémiquer sur le sujet. Il y a donc eu dans un premier temps un consensus d'adhésion à l'idée d'un partenariat économique avec ce pays ${ }^{4}$.

Une première confrontation entre le Parlement européen et la Commission a néanmoins débuté en 2011 notamment via l'apparition des premiers dossiers polémiques. Ainsi, les parlementaires ont progressivement commencé à s'intéresser à certaines informations communiquées sur le contenu du traité qui les ont conduites à faire une première série de réclamations et recommandations, notamment via la résolution du Parlement du 8 juin $2011 .^{5}$ C'est principalement dans cette dernière que l'assemblée a fixé ses préoccupations et guidelines majeures concernant l'accord avec le Canada. On y retrouve des préoccupations concernant la protection de la qualité des produits européens, la protection de l'environnement, mais également sur le respect de la nouvelle répartition des compétences accordant un plus grand rôle du Parlement européen dans les négociations. Il a ainsi été rappelé à l'exécutif son obligation de tenir les parlementaires informés au maximum sur l'évolution des négociations et, surtout, il y a été enjoint à la Commission d'attendre d'avoir reçu l'avis émis par le Parlement

\footnotetext{
1 ALEXOAEI, A. et COJANU, V. (2017), « Negotiating the Transatlantic deal: focus on the EU's domestic constraints », CES Working Papers, Centre for European Studies, Alexandru Ioan Cuza University, vol. 9, $n^{\circ} 3$, pp. 233-254.

${ }^{2}$ ROEDERER-RYNNING, C., op. cit.

Ibid.; European Parliament (2019), «European Parliament Committees », europa.eu, https://www.europarl.europa.eu/committees/en/parliamentary-committees.html.

${ }^{4}$ ROEDERER-RYNNING, C., op. cit.

5 European Parliament, «European Parliament resolution of 8 June 2011 on EU-Canada trade relations », Resolution, P7_TA(2011)0257, 8 June 2011.
} 
européen à chaque clôture de volet de négociations avant d'entamer le volet suivant. Règle que la Commission ne respectait pas avant la publication de cette note ${ }^{1}$.

Le point de friction le plus important a probablement été celui portant sur le volet « investissement» des négociations. L'un des impacts majeurs de l'implication du Parlement dans les négociations a ainsi été l'obtention en 2014-2015 la mise en place du Système Juridictionnel des Investissements (SJI) visant à régler les différends entre les États et les investisseurs et remplaçant le système de règlement des différends proposé par les négociateurs. Ce dernier ayant été très polémique parmi les parlementaires et parmi la société civile européenne car considéré comme trop intrusif, la polémique a par ailleurs porté sur le même sujet lors des négociations du TTIP ${ }^{2}$. Si ce nouveau système est resté lui aussi très polémique, il n'en reste pas moins que les négociateurs ont pris au sérieux l'avis négatif du Parlement européen sur ce sujet lorsque ce dernier a affirmé que l'accord ne serait pas adopté tant que le précédent système serait présent dans le traité. Par ailleurs, les parlementaires ont obtenu en 2015 la publication officielle du descriptif du mandat accordé par le Conseil à la Commission pour négocier ${ }^{3}$.

Il est intéressant de noter ici que les concessions majeures obtenues par le Parlement l'ont été après la clôture des négociations en 2014. Deux points peuvent expliquer cette réaction assez tardive du Parlement, de même que les concessions obtenues. D'une part, à la clôture des négociations du CETA en 2014, le public et les médias ont pris conscience de l'existence de ce traité et de nombreux parallèles ont été faits avec le TTIP 4 , contribuant à rendre l'accord d'emblée polémique. D'autre part, après la conclusion des négociations, le manque de transparence et de communication de la Commission a rapidement été critiqué et utilisé pour expliquer l'absence de suivi de l'évolution des négociations par le public européen ${ }^{5}$. Dès lors, face à ces polémiques, le Parlement a su une fois encore rebondir sur ces dernières afin d'émettre de nouvelles revendications ne pouvant être ignorées par la Commission.

Au terme des négociations, l'opinion du Parlement européen sur son implication dans le processus de négociation et sur la transparence de ces dernières s'est voulue globalement positive. Dans un rapport émis en 2017, il a ainsi constaté avoir largement pu exprimer ses idées et remarques dans la deuxième partie des négociations et il y a reconnu les efforts réalisés par la Commission en matière de transparence et pour tenir compte de l'avis des parlementaires alors même que l'accord avait déjà été conclu' 6 .

Avant sa ratification par le Parlement, plusieurs commissions parlementaires ont finalement pu s'exprimer sur le contenu du traité. Si la grande majorité de celles-ci ont approuvé la ratification du traité grâce aux mesures de protection prises par les négociateurs dans les secteurs sensibles, la Commission parlementaire de l'emploi et des affaires sociales du Parlement européen, elle, s'y est opposé ${ }^{7}$. Enfin, une délégation de la commission parlementaire chargée du commerce extérieur s'est rendue en mars 2016 à Ottawa dans l'optique de dialoguer

\footnotetext{
${ }^{1}$ SCHÖLLMANN, W. (2017), Briefing International Agreements in Progress: Comprehensive Economic and Trade Agreement (CETA) with Canada (PE 595.895), Bruxelles, European Parliament Research Service ; ROEDERER-RYNNING, C., op. cit.

${ }^{2}$ Ibid.

${ }^{3}$ European Parliament. (2019), EU-Canada comprehensive economic and trade agreement (CETA), (Legislative Train $\mathrm{n}^{\circ} 07.2019$ 6A), Bruxelles, https://www.europarl.europa.eu/legislative-train/api/stages/report/072019/theme/a-balanced-and-progressive-trade-policy-to-harness-globalisation/file/ceta.

${ }^{4}$ STEHRER, R. et STÖLLINGER, R. (2016), « CETA and TTIP: same-same but different? », Vienna Institute for International Economic Studies, 6 septembre ; ALEXOAEI, A. et COJANU, V., op. cit., pp. 233-254.

${ }^{5}$ DUCOURTIEUX, C. (2018), «Europe : Bruxelles contrainte à la transparence sous la pression des opinions publiques », Lemonde, 19 mai.

${ }^{6}$ SCHÖLLMANN, W., op. cit.

${ }^{7}$ VINCENTI, D. (2016), « Parliament committee gives CETA thumbs down », euractiv, 9 décembre.
} 
avec les différents groupes et représentants de la société canadienne ${ }^{1}$. De plus, le Parlement européen et le Parlement canadien ont annuellement effectué des réunions interparlementaires. Il ne s'agissait cependant pas de négociations, mais d'échanges visant à améliorer la communication et les compréhensions réciproques entre les deux institutions. Le CETA, bien que peu présent dans les discutions, y a été débattu quant à son image désastreuse dans l'opinion publique et quant aux dernières évolutions dans son contenu ${ }^{2}$. Aucune forme de négociations ou d'impact concret dans le contenu de l'accord ne peut donc en être retirée de ces différents échanges interparlementaires. Au final le traité a été approuvé par le Parlement européen en février $2017^{3}$.

On peut finalement retenir que si elles ne l'étaient pas au début, les négociations du TTIP et du CETA sont devenues par la suite extrêmement liées pour plusieurs raisons. D'une part, leurs négociations respectives se sont déroulées soit de manière concomitante, soit de manière successive. Par ailleurs, le contenu des échanges et des dossiers négociés a été similaire sur de nombreux points et caractéristiques dans les deux traités. Enfin, les polémiques les entourant ont été également semblables, notamment au niveau du système de règlement des différends et du débat sur la transparence. De ce fait, les concessions obtenues par le Parlement pour l'un des dossiers ont été transposées également dans l'autre. En contrepartie, les polémiques associées à l'un des accords en cours de négociation se sont vues également transvasées aux négociations pour l'autre ${ }^{4}$. On peut retenir au final que le point de divergence entre les deux processus fut le début de la période d'implication parlementaire soutenue. Si pour le CETA elle a été tardive, elle a par contre été très intense dès le début des échanges pour le TTIP.

\subsection{Le Congrès américain}

\section{a. TTIP}

Le Congrès américain a de prime abord exprimé un avis favorable sur les négociations entre les États-Unis et l'UE dès 2013. Via une résolution parlementaire, il a ainsi apporté son appui à l'initiative présidentielle et il a par ailleurs recommandé que ce dernier maintienne le Congrès informé sur l'évolution des négociations ${ }^{5}$. Cependant, la véritable mobilisation et implication concrète du Congrès américain dans les négociations sur le TTIP a eu lieu d'une manière différente et plus tardive que pour le Parlement européen. Il a en effet fallu que soit d'abord négociée entre les parlementaires et le président la mise en place de la procédure de

\footnotetext{
${ }^{1}$ Committee on International Trade. (2016). Mission Report: Following the ad-hoc delegation to Canada (Ottawa and Montreal) from 21 to 23 March 2016 ( CR\1089805EN.doc PE578.851v01-00), Bruxelles, European Parliament, https://www.europarl.europa.eu/cmsdata/102098/Canada_Mission_Report.pdf.

2 European Parliament Delegation for Relations with Canada (2019), «Welcome from the former Chair », europa.eu, https://www.europarl.europa.eu/delegations/en/d-ca/home; European Parliament Delegation for Relations with Canada. (2014), Delegation for Relations with Canada 36th EP-Canada Inter-Parliamentary Meeting Brussels 13 November 2014 (Mission Report of 2014), Bruxelles, European Parliament, https://www.europarl.europa.eu/cmsdata/124161/Report\%2036th\%20EP-Canada\%20IPM.pdf ; European Parliament Delegation for Relations with Canada. (2017), Delegation for Relations with Canada 37th EU-Canada Inter-Parliamentary Meeting Ottawa, Quebec and Montreal 16-20 May 2016 (Mission Report of 2016), Bruxelles, European Parliament, https://www.europarl.europa.eu/cmsdata/124140/Mission\%20report.pdf.

${ }^{3}$ European Parliament (2017), « CETA: MEPs back EU-Canada trade agreement », europa.eu, 2 février 2017, http://www.europarl.europa.eu/news/en/press-room/20170209IPR61728/ceta-meps-back-eu-canada-tradeagreement.

${ }^{4}$ ROEDERER-RYNNING, C., op. cit. ; ALEXOAEI, A. et COJANU, V., op. cit.

${ }^{5}$ US House of Representatives, « Expressing the sense of the House of Representatives that the United States and the European Union should pursue a Transatlantic Trade and Investment Partnership », Resolution, H.Res.76 $\left(113^{\text {th }}\right), 15$ February 2013.
} 
ratification simplifiée du traité. Grâce à celle-ci, le Congrès a pu s'impliquer officiellement dans l'analyse et l'évaluation du contenu des négociations dès que le mandat définissant ses objectifs, priorités, attentes et préoccupations concernant les négociations commerciales a été adopté. Néanmoins, cette procédure n'a été mise en place qu'en 2015, soit deux ans après le début des négociations, ces dernières ayant déjà bien avancé ${ }^{1}$. Néanmoins, des séances de briefing sur l'évolution des discussions avaient néanmoins été organisées épisodiquement dès 2013 par les négociateurs afin de briefer les parlementaires américains ${ }^{2}$.

Dès 2015, à travers des auditions parlementaires initiées par les différentes commissions internes des deux chambres, les parlementaires ont pu soumettre leurs préoccupations et interrogations aux négociateurs et experts en matière de commerce ${ }^{3}$. En autorisant la mise en place de la "trade promotion authority ", le Congrès a ainsi pu fixer de manière officielle les critères que l'exécutif se devait de respecter pour que l'accord soit adopté, lui donnant ainsi une influence indirecte, mais concrète sur le contenu de l'accord étant négocié.

Néanmoins, le mandat qui a été accordé en juin 2015 au président pour négocier des accords commerciaux n'était pas spécifique au TTIP, mais avait un caractère général destiné à l'ensemble des accords commerciaux négociés par le président sur une période comprise entre 2015 et le $1^{\text {er }}$ juillet 2018. Le Congrès a dès lors renoncé comme prévu à toute possibilité d'amender lui-même directement l'accord une fois celui-ci conclu. Il a en plus de cela cadré sa propre marge de manœuvre car il lui était impossible d'apporter, en plus des préoccupations développées dans la "trade promotion authority", d'éventuels nouveaux volets de préoccupations spécifiques au TTIP dans les négociations en cours ou après la conclusion éventuelle de celles-ci comme ce fut le cas du Parlement européen pour le TTIP et le CETA ${ }^{4}$.

Au-delà d'une définition de ses priorités, cette procédure lui a également permis d'obtenir un cadre légal faisant valoir son droit à être informé dans la suite de la procédure de négociation. Un représentant officiel chargé de faire respecter cette transparence a ainsi été nommé, de même que deux conseillers spéciaux représentants pour l'un la Chambre des représentants et pour l'autre le Sénat. Ces derniers étant affectés auprès du bureau du représentant américain au commerce extérieur (USTR) chargé des négociations ${ }^{5}$. De manière générale, la pratique des négociateurs américains lors de négociations commerciales est de garder la stratégie et la feuille de route des pourparlers secrètes afin de faciliter la tâche des diplomates. Dans cette optique, l'accès aux documents de négociation du TTIP a ainsi été strictement limité ${ }^{6}$. Néanmoins, de par la nature de la «trade promotion authority », il est avéré que le bureau du représentant au commerce américain a transmis en partie ces informations aux parlementaires et qu'il a fait preuve de plus de transparence que par le passé sur le contenu des négociations ${ }^{7}$. Cependant, pour certains parlementaires cette transparence a été très imparfaite

\footnotetext{
${ }^{1}$ US Congress, « Bipartisan Congressional Trade Priorities and Accountability Act of 2015 », Public Law, 114$26\left(114^{\text {th }}\right)$, Congress, 29 June 2015.

${ }^{2}$ Giovenco, A. (2013), « Chief U.S. and EU Negotiators Brief Congressional Staff on the First Round of TTIP Negotiations », Tradewinds, the official blog of the United States Trade Representative, juillet 2013, https://ustr.gov/about-us/policy-offices/press-office/blog/2013/july/negotiators-brief-hill-ttip.

${ }^{3}$ US House of Representatives, «U.S. Trade Policy Agenda », Hearings Before the Committee of Ways and Means, 114-FC02 $\left(114^{\text {th }}\right)$, 27 January 2015 ; United Sates Senate (2020), « Hearings \& Meetings », senate.gov, https://www.senate.gov/committees/hearings_meetings.htm; US House of Representatives Ways and Means' committee (2015), «Hearing on Trade», Way \& Means Committee, 22 Avril 2015, https://waysandmeans.house.gov/legislation/hearings/hearing-trade ; US House of Representatives, « Expanding American Trade with Accountability and Transparency », Hearings Before the Committee of Ways and Means, 114-FC04 (114 $\left.{ }^{\text {th }}\right)$, Congress, 22 April 2015.

${ }^{4}$ PUCCIO, L., op. cit.

${ }^{5}$ Le représentant américain au commerce est membre de l'exécutif américain.

${ }^{6}$ DAVIES BOREN, Z. (2015), « TTIP controversy: Secret trade deal can only be read in secure 'reading room' in Brussels », TheIndependent, 4 août.

${ }^{7}$ JANČIĆ, D. (2015), op. cit.
} 
et l'on a ainsi assisté à plusieurs polémiques concernant les documents transmis. Ces derniers étant critiqués pour leur contenu trop général ou approximatif. Le manque de transparence de l'exécutif a dès lors été très contesté dans le chef des parlementaires américains ${ }^{1}$.

Malgré tout, on a pu constater une certaine volonté de la part du Congrès à voir un accord aboutir et à poursuivre leur travail avec le représentant américain au commerce ${ }^{2}$.

Parallèlement, une coopération renforcée avec les parlementaires européens a également été encouragée par les représentants américains, notamment à travers le TLD et via plusieurs visites réciproques de délégations parlementaires au sein des assemblées et comités respectifs des deux groupes de négociateurs. Néanmoins, il apparait que si cette institution a permis l'échange d'informations et de point de vue entre parlementaires, il y a eu un manque important d'impact de la coopération interparlementaire sur les négociations ${ }^{3}$.

Les négociations du TTIP ont été mises en pause en 2017 après la prise en charge du nouvel exécutif américain se voulant beaucoup moins favorable aux traités de libre-échange. Il est intéressant de noter que les négociations n'ont pas été officiellement abandonnées, mais bien suspendues pour une durée indéterminée. Il semble cependant peu probable de les voir repartir sur base de ce qui avait déjà été négocié 4 .

\section{b. TPP}

Concernant le TPP, le contenu des négociations des États-Unis avec les pays de la région d'Asie-Pacifique et d'Amérique a pendant très longtemps été gardé secret par l'exécutif américain, ce qui a entrainé nombre de critiques tant dans le chef des parlementaires américains que dans le chef des assemblées des différentes Nations associées aux discussions ${ }^{5}$. Ainsi, les

\footnotetext{
${ }^{1}$ ILIAS AKHTAR, S. et JONES, V. (2014). Transatlantic Trade and Investment Partnership (T-TIP) Negotiations (R43387), Washington, Congressional Research Service, https://fas.org/sgp/crs/row/R43387.pdf.

${ }^{2}$ United States Senate Committee on Finance (2016), « Hatch, Brady Send Letter to USTR as TTIP Negotiations with EU Resume », US Senate Committee on Finance, 3 octobre 2016, https://www.finance.senate.gov/chairmans-news/hatch-brady-send-letter-to-ustr-as-ttip-negotiations-with-euresume ; JANČIĆ, D. (2015), op. cit.

${ }^{3}$ European Parliament Liaison Office in Washington DC (2013, April 11), « Transatlantic Trade and Investment Partnership: MEPs gauge 'increasingly positive mood' in Washington, outline key EU interests », europa.eu, 11 April 2013,

www.europarl.europa.eu/us/en/news events/news/news_2013/news_apr_2013/ttip_eu_interests.html ; European Parliament (2014), «Politics \& Policies - April $2014 », \quad$ europa.eu, 10 Avril 2014, https://www.europarl.europa.eu/unitedstates/en/eplo-news/politics-policies-april-2014; $\quad$ ARC (2014), «Transatlantic Dialogue between legislators on TTIP in European Parliament», Arc 2020, 21 juillet 2014, www.arc2020.eu/front/2014/07/transatlantic-dialogue-between-legislators-on-ttip-in-the-european-parliament ; European Parliament \& US House of Representatives. (2013), 74TH Inter-parliamentary meeting: Transatlantic Legislators' Dialogue Statement of 2013), Bruxelles, https://www.europarl.europa.eu/cmsdata/122911/TLD\%20June\%202013.pdf (consulté en août 2019) ; European Parliament \& US House of Representatives. (2014). 75TH Inter-parliamentary meeting: Transatlantic Legislators'

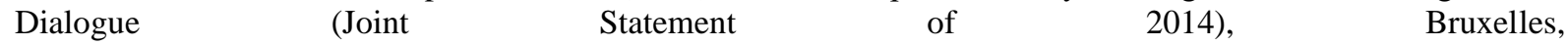
https://www.europarl.europa.eu/cmsdata/122912/TLD\%20March\%202014.pdf (consulté en août 2019); European Parliament \& US House of Representatives. (2015). 77TH Inter-parliamentary meeting: Transatlantic Legislators' Dialogue (2nd Joint Statement of 2015), Bruxelles, https://www.europarl.europa.eu/cmsdata/122148/Joint_Statement_EU-US_IPM 4-5_Nov_2015.pdf (consulté en août 2019).

${ }^{4}$ LAROCCO, L. A. (2017), « Wilbur Ross says he's 'open to resuming' talks on mega-trade deal with Europe », CNBC, 30 mai.

${ }^{5}$ NEW, W. (2012), « US Congress Members Demand Access To TPP; ACTA Criticised In Australia », Intellectual Property Watch, 27 juillet; ERMERT, M. (2015), « TPP Heads Into Ratification Game », Intellectual Property Watch, 6 octobre.
} 
négociations impliquant les États-Unis ont débuté en 2008 et, mis à part quelques fuites d'informations ${ }^{1}$, l'entièreté du contenu de ces dernières n'a été rendu publique qu'en novembre 2015, soit une fois que les négociations se sont terminées ${ }^{2}$. Ce manque de transparence a créé de nombreuses inquiétudes sur des sujets divers et variés dans le chef de la société civile américaine ainsi que dans le chef de plusieurs parlementaires américains relayant cette dernière. Inquiétudes par ailleurs similaires à celles qui ont été émises contre le TTIP à la même époque, mais avec cependant plus de virulence de la part des opposants à l'accord et avec davantage d'impact sur l'opinion publique'.

Si le président Barack Obama a remporté plusieurs victoires sur ce dossier, notamment lorsque le Congrès a adopté un nouveau «trade act» en juin 2015 initiant ainsi la procédure de ratification simplifiée, ainsi qu'une seconde victoire en novembre de la même année en ayant réussi à achever les négociations du TPP, il n'a jamais obtenu de vote du Congrès sur le document final de cet accord commercial ${ }^{4}$. Plusieurs raisons sont avancées pour donner une explication à cet échec.

D'une part, les négociations ont été maintenues secrètes pendant une très longue période et leur contenu n'a été complètement divulgué qu'en novembre 2015. Au cours des années précédentes, le Congrès a tenté en vain à plusieurs reprises d'obtenir des détails sur celles-ci. Ainsi, des auditions parlementaires ont eu lieu et de nombreux membres du Congrès ont exprimés leurs points de vue et préoccupations sur les négociations via des lettres publiques ainsi qu'au travers de consultations directes avec les membres de l'administration et de groupes d'influence ${ }^{5}$. Certaines séances de consultation de l'accord ont également été organisées avant la mise en place de la «trade promotion autority », néanmoins le nombre de parlementaires y ayant eu accès a été extrêmement limité et les conditions de consultations ont été très strictes afin de maintenir le secret sur le contenu de $1^{1}$ accord ${ }^{6}$. À terme, les différentes interventions et actions au Congrès ont eu peu d'impact sur l'attitude de l'exécutif, le manque de transparence des négociations s'est maintenu durant tout le processus diplomatique, augmentant et confortant le nombre d'opposants à cet accord tant dans le camp des législateurs démocrates, que dans celui des législateurs républicains ${ }^{7}$.

Une fois que les négociations ont été terminées et que l'accord commercial a été signé en février 2016 par le président, la suite logique aurait été la mise en place au Congrès de discussions sur la transposition du contenu du traité dans le droit américain, puis sur sa ratification par les deux chambres législatives ${ }^{8}$. Néanmoins, les élections présidentielles américaines sont venues chambouler ce processus. En effet, le mandat de Barack Obama arrivant à terme fin 2016, le président n'a disposé que d'une année pour faire adopter le TPP avant de voir son mandat se terminer. Sachant que l'ensemble des candidats à la présidentielle

1 THE GUARDIAN (2013), «WikiLeaks publishes secret draft chapter of Trans-Pacific Partnership », TheGuardian, 13 ovembre ; Wikileaks (2014), « Updated Secret Trans-Pacific Partnership Agreement (TPP) - IP Chapter (second publication) », wikileaks, 16 octobre 2014, https://wikileaks.org/tpp-ip2/.

${ }^{2}$ BINDER, K. (2017). Briefing: From TPP to new trade arrangements in the Asia-Pacific region (PE 603.953), Bruxelles, European Parliament Research Service.

${ }^{3}$ WILLIAMS, B.-R. et FERGUSSON, I.-F. (2018). TPP: Overview and Current Status. (IF10000 Version n ${ }^{\circ} 28$ ), Washington, Congressional Research Service.

${ }^{4}$ US Congress, « Bipartisan Congressional Trade Priorities and Accountability Act of 2015 », Public Law, 114$26\left(114^{\text {th }}\right)$, Congress, 29 June 2015.

${ }^{5}$ CALMES, J. (2015), «Trans-Pacific Partnership Is Reached, but Faces Scrutiny in Congress », The New York Times, 6 octobre ; SCHWARZ, J. (2015), « You Can't Read the TPP and You Can't Find Out Who in Congress Has », The Intercept, 13 juin.

${ }^{6}$ DOVERE, E.-I. (2015), « Extreme secrecy eroding support for Obama's trade pact », Politico, 5 avril.

${ }^{7}$ CALMES, J. (2016), « T.P.P. Faces Rough Road in Congress », The New York Times, 2 septembre ; CALMES, J., op. cit., 6 octobre 2016.

8 Office of the United States Trade Representative (2015), «TPP Congressional Timeline », USTradeRepresentative.gov, https://ustr.gov/Congressional-Timeline-TPP. 
s'y étaient progressivement opposés, le président a cherché durant cette période à voir le traité ratifié pour après les élections américaines et avant la mise en place des nouvelles assemblées et du nouvel exécutif américain ${ }^{1}$. Ce délai d'un an, combiné avec les élections américaines ont été déterminant pour expliquer la non-ratification par le Congrès.

En effet, la consultation du Congrès sur ce dossier est arrivée doublement trop tard et dans de mauvaises conditions. Trop tard de prime abord car, les négociations étant déjà achevées, le Congrès et les parlementaires n'ont à priori disposé que d'une très faible marge de manœuvre pour influencer le contenu de l'accord lorsqu'ils ont finalement pu s'inclure dans le processus. Ainsi, l'assemblée n'a pu que débattre sur le bien-fondé ou non des dispositions du document, sans avoir suffisamment le temps d'évaluer l'ensemble des conséquences possibles de la ratification et sans pouvoir discuter en profondeur d'une évolution de certains points avec le Président. Ce qui, étant donné le caractère très impopulaire de l'accord, a rendu la ratification rapide improbable car très risquée au vu de son impact potentiellement négatif, politiquement et économiquement ${ }^{2}$.

L'implication des parlementaires est également arrivée trop tard car, les élections présidentielles et législatives américaines étant en approche, il aurait été possible que le suffrage change les compositions politiques dans les deux chambres législatives, décourageant les implications parlementaires approfondies avant celles-ci. Par la suite, le Congrès a été peu motivé à ratifier le traité après les élections législatives/présidentielles de novembre 2016 comme le Président le souhaitait et avant la mise en place du nouveau Congrès en janvier 2017 de par le caractère illégitime et polémique que cela aurait donné à la ratification. D'autant plus que l'opposition au traité était devenue majoritaire parmi les législateurs ${ }^{3}$. Par ailleurs, il s'est avéré évident que le prochain président, démocrate ou républicain, allait tenter de remettre en cause certaines dispositions du traité.

Il est enfin intéressant de noter que les plus gros rapports du centre de recherche du Congrès sur l'impact du TPP et du TTIP sont parus seulement en 2016, même si des rapports intermédiaires existaient déjà avant ${ }^{4}$. Dans le cas du TPP, la sortie de ce rapport en juin 2016 a montré une fois encore l'implication tardive des parlementaires dans les débats sur le contenu du traité. On peut ainsi y retrouver le constat d'une forme d'impuissance de leur part à influencer l'accord ${ }^{5}$. Néanmoins, le Congrès américain a tenté tout de même d'effectuer son travail de supervision et d'analyse en déterminant si les effets de ratification du traité auraient été favorables ou non aux intérêts américains ${ }^{6}$. Ces derniers étant importants tant en cas de rejet qu'en cas d'adoption pour les États-Unis, le rapport de l'époque a souligné la nécessité de poursuivre plus longuement les travaux d'analyses et d'études sur la mise en œuvre du traité avant d'établir un constat définitif. Cela montre donc que le Congrès américain n'était pas prêt à ratifier le traité à court terme et il est très probable, comme le soulignent beaucoup d'analystes,

\footnotetext{
${ }^{1}$ Ballotpedia (2016), « 2016 presidential candidates on the Trans-Pacific Partnership trade deal », Ballotpedia, https://ballotpedia.org/2016 presidential candidates on the Trans-Pacific Partnership trade deal ; FRASURE, W. G. (2016), « Presidential Election Campaign Dims Prospects for TPP », TheDiplomat, 18 mai ; RITTER, M. (2016), « Approval of TPP in US Congress Seen as Difficult », Learning English, 28 mai.

${ }^{2}$ MCCARTIN, M. et MCCLURE, K. (2016), « What's Next for TPP: Will Congress Ratify in 2016? », global policy watch, 21 janvier; BINDER, K, op. cit.

${ }^{3}$ MARANS, D. (2016), « Progressives Gear Up To Kill TPP In Lame-Duck Congress », The Huffington Post, 19 août ; MCCARTIN, M. et MCCLURE, K., op. cit. ; BINDER, K., op. cit.

${ }^{4}$ WILLIAMS, B.-R. et FERGUSSON, I.-F. (2016), The Trans-Pacific Partnership (TPP): Key Provisions and Issues for Congress (R44489), Washington, Congressional Research Service ; ILIAS AKHTAR, S., JONES, V. et JOHNSON, R. (2016), Transatlantic Trade and Investment Partnership (T-TIP) Negotiations (R43387), Washington, Congressional Research Service.

${ }^{5}$ WILLIAMS Brock R., FERGUSSON Ian F., op. cit.

${ }^{6} \mathrm{Ibid}$.
} 
que l'accord n'aurait pas été ratifié par les parlementaires si Obama avait choisi de le soumettre à un vote de ratification, les forçant à se prononcer après 60 jours de débats ${ }^{1}$.

On peut donc dire que l'impact véritable du Congrès a été de tempérer radicalement le processus de ratification, ce qui a donné le temps au traité de devenir encore davantage un symbole des pertes progressives d'emploi aux États-Unis dans le domaine de la manufacture durant la campagne présidentielle américaine. Cela eu pour conséquences de décourager le Congrès, ainsi que le président Obama, de soumettre le traité à un vote de ratification avant l'élection d'un nouveau président et avant la mise en place des nouveaux députés et sénateurs ${ }^{2}$.

\section{Conclusion}

Peut-on dire au terme de cette analyse qu'il existe une influence claire des parlementaires européens et américains sur la diplomatie menée par les États, ou organisations régionales dans le cas de l'UE, dans la conclusion des traités commerciaux internationaux ?

La réponse est positive. On a pu le constater à plusieurs reprises à travers les différents terrains analysés. Via d'importants travaux de contrôle, d'évaluation et de supervision des négociations par les parlementaires, les institutions législatives peuvent réussir à créer le débat, à rebondir sur des polémiques, à définir leurs priorités et objectifs, à remettre en cause certains points ou décisions des traités négociés, à émettre des demandes et revendications, à discuter avec l'exécutif et au final à se faire entendre par ce dernier si elles en ont suffisamment la volonté. On a ainsi pu découvrir que grâce à ces pressions formelles et informelles de la part des pouvoirs législatifs, mais surtout de la part de la société civile, l'exécutif prend en compte les revendications des parlementaires représentant de cette dernière. Ou tout de moins il tend à le faire. L'augmentation de la transparence des négociations du TTIP et du CETA dans le cas du Parlement européen en est un exemple, de même que la définition des objectifs de négociations du TTIP via le TPA par le Congrès. Il est donc possible qu'une assemblée ait un réel impact sur l'orientation de la diplomatie commerciale de son pays. C'est d'autant plus le cas lorsque l'action ou la légitimité de l'exécutif et de l'accord est contestée ou remise en cause et que le positionnement des chambres législatives est nécessaire pour la ratification du traité, sa mise en œuvre ou son financement.

Le Parlement européen dispose ainsi dans les traités fondateurs de l'UE d'un pouvoir de véto sur les accords commerciaux, ce qui est également le cas du Congrès américain lorsque ce dernier se trouve impliqué via la procédure législative permettant d'adopter un «congressional-executive agreement». Cette dernière tend à être privilégiée par les Américains pour la légitimité démocratique qu'elle confère ou renforce à un accord. L'analyse du TPP a, à ce titre, montré que cette procédure de ratification était grandement compromise si l'exécutif fait cavalier seul dans les négociations sans impliquer suffisamment le Congrès, en l'impliquant trop tardivement ou en ne lui laissant assez de temps pour évaluer le contenu de l'accord final.

Néanmoins il faut cependant émettre des réserves à cette influence. On ne peut ainsi systématiser ces conclusions à l'ensemble des assemblées parlementaires des pays démocratiques et à l'ensemble des accords commerciaux devant être ratifié par le Congrès et le Parlement européen. La marge de manœuvre d'une assemblée législative va dépendre du système dans lequel elle évolue, de sa volonté à participer aux négociations, du contexte politique dans lequel l'accord est négocié et ratifié et enfin elle va dépendre de la complaisance de l'exécutif vis-à-vis du respect strict ou souple des règles de processus de négociation. L'implication d'un parlement n'est donc pas systématique à chaque État et sur chaque sujet. Si

\footnotetext{
${ }^{1}$ FRASURE, W. G., op. cit.

${ }^{2}$ Ibid.; MARANS, D, op. cit.; MORTIMER, C. (2016), « Trans-Pacific trade deal will not be passed by Congress before inauguration, White House admits », TheIndependent, 13 novembre.
} 
le Parlement européen a gagné sa participation dans les négociations commerciales du TTIP et du CETA grâce à une interprétation extensive de ses compétences et grâce à la bonne volonté de l'exécutif européen au vu du besoin croissant de conférer une légitimité démocratique aux accords commerciaux, il n'existe cependant dans les faits aucune règle formelle qui impose de pérenniser cette implication à un tel degré pour chaque accord commercial. Il serait donc possible que pour d'autres accords son influence soit plus limitée s'il n'est pas motivé à s'impliquer davantage que le nécessaire. Cela a d'ailleurs failli être le cas pour le CETA comme on a pu le voir.

À l'inverse, aux États-Unis l'exécutif est obligé légalement et juridiquement de donner une influence au Congrès dans la négociation du traité lorsque la procédure de «fast track » est initiée via la "trade promotion autority ». Néanmoins, la présence de cette règle ne veut pas dire pour autant que l'exécutif va l'appliquer au mieux. Ainsi l'implication du Congrès a été mise en œuvre quelques mois à peine avant que les négociations du TTP soient conclues, sans que l'une ou l'autre chambre législative ait pu avoir accès dans son ensemble et de manière approfondie au contenu du traité. On a pu constater que l'assemblée a été incapable, de par le mandat qu'elle avait accordé précédemment, de modifier par elle-même le contenu du traité et qu'elle n'avait par ailleurs, une fois une certaine période de temps écoulée, aucune motivation à s'impliquer davantage dans celui-ci pour qu'il soit modifié ou ratifié ; contrairement au Parlement européen qui a réussi à faire entendre ses revendications après la conclusion des négociations sur le CETA. La différence ici est que l'assemblée désirait majoritairement que le traité soit ratifié à terme, mais avec des modifications et clarifications. Ce qui fut le cas. On peut se demander dans le cas du Congrès américain si ce dernier aurait pu de la même manière réclamer certaines modifications ou interprétations sine qua non à la ratification du traité, s'il avait obtenu plus de temps pour l'analyser, s'il avait été inclus plus tôt dans les négociations et si cette assemblée avait eu effectivement la volonté de ratifier l'accord final. Ce fut par exemple le cas en janvier 2020 pour l'accord renégociant la zone de libre-échange nord-américaine où le Président a soumis une nouvelle version de l'accord après avoir négocié avec les parlementaires américains ${ }^{1}$. Le contexte et la mobilisation du pouvoir législatif sont donc deux données essentielles.

Par ailleurs, l'on a pu voir avec le CETA que l'influence d'une assemblée est beaucoup plus limitée si le Parlement ne communique pas et si l'accord ne suscite pas d'intérêt de la part du public ou reste relativement ignoré de celui-ci. A contrario, dans le cas présent, à partir du moment où la polémique a éclaté, le Parlement a finalement remis en cause une partie du contenu de l'accord négocié et exigé des réformes.

Dès lors, si l'on peut affirmer qu'il y a une implication croissante des assemblées dans les matières internationales, cela se fait à des échelles différentes en fonction des différents États concernés. Si on a pu voir une participation importante du Parlement européen dans les négociations commerciales étudiées, cette implication s'est faite de manière plus limitée pour les cas ciblant le Congrès des États-Unis. Celui-ci a bien fixé des objectifs et critères à faire remplir et a pu utiliser son pouvoir de supervision, mais son impact concret reste lui beaucoup moins visible dans le processus de négociations et sur le contenu des traités que dans le cas du Parlement européen car, contrairement à ce dernier, les parlementaires américains n’ont pas su tirer profit de l'impopularité des accords pour obtenir davantage de transparence ou d'implication du fait de la nature de la «fast track procedure » ou et de leur manque de motivation à voir un accord aboutir. Si l'on ne peut affirmer que cette situation est généralisable à l'ensemble des accords commerciaux américains, de par le faible nombre de cas analysés, il n'en reste pas moins une réalité dans les cas présents.

\footnotetext{
${ }^{1}$ COCHRANE, E. et SWANSON, A. (2019), « Trump Aides and Democrats Agree on Trade Pact With Mexico and Canada », The New York Times, 10 décembre.
} 
Par ailleurs, malgré cette participation du pouvoir législatif aux affaires de politique extérieure commerciale, on ne peut affirmer que les parlementaires sont devenus des diplomates. La meilleure manière pour une assemblée législative d'influencer l'exécutif n'est pas d'agir au niveau international, en dialoguant avec d'autres parlements ou en tentant d'établir des contacts diplomatiques, mais bien en soumettant ou en reprenant à son compte certaines pressions sur les négociateurs au niveau national, tout en appliquant ses compétences internes via les commissions parlementaires ou les débats en interne. On a pu voir le faible écho des relations interparlementaires américo-européenne ou canado-européenne sur le TTIP et le CETA, contrairement aux auditions parlementaires et aux déclarations ou avis des deux assemblées sur l'avancée des négociations. Finalement, l'utilisation de l'arme du droit de véto parlementaire sur un accord, élément de pouvoir le plus important des assemblées, reste un outil législatif à visée national, mais dont l'impact se veut international.

Il convient dès lors de tenir compte de l'influence des assemblées législatives sur la diplomatie des États en considérant l'ensemble des éléments venant d'être décrits dans la phase finale de cette analyse. Il est difficile d'affirmer que les tendances identifiées dans cette analyse se maintiendront, augmenteront ou diminueront pour les futures négociations commerciales internationales car, d'une part, la politique internationale est toujours soumise à de nouveaux développements, et d'autre part, la capacité d'apprentissage et d'adaptation des parlementaires sur ces questions est importante et pourrait évoluer de plusieurs manières par la suite. Les perspectives d'analyse restent donc très nombreuses dans le cadre de l'étude du rôle des assemblées parlementaires en politique commerciale extérieure et leur nombre ne manquera pas d'augmenter dans les années à venir.

\section{Bibliographie}

ALEXOAEI, A. et COJANU, V. (2017), « Negotiating the Transatlantic deal: focus on the EU's domestic constraints », CES Working Papers, Centre for European Studies, Alexandru Ioan Cuza University, vol. 9, $\mathrm{n}^{\circ}$ 3, pp. 233-254.

ARC (2014), « Transatlantic Dialogue between legislators on TTIP in European Parliament », Arc 2020, 21 juillet 2014, www.arc2020.eu/front/2014/07/transatlantic-dialogue-betweenlegislators-on-ttip-in-the-european-parliament (consulté en août 2019).

Ballotpedia (2016), « 2016 presidential candidates on the Trans-Pacific Partnership trade deal », Ballotpedia, https://ballotpedia.org/2016_presidential_candidates_on_the_TransPacific_Partnership_trade_deal (consulté en août 2019).

BEAUSSIER, A.-L. et BENJABALLAH, S. (2014), «Comparer le Parlement européen et le Congrès américain. Un état des lieux théorique et méthodologique », Revue internationale de politique comparée, vol. 21, $\mathrm{n}^{\circ} 3$, pp. 9-30.

BERGBOWER, M. L. et SCHMITT, C. (2015), « Congressional Activism in the Foreign Policy Arena: A Case Study of the 1994 Rwandan Genocide », Democracy and Security, vol. 11, n 4 , pp. 353-372.

BINDER, K. (2017). Briefing : From TPP to new trade arrangements in the Asia-Pacific region(PE 603.953), Bruxelles, European Parliament Research Service, https://www.europarl.europa.eu/RegData/etudes/BRIE/2017/603953/EPRS_BRI(2017)60395 3_EN.pdf (consulté en août 2019). 
BRICART, V. (2017), «Le Congrès américain et les pouvoirs de guerre : de la théorie à la pratique », CEFIR Working Paper, n 3, pp. 1-19.

CALMES, J. (2015), « Trans-Pacific Partnership Is Reached, but Faces Scrutiny in Congress », The New York Times, 6 octobre.

CALMES, J. (2016), «T.P.P. Faces Rough Road in Congress », The New York Times, 2 septembre.

COCHRANE, E. et SWANSON, A. (2019), «Trump Aides and Democrats Agree on Trade Pact With Mexico and Canada », The New York Times, 10 décembre.

Committee on International Trade. (2016). Mission Report: Following the ad-hoc delegation to Canada (Ottawa and Montreal) from 21 to 23 March 2016 ( CR\1089805EN.doc PE578.851v01-00), Bruxelles, European Parliament, https://www.europarl.europa.eu/cmsdata/102098/Canada_Mission_Report.pdf (consulté en août 2019).

Committees (2019), «Hearings», European Parliament Committees, https://www.europarl.europa.eu/committees/en/indexsearch.html?term=9\&query=TTIP (consulté en août 2019).

COSTA, O. (2014), « Que peut le Parlement européen ? », Pouvoirs, vol. 149, n 2, pp. 77-89. COURMONT, B. (2001), «Le Congrès et son poids dans la formulation de la politique étrangère américaine », Revue internationale et stratégique, vol. 42, n 2, pp. 87-97.

Damen, D. (2019), «L’Union européenne et ses partenaires commerciaux », Fiches thématiques l'Union européenne, novembre 2019, http://www.europarl.europa.eu/factsheets/fr/sheet/160/1-union-europeenne-et-ses-partenairescommerciaux (consulté en août 2019).

DAVID, C-P. (éd.) (2015), La politique étrangère des Etats-Unis : fondements, acteurs,

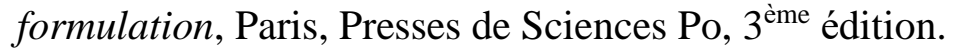

DAVIES BOREN, Z. (2015), « TTIP controversy: Secret trade deal can only be read in secure 'reading roo' in Brussels », TheIndependent, 4 août.

DEL MONTE, M. et PUCCIO, L. (2016). Rôle du Congrès des États-Unis dans les accords commerciaux, La procédure accélérée "Fast-Track procedure "(PE 577.999), Bruxelles, European Parliament Research Service https://www.europarl.europa.eu/RegData/etudes/IDAN/2016/577999/EPRS_IDA(2016)57799 9_FR.pdf (consulté en août 2019).

DOVERE, E.-I. (2015), « Extreme secrecy eroding support for Obama's trade pact », Politico, 5 avril.

DUCOURTIEUX, C. (2016), « La galaxie hétéroclite des anti-TTIP », Lemonde, 16 septembre.

DUCOURTIEUX, C. (2016), «Les autorités peinent à convaincre les opinions publiques », Lemonde, 30 avril. 
DUCOURTIEUX, C. (2018), « Europe : Bruxelles contrainte à la transparence sous la pression des opinions publiques », Lemonde, 19 mai.

ERMERT, M. (2015), «TPP Heads Into Ratification Game », Intellectual Property Watch, 6 octobre.

European Commission (2014), «Online public consultation on investment protection and investor-to-state dispute settlement (ISDS) in the Transatlantic Trade and Investment Partnership Agreement (TTIP)», europa.eu, juillet 2014, http://trade.ec.europa.eu/consultations/index.cfm?consul_id=179 (consulté en août 2019).

European Commission (2015), «Dans un souci de transparence, la Commission européenne publie des textes juridiques concernant le TTIP», europa.eu, 7 janvier 2015, https://europa.eu/rapid/press-release_IP-15-2980_fr.htm (consulté en août 2019).

European Commission (2015), «Présentation ce jour d'un rapport sur la consultation concernant la protection des investissements dans les négociations commerciales UE-EtatsUnis », europa.eu, 13 janvier 2015, https://europa.eu/rapid/press-release_IP-15-3201_fr.htm (consulté en août 2019).

European Commission (2016), «EU negotiating texts in TTIP », europa.eu, 14 juillet 2016, http://trade.ec.europa.eu/doclib/press/index.cfm?id=1230 (consulté en août 2019).

European Commission. (2015). Online public consultation on investment protection and investor-to-state dispute settlement (ISDS) in the Transatlantic Trade and Investment Partnership Agreement (TTIP) (13.1.2015 SWD (2015) 3 final), Bruxelles, http://trade.ec.europa.eu/doclib/docs/2015/january/tradoc_153044.pdf (consulté en août 2019).

European Parliament (2010), «SWIFT: European Parliament votes down agreement with the US », europa.eu, 11 février 2010, https://www.europarl.europa.eu/sides/getDoc.do?pubRef=//EP//TEXT+IM-PRESS+20100209IPR68674+0+DOC+XML+V0//EN (consulté en août 2019).

European Parliament (2014), «Politics \& Policies - April 2014 », europa.eu, 10 avril 2014, https://www.europarl.europa.eu/unitedstates/en/eplo-news/politics-policies-april-2014 (consulté en août 2019).

European Parliament (2017), «CETA: MEPs back EU-Canada trade agreement », europa.eu, 2 février 2017, http://www.europarl.europa.eu/news/en/press-room/20170209IPR61728/cetameps-back-eu-canada-trade-agreement (consulté en août 2019).

European Parliament (2019), «Bureaux de liaison dans votre pays », europa.eu, http://www.europarl.europa.eu/at-your-service/fr/stay-informed/liaison-offices-in-yourcountry (consulté en août 2019).

European Parliament (2019), «European Parliament Committees », europa.eu, https://www.europarl.europa.eu/committees/en/parliamentary-committees.html (consulté en août 2019). 
European Parliament \& US House of Representatives. (2013). $74^{\text {TH }}$ Inter-parliamentary meeting: Transatlantic Legislators' Dialogue (Joint Statement of 2013), Bruxelles, https://www.europarl.europa.eu/cmsdata/122911/TLD\%20June\%202013.pdf (consulté en août 2019).

European Parliament \& US House of Representatives. (2014). $75^{\text {TH }}$ Inter-parliamentary meeting: Transatlantic Legislators' Dialogue (Joint Statement of 2014), Bruxelles, https://www.europarl.europa.eu/cmsdata/122912/TLD\%20March\%202014.pdf (consulté en août 2019).

European Parliament \& US House of Representatives. (2015). $77^{T H}$ Inter-parliamentary meeting: Transatlantic Legislators' Dialogue (2 ${ }^{\text {nd }}$ Joint Statement of 2015), Bruxelles, https://www.europarl.europa.eu/cmsdata/122148/Joint_Statement_EU-US_IPM_4-

5_Nov_2015.pdf (consulté en août 2019).

European Parliament Delegation for Relations with Canada (2019), « Welcome from the former Chair », europa.eu, https://www.europarl.europa.eu/delegations/en/d-ca/home (consulté en août 2019).

European Parliament Delegation for Relations with Canada. (2014). Delegation for Relations with Canada $36^{\text {th }}$ EP-Canada Inter-Parliamentary Meeting Brussels 13 November 2014 (Mission Report of 2014), Bruxelles, European Parliament, https://www.europarl.europa.eu/cmsdata/124161/Report\%2036th\%20EP-Canada\%20IPM.pdf (consulté en août 2019).

European Parliament Delegation for Relations with Canada. (2017). Delegation for Relations with Canada $37^{\text {th }}$ EU-Canada Inter-Parliamentary Meeting Ottawa, Quebec and Montreal 1620 May 2016 (Mission Report of 2016), Bruxelles, European Parliament, https://www.europarl.europa.eu/cmsdata/124140/Mission\%20report.pdf (consulté en août 2019).

European Parliament Liaison Office in Washington DC (2013), « Transatlantic Trade and Investment Partnership: MEPs gauge 'increasingly positive mood' in Washington, outline key EU interests », europa.eu, 11 april 2013, www.europarl.europa.eu/us/en/news_events/news/news_2013/news_apr_2013/ttip_eu_interes ts.html (consulté en août 2019).

European Parliament, «EU trade and investment agreement negotiations with the US », Resolution, P7_TA (2013)0227, 23 May 2013.

European Parliament, «European Parliament resolution of 8 June 2011 on EU-Canada trade relations », Resolution, P7_TA (2011)0257, 8 June 2011.

European Parliament, «European Parliament's Recommendations to the European Commission on the Negotiations for the Transatlantic Trade and Investment Partnership (TTIP) », Resolution, P8_TA(2015)0252, 8 July 2015.

European Parliament, «TTIP: Challenges and Opportunities for the Internal Market», Joint Public Hearing Committee on the Internal Market and Consumer Protection Committee on 
International Trade,

http://www.europarl.europa.eu/committees/en/inta/eventshearings.html?id=20150210CHE00121, 24 February 2015.

European Parliament, «TTIP: What's in it for Europeans? », Public Hearing Committee on International Trade, DV $1053409 E N . d o c, 18$ March 2015.

European Parliament. (2019). EU-Canada comprehensive economic and trade agreement (CETA) (Legislative Train $\mathrm{n}^{\circ} 07.2019$ 6A), Bruxelles, https://www.europarl.europa.eu/legislative-train/api/stages/report/07-2019/theme/a-balancedand-progressive-trade-policy-to-harness-globalisation/file/ceta (consulté en août 2019).

FERGUSSO, I.-F. (2015). Trade Promotion Authority (TPA) and the Role of Congress in Trade Policy (RL33743), Washington, Congressional Research Service, https://fas.org/sgp/crs/misc/RL33743.pdf (consulté en août 2019).

FORTMANN, M. (dir.) et MARTIN P. (dir.) (2013), Le système politique américain, Montréal,

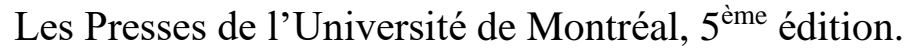

FRASURE, W. G. (2016), «Presidential Election Campaign Dims Prospects for TPP», TheDiplomat, 18 mai.

FROMAGE, D. (2018), «The European Parliament in the post-crisis era: an institution empowered on paper only?», Journal of European Integration, vol. 40, n 3, pp. 281-294.

Giovenco, A. (2013), « Chief U.S. and EU Negotiators Brief Congressional Staff on the First Round of TTIP Negotiations », Tradewinds, the official blog of the United States Trade Representative, juillet 2013, https://ustr.gov/about-us/policy-offices/pressoffice/blog/2013/july/negotiators-brief-hill-ttip (consulté en août 2019).

HUBER, K. (2015), «The European Parliament as an actor in EU border policies: its role, relations with other EU institutions, and impact », European Security, vol. 24, n 3, pp. 420437.

ILIAS AKHTAR, S. et JONES, V. (2014). Transatlantic Trade and Investment Partnership (TTIP) Negotiations (R43387), Washington, Congressional Research Service, https://fas.org/sgp/crs/row/R43387.pdf (consulté en août 2019).

ILIAS AKHTAR, S., JONES, V. et JOHNSON, R. (2016). Transatlantic Trade and Investment Partnership (T-TIP) Negotiations (R43387), Washington, Congressional Research Service, https://nationalaglawcenter.org/wp-content/uploads//assets/crs/R43387.pdf (consulté en août 2019).

JANČIĆ, D. (2015), «Transatlantic Regulatory Interdependence, Law and Governance: The Evolving Roles of the EU and US Legislatures », Cambridge Yearbook of European Legal Studies, vol. 17, pp. 334-359.

JANČIĆ, D. (2016), « The Role of the European Parliament and the US Congress in Shaping Transatlantic Relations: TTIP, NSA Surveillance, and CIA Renditions », Journal of Common Market Studies, vol. 54, n 4, pp. 896-912. 
JANČIĆ, D. (2017), «TTIP and legislative-executive relations in EU trade policy », West European Politics, vol. 40, n 1, pp. 202-221.

KANDEL, M. (2016), «Le rôle du Congrès américain dans le processus de décision en politique étrangère : les accords de Dayton (1995) », Critique internationale, vol. 71, $\mathrm{n}^{\circ}$ 2, pp. 109-127.

KEUKELEIRE, S. et DELREUX, T. (2014), The Foreign Policy of the European Union, Londres, MacMillan Education UK, 2 ème édition.

LAROCCO, L. A. (2017), «Wilbur Ross says he's 'open to resuming' talks on mega-trade deal with Europe », $C N B C, 30$ mai.

Malmström, C. (2014), «The Trade Commissioner and Parliament: A Vital Relationship », europa.eu, 3 décembre 2014, https://europa.eu/rapid/press-release_SPEECH-14-2348_en.htm (consulté en août 2019).

MARANS, D. (2016), « Progressives Gear Up To Kill TPP In Lame-Duck Congress », The Huffington Post, 19 août.

MCCARTIN, M. et MCCLURE, K. (2016), «What's Next for TPP: Will Congress Ratify in $2016 ?$ ?, global policy watch, 21 janvier.

MORTIMER, C. (2016), « Trans-Pacific trade deal will not be passed by Congress before inauguration, White House admits », TheIndependent, 13 novembre.

NEW, W. (2012), «US Congress Members Demand Access To TPP; ACTA Criticised In Australia », Intellectual Property Watch, 27 juillet.

Office of the United States Trade Representative (2015), «TPP Congressional Timeline », USTradeRepresentative.gov, https://ustr.gov/Congressional-Timeline-TPP (consulté en août 2019).

PASQUARIELLO MARIONO, K. L. et THODORO LUCIONA, B. (2018), "The parliamentarization of EU trade policy: unveiling the European Parliament's involvement in EU-MERCOSUR trade negotiations », European Politics and Society, vol. 20, $\mathrm{n}^{\circ}$ 5, pp. 591-608.

PUCCIO, L. (2016). Négociations UE/États-Unis sur le PTCI, Vue d'ensemble des questions en suspens (PE 586.606), Bruxelles, European Parliament Research Service, https://www.europarl.europa.eu/RegData/etudes/IDAN/2016/586606/EPRS_IDA(2016)58660 6_FR.pdf (consulté en août 2019).

RIDDERVOLD, M. et ROSÉN, G. (2016), « Trick and treat: how the Commission and the European Parliament exert influence in EU foreign and security policies », Journal of European Integration, vol. 38, $\mathrm{n}^{\circ}$ 6, pp. 687-702.

RIPOLL SERVENT, A. (2014), «The role of the European Parliament in international negotiations after Lisbon », Journal of European Public Policy, vol. 21, n 4, pp. 568-586. 
RITTER, M. (2016), «Approval of TPP in US Congress Seen as Difficult », Learning English, 28 mai.

ROEDERER-RYNNING, C. (2017), «Parliamentary assertion and deep integration: the European parliament in the CETA and TTIP negotiations », Cambridge Review of International Affairs, vol. 30, n ${ }^{\circ}$ 5-6, pp. 507-526.

ROEHRIG, T. et WESSEL, L. A. (2011), « Congress and U.S.-North Korean Relations: The Role of the Entrepreneur », Asian Affairs: An American Review, vol. 38, n 2, pp. 89-108.

ROSÉN, G. (2017), « The impact of norms on political decision-making: how to account for the European Parliament's empowerment in EU external trade policy », Journal of European Public Policy, vol. 24, n ${ }^{\circ}$ 10, pp. 1450-1470.

SCHÖLLMANN, W. (2017). Briefing International Agreements in Progress: Comprehensive Economic and Trade Agreement (CETA) with Canada (PE 595.895), Bruxelles, European Parliament Research Service, https://www.europarl.europa.eu/RegData/etudes/BRIE/2017/595895/EPRS_BRI(2017)59589 5_EN.pdf (consulté en août 2019).

SCHWARZ, J. (2015), « You Can't Read the TPP and You Can't Find Out Who in Congress Has », The Intercept, 13 juin.

STEHRER, R. et STÖLLINGER, R. (2016), « CETA and TTIP: same-same but different? », Vienna Institute for International Economic Studies, 6 septembre.

THE GUARDIAN (2013), «WikiLeaks publishes secret draft chapter of Trans-Pacific Partnership », TheGuardian, 13 novembre.

Traité sur l'Union Européenne (TUE), signé à Maastricht le 7 février 1992, modifié le 13 décembre 2007.

Traité sur le Fonctionnement de l'Union européenne (TFUE), signé à Rome le 25 mars 1957, modifié le 13 décembre 2007.

Transatlantic Legislators' Dialogue (2019), « Transatlantic Legislators' Dialogue : Welcome », europa.eu, https://www.europarl.europa.eu/intcoop/tld/default_en.htm (consulté en août 2019).

United Sates Senate (2019), «Hearings \& Meetings », senate.gov, https://www.senate.gov/committees/hearings_meetings.htm (consulté en août 2019).

United States Constitution, signée à Philadelphie le 17 septembre 1787, modifiée le 7 mai 1992.

United States Senate Committee on Finance (2016), «Hatch, Brady Send Letter to USTR as TTIP Negotiations with EU Resume », US Senate Committee on Finance, 3 octobre 2016, https://www.finance.senate.gov/chairmans-news/hatch-brady-send-letter-to-ustr-as-ttipnegotiations-with-eu-resume (consulté en août 2019).

US Congress, «Bipartisan Congressional Trade Priorities and Accountability Act of 2015 », Public Law, 114-26 (114 $\left.{ }^{\text {th }}\right)$, Congress, 29 June 2015. 
US House of Representatives Ways and Means' committee (2015), « Hearing on Trade », Way $\&$ Means https://waysandmeans.house.gov/legislation/hearings/hearing-trade (consulté en août 2019).

US House of Representatives, «Expanding American Trade with Accountability and Transparency », Hearings Before the Committee of Ways and Means, 114-FC04 $\left(114^{\text {th }}\right)$, Congress, 22 April 2015.

US House of Representatives, «Expressing the sense of the House of Representatives that the United States and the European Union should pursue a Transatlantic Trade and Investment Partnership », Resolution, H.Res.76 $\left(113^{\text {th }}\right)$, 15 February 2013.

US House of Representatives, «U.S. Trade Policy Agenda », Hearings Before the Committee of Ways and Means, 114-FC02 (114 $\left.{ }^{\text {th }}\right), 27$ January 2015.

VINCENTI, D. (2016), «Parliament committee gives CETA thumbs down», euractiv, 9 décembre.

Wikileaks (2014), «Updated Secret Trans-Pacific Partnership Agreement (TPP) - IP Chapter (second publication) », wikileaks, 16 octobre 2014, https://wikileaks.org/tpp-ip2/ (consulté en août 2019).

WILLIAMS, B.-R. et FERGUSSON, I.-F. (2016). The Trans-Pacific Partnership (TPP): Key Provisions and Issues for Congress (R44489), Washington, Congressional Research Service, https://fas.org/sgp/crs/row/R44489.pdf (consulté en août 2019).

WILLIAMS, B.-R. et FERGUSSON, I.-F. (2018). TPP: Overview and Current Status. (IF10000 Version $\mathrm{n}^{\circ} 28$ ), Washington, Congressional Research Service, https://crsreports.congress.gov/product/pdf/IF/IF10000/28 (consulté en août 2019).

WINZEN, T. (2011), « Technical or Political? An Exploration of the Work of Officials in the Committees of the European Parliament », The Journal of Legislative Studies, vol. 17, $\mathrm{n}^{\circ} 1$, pp. 27-44. 


\title{
Jeux et enjeux de l’Union Européenne : quels enseignements peut-on tirer?
}

\author{
Liridon Lika ${ }^{1}$ et Audrey Weerts ${ }^{2}$
}

Mots-clés: Union Européenne ; politique étrangère ; politique commerciale ; atouts ; défis ; enjeux

Les contributions de ce numéro spécial ont confirmé l'intérêt qui existe autour du projet européen. Depuis les premières étapes de la construction européenne dans les années 1950, l'Union Européenne (UE) a bien évolué. Partagée entre mouvements d'approfondissement et d'élargissement, elle reste toujours omniprésente dans les débats scientifiques.

Le présent numéro avait précisément pour objectif d'analyser les atouts dont dispose l'UE dans un contexte où les défis et les enjeux sont nombreux pour l'Organisation, tant dans une dimension interne qu'externe. Si l'UE présente de nombreux atouts majeurs en matière de pacification, de réconciliation, de prospérité ou encore de rapprochement entre les populations, les défis et les enjeux pour les instances européennes restent multiples et importants. La question de l'élargissement, celle du Brexit, la crise migratoire, la montée des extrémismes, la pandémie du coronavirus, l'action extérieure, les relations avec le reste du monde, ou encore les réformes institutionnelles animent les débats au sein de l'UE. Dans un tel contexte, de quelles forces dispose l'UE pour mener ces projets ? À l'opposé, quels facteurs la déstabilisent ?

Deux angles ont été particulièrement ciblés dans les contributions, le premier concerne la politique étrangère et de sécurité, le second la politique commerciale de l'UE. Après une présentation générale de Sebastian Santander, les contributions d'André Dumoulin et de Kamal Bayramzadeh se sont interrogées sur les domaines de défense et de sécurité. Quant à celles de Philippe Vincent et de Vincent Bricart, elles se sont focalisées sur la politique commerciale.

\section{L'UE sous différents angles : l'apport des différentes contributions}

Comme nous l'a rappelé Sebastian Santander dans son article, l'UE est une entité au dessein ambitieux et évolutif. Une fois les premiers objectifs atteints (contrer le déclin de l'Europe et pacifier le continent), l'UE a sans cesse travailler à développer et consolider son projet et sa structure. Dans ce cheminement, il y a eu évidemment des obstacles, des défis et même des crises, qui ont aussi contribué à façonner l'entité que nous connaissons aujourd'hui. L'UE, avec ses atouts et ses faiblesses, a toujours suscité l'intérêt des chercheurs. Initialement cependant, la dimension interne au projet était privilégiée par les chercheurs. Néanmoins, à mesure que le projet européen s'est développé et étoffé, l'intérêt pour la dimension extérieure

\footnotetext{
${ }^{1}$ Liridon Lika est chargé de cours adjoint et maître de conférences au Center for International Relations Studies (CEFIR) du Département de Science politique de l'Université de Liège (ULiège). Il est également chercheur postdoctoral à la Faculty of Arts and Social Sciences FASoS) de l'Université de Maastricht (UM). Liridon Lika est titulaire d'une thèse de doctorat en sciences politiques et sociales de l'ULiège (2020).

${ }^{2}$ Audrey Weerts est assistante au Département de Science politique de l'Université de Liège (ULiège). À la fois membre de l'unité d'étude des systèmes politiques belges et de la Cellule d'Appui Politologique Afrique-Caraïbes (CAPAC-ULiège), elle est titulaire d'un master en relations internationales (ULiège) et d'un master en sciences de gestion (HEC-ULiège).
} 
du projet est allé grandissant. Les contributions de ce numéro le démontrent très bien et vont nous permettre de mieux appréhender cette entité sui generis et son activité extérieure.

Dans son article André Dumoulin a analysé la flexibilité conditionnelle dans le domaine de la sécurité coopérative et de la défense au sein de l'UE qui renvoie à l'idée de volontariat et de souveraineté des États. Il a mis en exergue que, dans le domaine de la sécurité-défense, les États membres sont les maîtres du jeu. Dès lors, il souligne que l'aboutissement d'une véritable autonomie diplomatique européenne, parallèlement à une souveraineté européenne partagée, est dépendant d'une analyse commune des menaces, de la définition des intérêts et des capacités, et notamment de la cohérence des États membres dans le domaine de la politique étrangère. L'auteur montre que, bien que l'UE pèse $22 \%$ de l'économie mondiale, elle ne dispose pas encore d'une analyse vraiment partagée de la menace aboutissant à une vision stratégique commune, impliquant un territoire à défendre et une puissance à affirmer face aux nouveaux défis mondiaux. Pour l'auteur, l'intégration politico-militaire est lente et reste fragile mais elle devrait aboutir plus rapidement si le paysage européen devait être concrètement menacé dans un environnement qui, aujourd'hui, voit réapparaitre la compétition militaire parallèlement à la compétition commerciale et technologique et des rivalités de puissance. Dans ce cas-ci, l'idée d'aller vers une plus grande intégration politico-militaire est mise en avant. De plus, l'auteur souligne que l'avenir de la Politique de Sécurité et de Défense Commune (PSDC) sera dépendant aussi du paysage extrêmement mouvant d'aujourd'hui : Brexit, place de la Turquie dans le champ sécuritaire euro-atlantique, positionnement du curseur transatlantique et américain en Europe, perception sécuritaire des mouvements migratoires et le niveau d'implication de la PSDC dans ce cadre, ou encore l'évolution des relations franco-allemandes.

Kamal Bayramzadeh a proposé une contribution avec pour objectif de montrer la limite de la puissance de l'UE dans les relations internationales. Il s'est notamment concentré sur l'exemple du projet nucléaire iranien de 2015 afin d'analyser les divergences entre les ÉtatsUnis et l'UE sur ce sujet, plus particulièrement depuis l'arrivée au pouvoir de Donald Trump. Afin d'étudier cette thématique, il a mobilisé plusieurs concepts des relations internationales tels que celui d'acteur, de puissance douce (soft power) et de puissance normative. Dans cette contribution l'auteur a montré que depuis 1991, l'UE a l'ambition de devenir un acteur important des relations internationales, en participant à la médiation, à la gestion des crises, à l'instauration de la paix et à la démocratisation de plusieurs pays. Cependant, il a souligné également que son rôle doit être mesuré en fonction du contexte, des conditions politiques et du facteur des rapports des forces. Étant donné que l'UE est une organisation régionale, elle ne peut pas être comparée à la puissance d'un État. D'après l'auteur, bien que la puissance normative de l'UE trouve un écho favorable dans ses relations internationales en particulier parmi les pays qui sont candidats ou candidats potentiels à l'adhésion dans l'UE, tels que ceux des Balkans occidentaux, elle connaît des limites dans d'autres pays comme la Russie et la Chine qui n'acceptent pas les normes européennes relatives à la question des droits de l'homme. Pour ce qui est de la limite de la puissance normative de l'UE à l'égard de l'Iran, il l'a examiné à travers quatre périodes de leurs relations : 1) de 1992 à 1997, 2) de 1998 à 2005, 3) de 2005 à 2013 et 4) de 2013 à 2020.

Philippe Vincent s'est ensuite intéressé aux nouveaux accords commerciaux conclus par l'UE ces dernières années. Il dresse le constat, qu'à nos jours, le cadre des relations commerciales de l'UE a énormément changé par rapport à celui qui était en vigueur en 1994 au moment de l'officialisation de l'Organisation Mondiale du Commerce (OMC). Dans son développement, il souligne que l'échec du multilatéralisme commercial a incité la plupart des États du monde, tant émergents qu'industrialisés, a adopté leurs stratégies bilatérales. Ainsi, les puissances émergentes comme la Chine et l'Inde se sont lancées dans le bilatéralisme, négociant des accords avec de nombreux pays du monde. En même temps, souligne l'auteur, les ÉtatsUnis ont, depuis l'arrivée au pouvoir de Donald Trump, fait retour en arrière sur la plupart des 
traités bilatéraux ou multilatéraux restreints qu'ils étaient en train de négocier et n'hésitent pas à appliquer des surcharges tarifaires unilatérales lorsqu'ils estiment que leurs partenaires commerciaux, plus particulièrement l'UE, ne respectent pas les règles du jeu commercial international. Quant à l'UE, il précise qu'elle multiplie les accords, même si ceux-ci se heurtent à l'opposition d'une partie de l'opinion publique, qui est critique et perçoit ces accords comme des simples instruments au service des multinationales visant à réaliser des profits et dans certains cas échappant à l'ordre juridique national des États hôtes. L'auteur s'est également penché sur une brève analyse du contenu des accords, touchant les aspects du commerce des marchandises, du commerce des services, de la propriété intellectuelle, des marchés publics, ou encore sur la question de la protection des investissements.

Toujours en matière de politique commerciale, Vincent Bricart s'est quant à lui penché sur le rôle des assemblées parlementaires dans la politique commerciale extérieure des ÉtatsUnis et de l'UE. Il a apporté une réponse positive à l'analyse de l'existence d'une influence claire des parlementaires européens et américains sur la diplomatie menée par les États-Unis et l'UE, dans la conclusion des traités commerciaux internationaux. Il a démontré que l'influence se manifeste de nombreuses manières telles que, entre autres, le contrôle, l'évaluation et la supervision des négociations par les parlementaires, la création du débat par les institutions législatives en définissant leurs priorités et objectifs, remettant en cause certains points ou décisions des traités négociés, élaborant des demandes et discutant avec l'exécutif afin de se faire entendre par ce dernier. Ainsi, l'auteur constate que ces pressions formelles et informelles, venant des pouvoirs législatifs, mais surtout de la société civile, incitent l'exécutif à prendre en considération les revendications des parlementaires. Pour illustrer ses propos, l'auteur évoque les exemples de l'augmentation de la transparence des négociations du Partenariat Transatlantique de Commerce et d'Investissement ou en anglais Transatlantic Trade and Investment Partnership (TTIP) et de l'Accord Économique et Commercial Global ou en anglais Comprehensive Economic and Trade Agreement (CETA) dans le cas du Parlement européen, d'un côté, et de la définition des objectifs de négociations du TTIP par le Congrès, de l'autre. Néanmoins, l'auteur émet également des réserves à cette influence, puisque l'implication de l'ensemble des assemblées parlementaires des pays démocratiques et à l'ensemble des accords commerciaux n'est pas systématique à chaque État et sur chaque sujet.

\section{Politique étrangère et politique commerciale : quels atouts, quels défis ?}

D'un point de vue externe, l'UE s'est imposée comme un modèle de référence en matière d'intégration régionale et son pouvoir d'attraction reste considérable. Elle exerce une présence solide et une activité multidimensionnelle sur la scène internationale. Cependant, elle peine encore parfois à s'exprimer d'une seule voix et à développer une politique étrangère commune. De ce fait, plusieurs recherches ont abordé la question de la qualification de l'UE comme acteur international à part entière ${ }^{1}$. Dans un contexte de décentrage du pouvoir mondial, quelle peut être la place occupée par l'UE ? Quels sont les atouts dont elle dispose pour ce faire ? Quelles relations entretient-elle avec les grandes puissances, les puissances émergentes ou encore les autres organisations régionales?

Les contributions de ce numéro nous permettent d'apporter quelques éclairages à ces interrogations. Deux angles particuliers ont été traités par les auteurs : celui de la politique étrangère et de la politique commerciale.

\footnotetext{
${ }^{1}$ MERLE, M. (1988), Sociologie des relations internationales, Paris, Dalloz, 4 e édition, p. 317 ; JUPILLE, J. and CAPORASO, J. A. (1998), « States, Agency, and Rules: The European Union in Global Environmental Politics », in RHODES, C. (dir.), The European Union in the World Community, Boulder, Lynne Rienner, p. 214; BRETHERTON, C. and VOGLER, J. (2006), The European Union as a Global Actor, London and New York, Routledge; HILL, C., SMITH, M., and VANHOONACKER, S. (2017), International Relations and the European Union, Oxford, Oxford University Press; PETITEVILLE, F. (2002), « L’Union européenne, acteur international 'global' ? Un agenda de recherche », Revue internationale et stratégique, ${ }^{\circ}$ 47, p. 156.
} 


\section{Politique étrangère}

C'est avec le traité de Maastricht signé en 1992 que l'UE s'est dotée d'une politique étrangère et de sécurité commune plus connue sous le sigle de PESC. Si les États membres conservent bien leur souveraineté en matière de politique étrangère, la PESC offre à ces derniers la possibilité de parler d'une seule voix lorsque les intérêts communs le permettent en leur donnant des moyens pour agir ensemble en la matière. Dans ce cadre, l'UE s'est dotée aussi de la PSDC (anciennement Politique Européenne de Sécurité et de Défense, PESD). Avec ces outils, l'UE ambitionne donc de jouer un rôle dans les relations internationales. Mais qu'en estil dans la pratique?

La contribution d'André Dumoulin nous a confirmé que, pour la PSDC, c'est la dimension intergouvernementale qui est bien prédominante. L'UE n'est pas un État, et de ce fait n'a pas de base accès à des compétences régaliennes. Conservant leur souveraineté, les États membres peuvent toujours, pour des motifs divers, refuser de s'engager. S'il existe bien des mécanismes communs, ceux-ci restent limités. L'intégration politico-militaire se fait donc lentement et surtout elle reste fragile. Ce faisant, l'action européenne dans le domaine de la high politics reste limitée. Toutefois, même si elle ne dispose pas de la force, l'UE peut compter sur d'autres atouts pour peser comme puissance sur la scène internationale, à savoir les normes et le commerce ${ }^{1}$. Comme nous l'a montré la contribution de Kamal Bayramzadeh, il semble que ce soit plutôt sous l'angle des normes que l'UE compte exercer sa puissance. L'UE s'appuierait ainsi sur sa capacité à produire des normes (qui discipline et tend à rendre prévisible les actions des autres acteurs). Certaines normes européennes dépassent aujourd'hui le cadre de l'UE, étendant de la sorte la capacité d'influence par exemple sur les six États des Balkans occidentaux (Albanie, Bosnie-Herzégovine, Kosovo, Macédoine du Nord, Monténégro, Serbie) qui visent à adhérer dans le projet commun européen ${ }^{2}$. L'étude proposée par Kamal Bayramzadeh, concernant le cas de l'Iran, a cependant montré que cette politique donnait lieu à des résultats variables selon le contexte, les conditions politiques et les rapports de force et qu'il fallait donc aussi parfois relativiser la puissance normative de l'UE.

\section{Politique commerciale}

Le commerce a toujours été au cœur du projet européen, en prenant une place grandissante jusqu'à aujourd'hui. Actuellement, au niveau mondial, l'UE constitue un grand marché industrialisé. En 2019, le Fonds Monétaire International (FMI), sur base du Produit Intérieur Brut (PIB) montrait que l'UE représente la deuxième puissance économique mondiale après les États-Unis.

En matière de politique commerciale, Philippe Vincent et Vincent Bricart dressent un constat identique : celui de la multiplication de vastes accords commerciaux par l'UE, mais aussi une façon pour l'UE d'imposer ses normes à ses partenaires. Ce changement de cadre commercial pour l'Union s'explique par l'échec du multilatéralisme commercial. Le blocage des négociations dans le cadre de l'OMC ouvre donc la porte à cette " nouvelle génération d'accords ». Si ce changement de paradigme permet à l'UE de rester dans la course face à d'autres acteurs puissants sur la scène internationale, cela suscite aussi des oppositions : manque de transparence, citoyens/consommateurs délaissés pour le profit, risques économiques ou encore risques pour la santé.

\footnotetext{
${ }^{1}$ MANNERS, I. (2002), « Normative Power Europe: A Contradiction in Terms? », Journal of Common Market Studies, vol. 40, n 2, p. 252; LAÏDI, Z. (2009), « L'Europe, puissance normative internationale », in DEHOUSSE R. (dir.), Politiques européennes, Paris, Presses de Sciences Po, pp. 227-242.

${ }^{2}$ LIKA L. (2020), Les Balkans occidentaux à la croisée de l'intégration européenne et de la projection des puissances émergentes. Analyse du cadre triangulaire entre les Balkans occidentaux, l'Union européenne et la Turquie, Thèse de doctorat en science politique et sociale, Université de Liège, mai 2020, pp. 159-164.
} 
Pour compléter cet aperçu sur la politique commerciale, Vincent Bricart ajoute un autre constat, à savoir celui de l'implication croissante des assemblées parlementaires dans le processus de négociation/conclusion des traités commerciaux internationaux : un facteur qui a toute son importance dans le contexte des oppositions à la politique commerciale de l'UE, car cette inclusion du Parlement permet aux dirigeants de l'UE d'apporter une légitimité nouvelle à sa politique.

\section{L'UE à la recherche d'un nouveau narratif mobilisateur : combiner la norme et la force ?}

La variété des articles présentés dans ce numéro spécial nous a permis de conclure que, bien que l'UE soit analysée sous différents angles, elle présente néanmoins de nombreux traits communs.

Depuis 2008, suite à la crise économique et financière, le projet européen a connu une importante crise. D'autres crises peuvent être ajoutées à la liste, comme celles des réfugiés, des conflits géopolitiques autour de l'UE, les populismes, le Brexit, ou encore la plus récente la pandémie du coronavirus. Par exemple, les crises migratoires et du coronavirus ont démontré un certain manque de solidarité entre les États membres qui n'arrivent pas à parler d'une seule voix. Autrement dit, celles-ci ont mis en lumière un manque de cohérence en matière de politique étrangère, voire une absence de vision stratégique commune. Ainsi, certains soulignent que la crise européenne est à la fois une crise d'identité, de fonctionnement, de projet et de finalité ${ }^{1}$. Pour ces derniers, ce qui manque à l'UE c'est un narratif mobilisateur, c'est-àdire l'histoire d'un projet collectif sur l'utilité de l'UE au $\mathrm{XXI}^{\mathrm{e}}$ siècle ; autrement dit, soulignent-ils, l'UE a besoin d'un nouveau contrat basé sur la combinaison de la norme et de la force ${ }^{2}$.

Parmi les atouts clés de l'UE restent sa puissance économique et son pouvoir d'attraction. Comme déjà indiqué supra, sur le plan économique, d'après le FMI et sur base du PIB en 2019, les États-Unis occupent la première place tandis que l'UE représente la deuxième puissance mondiale. Ainsi, dans l'action extérieure de l'UE le commerce est aussi au service de la norme. Sur le plan politique, l'UE exerce un poids de soft power conséquent à l'extérieur. Les Balkans occidentaux constituent un exemple illustratif. L'adhésion à l'UE pour des États comme l'Albanie, le Kosovo, le Monténégro ou encore la Macédoine du Nord est une priorité stratégique de leur gouvernements respectifs ainsi que la volonté d'une très importante partie de leurs citoyens.

\section{Bibliographie}

BRETHERTON, CHARLOTTE and VOGLER, JOHN (2006), The European Union as a Global Actor, London and New York, Routledge.

HILL, CHRISTOPHER, SMITH, MICHAEL and VANHOONACKER, SOPHIE (2017), International Relations and the European Union, Oxford, Oxford University Press.

JUPILLE, JOSEPH and CAPORASO, JAMES A. (1998), "States, Agency, and Rules: The European Union in Global Environmental Politics », in RHODES CAROLYN (dir.), The European Union in the World Community, Boulder, Lynne Rienner.

\footnotetext{
${ }^{1}$ LAMY, P. et GNESSOTO, N. avec BAER, J-M. (2017), Où va le monde? Le marché ou la force?, Paris, Odile Jacob., pp. 175-176.

${ }^{2}$ Ibid., pp. 169-227.
} 
LAÏDI, Z. (2009), « L'Europe, puissance normative internationale », in DEHOUSSE R. (dir.), Politiques européennes, Paris, Presses de Sciences Po, pp. 227-242.

LAMY, P. et GNESSOTO, N. avec BAER, J-M. (2017), Où va le monde? Le marché ou la force?, Paris, Odile Jacob.

LIKA L. (2020), Les Balkans occidentaux à la croisée de l'intégration européenne et de la projection des puissances émergentes. Analyse du cadre triangulaire entre les Balkans occidentaux, l'Union européenne et la Turquie, Thèse de doctorat en science politique et sociale, Université de Liège, mai 2020, 472 p.

MANNERS, I. (2002), « Normative Power Europe: A Contradiction in Terms? », Journal of Common Market Studies, vol. 40, $\mathrm{n}^{\circ}$ 2, pp. 235-258.

MERLE, M. (1988), Sociologie des relations internationales, Paris, Dalloz, $4^{\mathrm{e}}$ édition.

PETITEVILLE, F. (2002), « L’Union européenne, acteur international 'global' ? Un agenda de recherche », Revue internationale et stratégique, $\mathrm{n}^{\circ} 47$, pp. 145-157. 